NBER WORKING PAPER SERIES

\title{
WHERE DOES VOUCHER FUNDING GO? HOW LARGE-SCALE SUBSIDY PROGRAMS AFFECT PRIVATE-SCHOOL REVENUE, ENROLLMENT, AND PRICES
}

\author{
Daniel M. Hungerman \\ Kevin Rinz \\ Working Paper 21687 \\ http://www.nber.org/papers/w21687
NATIONAL BUREAU OF ECONOMIC RESEARCH
1050 Massachusetts Avenue
Cambridge, MA 02138
October 2015

We thank Ida Smith Williams for help and Sarah Senseman for excellent research assistance. David Figlio, Jonathan Gruber, audiences at South Carolina, the ASREC conference, and the NBER Education Program conference provided valuable feedback. This work was supported by the John Templeton Foundation. Email the authors at dhungerm@nd.edu and krinz@nd.edu. The views expressed herein are those of the authors and do not necessarily reflect the views of the National Bureau of Economic Research.

NBER working papers are circulated for discussion and comment purposes. They have not been peerreviewed or been subject to the review by the NBER Board of Directors that accompanies official NBER publications.

(C) 2015 by Daniel M. Hungerman and Kevin Rinz. All rights reserved. Short sections of text, not to exceed two paragraphs, may be quoted without explicit permission provided that full credit, including (C) notice, is given to the source. 
Where Does Voucher Funding Go? How Large-Scale Subsidy Programs Affect Private-School

Revenue, Enrollment, and Prices

Daniel M. Hungerman and Kevin Rinz

NBER Working Paper No. 21687

October 2015

JEL No. H2,I2,I22

\begin{abstract}
$\underline{\text { ABSTRACT }}$
Using a new dataset constructed from nonprofit tax-returns, this paper explores how vouchers and other large-scale programs subsidizing private school attendance have affected the fiscal outcomes of private schools and the affordability of a private education. We find that subsidy programs created a large transfer of public funding to private schools, suggesting that every dollar of funding increased revenue by a dollar or more. Turning to the incidence of subsidies and the impact of subsidies on enrollment, our findings depend on the type of program introduced, with programs restricting eligibility to certain groups of students creating relatively large enrollment gains and small price increases compared to unrestricted programs. We calculate elasticities of demand and supply for private schools, and discuss welfare effects.
\end{abstract}

Daniel M. Hungerman

Department of Economics

University of Notre Dame

439 Flanner Hall

Notre Dame, IN 46556-5602

and NBER

dhungerm@nd.edu

Kevin Rinz

University of Notre Dame

434 Flanner Hall

Notre Dame, IN 46556

krinz@nd.edu 


\section{Introduction}

The United States is currently undergoing a revolution in the subsidization of private education, with dozens of states considering or recently enacting large-scale laws that use public resources to promote attendance at private elementary and secondary schools. Currently, over a million U.S. families participate in such programs and recent legislation in several states will push this number higher in coming years (Friedman Foundation, 2013).

But the proliferation of these programs across the country should not be taken as evidence that observers agree on how they work. Several elements of subsidy programs remain highly controversial. In particular, arguments often focus on the financial implications of these policies. On the one hand, these programs are sometimes depicted as providing resources to disadvantaged families (Governor Mitch Daniels, 2011; Governor Jan Brewer, 2012) or to wealthy families whose children would attend private school in any event (Reese, 2009; People for the American Way, 2003). But families are not the only potential beneficiaries of private-school subsidies; some observers emphasize that these subsidies represent a new and unprecedented source of financial support for schools themselves (Crothers, 2014). The validity of these descriptions depends upon how these programs impact the cost and prevalence of private education, and whether subsidy funding ultimately goes to families or schools.

Prior research offers little evidence regarding these outcomes. Of course, there is a large literature exploring the impact of voucher programs on economically important activities; Figlio (2009), Hoxby (2003), and the Center on Education Policy (2011) provide useful background on research here. But most of this prior work considers outcomes such as student achievement, Tiebout sorting, and public-school performance. Using sophisticated theoretical models, some studies predict how vouchers might impact private school enrollment or tuition (Epple and Romano, 1998; Ferreyra, 2007; and Nechyba, 2000) but the empirical validity of these studies is unproven. Evidence for how subsidies affect private school finances, or evidence on the incidence of school subsidies generally, is difficult to find. The goal of this paper is to contribute such evidence.

A key challenge in doing so is finding data on private-school finances. For this, we turn to a largelyunnoticed source of data: nonprofit tax returns. Using a dataset of IRS Form 990 returns made available by the National Center for Charitable Statistics, we construct a panel dataset with detailed financial information for thousands of private schools each year. Our sample covers about $20 \%$ of all private school enrollment in the country. While some important groups of private schools, such as Catholic schools, are not included in the sample, we provide several pieces of evidence which give us optimism that estimates from this sample could be informative for all private schools.

We first investigate whether school revenue increases when a policy to subsidize private schooling is 
implemented. We focus on large-scale statewide subsidy programs. These programs are notable for their extraordinary (and ongoing) proliferation, and their large size suggests that they could have important effects on school enrollment and finances even at the state level, unlike the smaller-scale voucher programs that have been the focus of past work. Our data cover the years 1991 to 2009; there are several states that enacted large-scale programs to subsidize private-school attendance that we use in our baseline estimates. We discuss these programs and their enactment in more detail below.

We find robust evidence that school subsidies raise revenue for the private schools in our sample and that the magnitude of this effect is large; even conservative extrapolations to all private schools indicate that a dollar of subsidy funding raises private school revenue by a dollar or more. However, we find that the impact depends crucially on the type of program enacted. Several programs we study place important restrictions on which students in a state can qualify for the subsidy (e.g., the programs are means-tested). We call these restricted programs. In contrast, unrestricted programs explicitly or in practice allow families to receive subsidies for expenditures on their own children and are not means tested nor otherwise restricted.

We find evidence of private school enrollment growth following the establishment of a restricted program, but not for unrestricted programs. We further find increases in per-student revenue (specifically, per-student program service revenue, a proxy for tuition) in response to unrestricted programs, but not for restricted programs. Thus both types of program raise school revenue, but in very different ways. For unrestricted programs we cannot reject that the incidence of the subsidy falls entirely on schools while for other laws we cannot reject that it falls entirely on families. These results are consistent with several depictions of private education, as we discuss below.

Finally, we construct a simple estimate of the price elasticity of demand for private schooling and a very simple estimate of the deadweight loss created for each dollar of public revenue spent on private-school subsidization. Our results suggest a price elasticity of -0.52 ; this is slightly larger in absolute value than the baseline estimate in Dynarski, Gruber, and Li (2009), although one could argue that the population they study (families with siblings already in private school) would be less price sensitive than the population affected by publicly-funded subsidies that we consider here. Our simple estimate of deadweight loss is 3 cents per dollar spent; we know of no comparable estimate for this number.

The rest of this paper is organized as follows. The next section describes the school subsidy laws used here. Section 3 discusses the data, section 4 the specifications, section 5 the results, and section 6 concludes. 


\section{School Subsidy Laws}

The main estimates in this paper focus on what we refer to as "school subsidy laws." By this, we mean laws that use government funds to subsidize private school tuition. This includes both traditional vouchers and related tax-credit based subsidy laws; while technically distinct from traditional school vouchers, tuition tax credits serve the same purpose and work in a very similar way. A typical voucher program consists of a government agency distributing money, which has been collected through taxation, to the families of students on the condition that the money will be spent on private schooling. In a typical tax credit program, the government reduces the tax liability, often dollar for dollar up to some limit, of a taxpayer that has provided funding to support students' private schooling. In both cases, states dedicate public resources to private school attendance for select students. The similarities between vouchers and tuition tax credits have led some to refer to these tax credits as "neovouchers" (Welner, 2008), or sometimes simply as "vouchers" (e.g., Caputo, 2013). We will refer to these laws as subsidies and, when using the term vouchers hereafter, we will endeavor to clarify whether the term refers to subsidies generally or strictly to traditional voucher programs that use vouchers per se as a financing mechanism.

Our focus will be on several large statewide laws that affected reasonably large groups of students between 1991 and 2009. With the exception of Chan (2006), who looks at the effect of a tax-credit law in Ontario on public school performance, and Rinz (2015), which explores how these laws affect student/teacher ratios and other educational inputs for students of different races, we know of no economic research on these laws. ${ }^{1}$ The discussion here draws on discussions in Welner (2008), the Friedman Foundation (2013), Schaeffer (2009), and a report compiled by the Research Department of the Minnesota House of Representatives (2011).

Tax-credit subsidy laws for private school tuition fall into two areas: credits for individuals and credits for corporations. Corporate tax credit programs provide an income-tax credit for corporate donations to a school tuition organization, or STO, which then uses the donated funds to award scholarships to children attending private schools. ${ }^{2}$ There are three states which enacted corporate tax credits of this kind during the period of study here: Arizona, Florida, and Pennsylvania. These programs use credits, not deductions, so that the financial incentive created by the program can be quite large even if the state income tax rate is small. For example, in Florida during the time of this study the corporate income tax rate was 5.5\%, but Florida's tax credit program awards a credit dollar-for-dollar with respect to donations to STOs. A program in Florida that used a tax deduction for corporate donations would thus lower the opportunity cost of a

\footnotetext{
${ }^{1}$ Some state-government reports consider the financial effect of these laws on public school funding. That is not the focus of this paper, although it is certainly an important topic. Studies considering issues related to public finance and public education include Murray, Evans, and Schwab (1998) and Fischel (2006).

${ }^{2}$ In recent years the tax base for some corporate credits has been expanded; for example in 2009 (beyond the period of study here) Arizona and Florida both expanded corporate tax credit programs to the insurance premiums tax.
} 
dollar given to STOs down from one dollar to 95 cents, but the tax credit program lowers the cost of this donation from one dollar to zero. Indeed, with dollar-for-dollar credits the actual marginal income tax rate is irrelevant. This extreme reimbursement rate creates a program that could in practice operate similarly to a traditional voucher program, but the circuitous design of the program (having the subsidy delivered by way of a corporately-supported STO, rather than by the government directly) is attractive from a legal standpoint. We discuss the legal challenges to these subsidy programs more below. ${ }^{3}$

Individual income tax credit programs may either award a credit for donations made to STOs, or for a household's own spending on private school tuition and other private school expenses. There are three states with programs of this kind during the period of our study: Arizona, Iowa, and Illinois. Even though many state's individual income tax rates are relatively low (compared to federal rates), these programs create large financial subsidies since they use credits rather than deductions. But most individual credits are different from other subsidy programs in that they both (a) allow individuals to claim credits for private school tuition for their own children and (b) are not restricted to certain types of students, such as low income students, students with special educational needs, or students initially in public schools.

Table 1 provides information on the laws used in the main part of this study (we discuss several other laws momentarily). There are eight laws that are the focus here: an individual and corporate credit in Arizona, a voucher program and corporate credit in Florida, an individual credit in Illinois, two individual credits in Iowa (one restricted, one not), and a corporate credit in Pennsylvania. ${ }^{45}$ As the table suggests, several programs are not means tested, and have relatively weak restrictions on student use. Appendix A provides some additional information on each state's programs.

Figure 1 shows total spending each year from 1991 to 1999 on the programs listed in Table 1 (in year 2012 dollars). Here, "spending" refers to (a) credits claimed for individual- and corporate-income tax programs

\footnotetext{
${ }^{3}$ The Florida credit is capped at $75 \%$ of corporate taxes due. Arizona's corporate income tax rate during the period of its corporate tax credit here was $6.968 \%$; its program also awarded credits dollar-for-dollar. Pennsylvania's program awarded a credit based on either $75 \%$ or $90 \%$ of a donation depending on whether the donation was a one time or repeated contribution; the fact that the credit is less than one-for-one means that the tax rate affects the cost of the donation. Pennsylvania's corporate income tax rate during the period of study here was $9.99 \%$. As of 2015 , about 2,300 companies receive this Pennsylvania credit (see page D9 of Wolf, 2015) (this credit is capped at $\$ 300,000$ a year during our period of study). Appendix A has more details on these laws.

${ }^{4}$ There was a second voucher program in Florida that coincided with the McKay program, the A+ Accountability and School Choice Program. This program allowed students at public schools which had been awarded a grade of "F" in two of the prior 4 years to receive a voucher. Economists have studied the impact of this program on public school behavior; see Chakrabarti (2013) for a discussion. While the A+ program had the potential to influence public school behavior in interesting and important ways, the number of actual vouchers awarded under the program was much more limited than either of the programs in Table 1 (partly because of court rulings) and the program was ruled unconstitutional in 2006. In a typical year only a few hundred students used the program to attend private schools (Forster, 2008). Given that the program's enrollment prior to 2001 (the year the corporate credit began) was even more limited (only two schools qualified for vouchers in the first possible year, 1999; and no schools did so in the second year) the baseline specifications below would be unchanged even if A+ vouchers had become much more widespread in later years than they actually did (Greene, 2001).

${ }^{5}$ In 2009, "Lexie's Law" established a corporate tax credit in Arizona to fund STO scholarships specifically for students with disabilities. However, since corporate-tax-credit-financed STO scholarships with student eligibility restrictions already existed in Arizona and the size of this program was relatively small (in 2010 only about 100 students participated according to the Friedman Foundation, 2013), we treat Lexie's Law as part of Arizona's pre-existing restricted corporate tax credit program rather than as a separate entity.
} 
and (b) traditional voucher spending under the McKay program. The figure shows that at the turn of the century there was a surge in school subsidies, with total funding reaching nearly half a billion dollars - a reasonably large amount given that these programs focus only on a select group of children. ${ }^{6}$

Figure 2 shows the number of individuals assisted by these laws. To count the number of individuals, the figure sums three things: first, the number of scholarships awarded in each state and year by STOs that qualify for tax-credit status; second, the number of traditional vouchers paid out; and third, the total number of individual tax returns claiming a tax credit under a school-subsidy program. This figure may not exactly represent the number of students in school-subsidy policies, as the number of taxpayers claiming individual credits could differ from the number of students benefiting from the tax-exempted expenditures. ${ }^{7}$ But the figure nonetheless clearly shows striking growth over the past two decades in participation in these programs, with over half a million individuals each year in the more recent years. The jump from 1999 to 2000 reflects the expansion of several programs but is primarily driven by the Illinois program's adoption.

While Figures 1 and 2 show that the programs in Table 1 were large in terms of funding and scope, there were several other more limited programs enacted during the time period of available data here, particularly towards the end of the sample. Rhode Island introduced a corporate credit for donations to STOs in 2007, where a dollar of donations resulted in a 75 cent credit (or a 90 cent credit if donations are made in two consecutive years). But, aside from the fact that the program was adopted nearly at the end of the period of study here, total eligible credits was capped at only $\$ 1$ million annually.

State voucher programs were also introduced in DC, Georgia, Ohio, and Utah. ${ }^{8}$ The District of Columbia Opportunity Scholarship program was launched in 2004 and provided vouchers for K-12 students who qualify for free and reduced-price lunches, although the program had a "relatively small annual budget" (Friedman Foundation, 2013). The Georgia Special Needs Scholarship program, enacted in 2007, allows any student with a disability who was previously enrolled in public school to obtain a voucher to attend private school, although the program's participation was relatively low_about a thousand students annually—for the period studied here. The Ohio Autism Scholarship Program, enacted in 2003, and later the Educational Choice Scholarship Program in 2006, both provide vouchers to students across the state. The former program is limited only to students diagnosed with an autism spectrum disorder and registered in the public school special education system; participation in this program was relatively low during the period of study here. The Educational Choice program provides vouchers to students who attend poorly-performing local public

\footnotetext{
${ }^{6}$ Appendix Figure 1 provides a state-by-state breakdown of this figure.

${ }^{7}$ The relevant individual-credit programs here limit credits to expenditures on dependents, so that very high discrepancies between credits claimed and students is unlikely. If multiple dependents benefit from a single taxpayer's credit then the figure would underestimate the number of students assisted by these policies.

${ }^{8} \mathrm{~A}$ voucher program was also considered in Colorado before being invalidated by a court ruling. Colorado has subsequently introduced a pilot voucher program in 2011, but this is after the period of study here.
} 
schools (or who attend a charter school but who would be assigned to such a school otherwise). Although participation was relatively small in the early years of the program (and the period of study used here), it has since become a large program with annual expenditures of nearly $\$ 60$ million (Alliance for School Choice, 2012). As these programs were more limited in scope or student availability during the years covered by the data below, we will exclude these programs. Many states have also passed related laws following the period of analysis used here, including Colorado, Indiana, Louisiana, Mississippi, New Hampshire, North Carolina, Oklahoma, Virginia, and Wisconsin.

The set of laws we study thus represents a fraction of the current set of laws. However, our laws have features in common with many subsequent programs. For example, the corporate tax credit programs that we use appear to be good models for subsequently enacted programs that use tax credits to direct donations to third-party scholarship granting organizations, particularly with regard to means testing. Each of these programs used here are means-tested; of the ten STO-style programs enacted since 2006, eight are means-tested. Moreover, many later voucher programs have important similarities with Florida's McKay voucher program. Of the 17 subsequent voucher programs we know of that were enacted after the McKay program, nine are targeted at students with disabilities. Of those nine, six also have prior public school enrollment requirements that apply in at least some cases, so that McKay-style voucher programs account for the majority of both voucher programs and programs for students with disabilities enacted after the cutoff for inclusion in our analysis. Student eligibility for the individual tax credit programs we include, on the other hand, is unrestricted. The only subsequent programs with completely unrestricted eligibility are subsidies provided via reductions in individual income tax. ${ }^{9}$ This of course does not necessarily mean that our results will be informative for all future law changes. But it is noteworthy that, while we use a limited number of laws, they contain features relevant to many subsequent laws, and we will (as discussed below) use subsequent adopters for robustness purposes in our analysis. ${ }^{10}$

One might naturally wonder about the circumstances behind these states adopting large school subsidy laws before other states. As Table 1 suggests, the policies passed by states here include several relatively large states but feature states from across different parts of the country; the laws were signed both by democratic and republican governors. Moreover, while five states are included, the number of states seriously pursuing or subsequently enacting similar school subsidy programs is much larger; Huerta and d'Entremont (2007) count at least 40 states considering tax credit programs along the lines of the programs used here. ${ }^{11}$ Further, several

\footnotetext{
${ }^{9}$ There are subsequent programs of this type in three states: Indiana, Louisiana, and Wisconsin. One program, enacted in Alabama in 2013, operates through the individual tax code and includes a student eligibility restriction. The program provides a refundable tax credit to parents who transfer children out of failing public schools.

${ }^{10}$ The continued commonality in shared characteristics also suggests that, even if a fuller set of subsequent laws were available, parsimonious specifications would likely still be needed for estimations exploring heterogeneous effects.

${ }^{11}$ Although they do not figure in our analysis, state charter school programs were also becoming widespread during and after our analysis period; all five states with tax credits we use in our main specifications also have charter school programs. With
} 
states have had attempted passage of programs blocked by court ruling or referenda, including California, Colorado, Florida, Michigan, Vermont, and Washington. ${ }^{12}$ These recent adopters can be exploited to create a more refined control-group for estimation below - that is, if estimates using "late" adopters as a control group yield highly different estimates than estimates using all non-Table-1 states as a control group, it would raise concerns that there are strong differences in private school markets that are related to (eventual) school-subsidy adoption. Similar estimates regardless of the control group used would lessen this concern. We explore this below.

But while the large number of states eventually undertaking school subsidy programs can allow some investigation into the selectivity of states listed Table 1, one might wonder what determined the timing of law passage in different states. In some cases the timing stems in part from political events. ${ }^{13}$ But the prominent force in the timing of these laws was perhaps judicial. School subsidy programs face important legal hurdles, with a foremost obstacle being the historical presence of Blaine Amendments in several state constitutions. In 1875, James Blaine, a congressional representative in Maine, proposed an amendment to the constitution to preclude grants or appropriations to sectarian institutions or organizations. ${ }^{14}$ While the amendment was not adopted (falling four votes short of adoption in the Senate), 37 states subsequently adopted "Blaine Amendments" to their constitutions. ${ }^{15}$ The movement to adopt these amendments was often associated with anti-Catholic sentiment (Huerta and d'Entremont, 2007). Further, 29 states include a constitutional clause to prohibit the state from forcing residents to support any ministry (as states sometimes did in Colonial times). Only three states have neither a Blaine Amendment nor a compelled support clause. ${ }^{16}$

Blaine Amendments and anti-support clauses have historical roots that far precede the modern schoolchoice movement; to quote Duncan (2003), "the social and religious contexts in which the State Blaines operate today are far different from those of their origins." But they have proven to be somewhat unpredictable determinants of the legality of school-subsidy policies today. Court decisions over the validity of these policies have varied. In Illinois, two separate cases on the legality of the state's tax-credit program

the exception of Iowa, each state's charter program preceded its tax credit by at least three years. Given the differential timing of charter expansion, these programs should not drive the effects we report here; if anything, the availability of these alternative public-school programs would mitigate any effects of private-school subsidies on private school revenue and enrollment.

${ }^{12}$ Additionally, in May 2013, Senator Marco Rubio (R-FL) introduced a bill to establish a federal tax credit that would be available to both individuals and corporations.

${ }^{13}$ For example, Florida's programs coincided with Jeb Bush's election in 1998 after he narrowly lost his electoral bid in 1994, and the corporate tax credit in Arizona was made law by governor Janet Napolitano in a compromise with the state legislature during state budget negotiations after she had vetoed four such bills earlier (Welner, 2008). Tom Ridge signed Pennsylvania's law after four failed attempts to get vouchers through the legislature (Averett and Wilkerson, 2001), although Adams (2002) refers the adoption of Pennsylvania's credit as "quiet" and "little noticed."

${ }^{14}$ During his career, Blaine also served as Secretary of State, Speaker of the House, a Republican Presidential nominee, and a member of the Senate.

${ }^{15}$ The wording of Blaine's proposed amendment was, "No State shall make any law respecting an establishment of religion, or prohibiting the free exercise thereof; and no money raised by taxation in any State for the support of public schools, or derived from any public fund therefor, nor any public lands devoted thereto, shall ever be under the control of any religious sect; nor shall any money so raised or lands so devoted be divided between religious sects or denominations."

${ }^{16}$ The three states are Louisiana, North Carolina, and, unexpectedly, James Blaine's own state of Maine. 
yielded six separate decisions before the legality of the program was recognized (Huerta and d'Entremont, 2007). When Arizona enacted the first tax-credit school-subsidy program the legislature was in fact uncertain of the program's legality (Werner, 2008), although the legality was ultimate affirmed in the State Supreme Court ruling of Kotterman V. Killian in 1999. But state-constitutional clauses on religion have provided limitations on school subsidies, as discussed in chapter 5 in Werner (2008). In some states where it appears that Blaine Amendment language may preclude subsidies, there have been attempts to alter the language of the law. ${ }^{17}$ Thus, the process for enacting subsidies can involve legislative and judicial deliberation, creating uncertainty on the timing of enactment within adopting states.

The decision of governments and courts to revisit legal provisions that have "slumbered in state constitutions for over a century" (Duncan, 2003) may in part coincide with other efforts to reform public education. This appears to be true in several of the states listed in Table 1. In particular, the establishment of Florida's McKay program coincided with an increase in public school funding for school construction and maintenance, and Pennsylvania's tax-credit program coincided with a program to support educational improvement organizations that provide innovative public school programs. However, if these coincidental laws made public schooling more attractive, they presumably worked against the efficacy of laws intending to facilitate student's matriculation to private schools.

Another concern is simply one of reverse causation-growth in private school revenue may allow for private schools to devote lobbying resources towards school subsidies, so increases in private school revenue lead to greater school subsidies, not the other way around. Although such a coincidental timing pattern might be unlikely given the discussion above, we can address these concerns in the empirical part of the paper by including a number of controls for a state's socioeconomic circumstances and the population of school-aged children. Additionally, we discuss empirical tests of this concern below. Before turning to the empirical methodology, however, we next discuss the data used.

\section{Data}

This section discusses the data used; additional details are provided in the appendix. The primary financial data we use come from the Core Financial Files produced by the National Center for Charitable Statistics (NCCS). These files contain information collected from Internal Revenue Service (IRS) Form 990 and Form 990-EZ for 501(c)(3) public charities with at least $\$ 25,000$ in receipts. Although these organizations are "non profit", they must file tax returns containing detailed financial information. As mentioned in the last section, several states changed their laws in limited ways or very late in our sample (Ohio after 2003; Utah after 2005;

\footnotetext{
${ }^{17}$ For example, in 2013 North Dakota considered a bill (HC3037) to alter the state's constitution to make it easier to permit state support of sectarian education.
} 
Georgia and Rhode Island after 2007; and Louisiana after 2008); we omit these state/year observations. The primary financial variable we use is program service revenue, which is revenue earned from activities that form the basis of an organization's exemption from tax. Tuition charged by a private school is a canonical example, although some other revenue, such as from the sale of school supplies, would also be included in the figure we use. Using a figure that includes all program service revenue, rather than just tuition, is sensible as schools may potentially attempt to obtain school-subsidy rents by raising both tuition and other student fees. ${ }^{18}$ It also reflects true revenue, as opposed to estimating revenue based on "sticker" tuition prices. ${ }^{19}$ Our NCCS data use tax returns covering fiscal years from 1991 to 2009. We know of no other large-scale annual dataset that provides this type of financial information for US private schools. ${ }^{20}$

This nonprofit tax-return data includes information for all nonprofits filing such returns, not just schools. To identify private schools in the tax return data, we match the tax return data to information in the Private School Universe Survey (PSS). Conducted biennially by the National Center for Education Statistics, the PSS is intended to be a census of private schools in the United States, but it does not include any financial information about schools. We match the two datasets using information on school name and address. As discussed in the appendix, school names and addresses are only available in the PSS beginning in 2005/06 but are available for all years in the NCCS data. This allows us to match any school in the PSS from 2005 onwards, and then "follow" that school back in time. However, this procedure will miss schools that existed during the period of our sample (e.g., the 1990s) and exited the sample before the 2005/2006 PSS.

There are several steps we can take to address this fact. First, we explored the degree of "churn" in our data to see if there is strong attrition as the sample goes back into the 1990s. Fortunately, this is not the case, as over 70 percent of the observations in our matched sample can be followed back to 1995 and over half can be followed back to 1991. Next, we address this concern by identifying schools in the NCCS using additional information on charities' tax returns. NCCS data include a charity's National Taxonomy of Exempt Entities (NTEE) Classification System code, which describes an organization's primary purpose. We identify charities that classify themselves using codes B20 (elementary and secondary schools), B24 (primary

\footnotetext{
${ }^{18}$ Other examples of program service revenue would include admissions fees charged by a museum, or conference registration fees charged by the ASSA for attending its annual meeting.

${ }^{19}$ One may wonder how financial aid awarded by a school relates to reported program service revenue. There may be several ways that in practice private schools adjust program service revenue when awarding financial aid; it appears to us that reporting financial aid as reduced program service revenue is a much more common practice among schools than other possible alternatives. The vast majority of private schools (on the order of 95\%) report providing financial aid. While the dataset in this paper does not provide information on expenditures comparable to the information available on revenue, we obtained a set of fuller 990 forms for some of our sample via Morningstar, and in these cases positive grant expenditures are reported on Form 990 for only about $30 \%$ of school-years. If schools in our sample make financial aid available at the same rate as schools at large do, then most are reporting it as reduced program service revenue. In that case, decreases in aid in response to subsidies will be captured by as an increase in program service revenue (and revenue per student, all else equal) in the results below.

${ }^{20}$ There are several concepts of "year" that are relevant here. As discussed in the appendix, the NCCS uses several notions of year when compiling the data; our use of the term reflects the fiscal year for which a charity files its tax return. The PSS timing is to October of a given year; we thus match NCCS and PSS data together based on the October in which the relevant fiscal year falls. Since most fiscal years are either calendar years or July-to-June fiscal years, this matching procedure should work well. We discuss a few additional issues with handling the timing of school subsidy laws more below.
} 
and elementary schools), and B25 (secondary and high schools). The benefit of identifying schools in this way is that it avoids the bias towards schools that are open towards the end of the sample period. ${ }^{21}$ Below, we show results using the PSS matched schools and then present estimates where additional NCCS-identified schools are added. The estimates are quite similar, suggesting that our matching procedure works well.

The populations of schools in the PSS and NCCS datasets are potentially different; most notably, some religiously affiliated private schools - particularly Catholic Schools - are not required to file tax returns and almost never voluntarily do so. Our sample essentially excludes Catholic schools. Our matched sample contains in an average year about 3,200 schools with about 800,000 students; or about one out of every nine private schools and one out of every five private-school students in a typical year. Appendix Table 1 shows our success rate in matching schools between the tax data and the PSS and shows that our sample consists of schools that are larger and less likely to be religious than the average private school. However, the PSS data contain information on religious affiliation, and about half of all schools in the sample report that they are religiously affiliated. Appendix Table 2, and its accompanying text, gives a state-by-state breakdown.

Nonetheless, one might wonder how the results for our sample of schools might extend to other schools. We will attempt to be careful in drawing strong conclusions for all schools from the results below. But we note that several of our results would be noteworthy even if they pertained to our sample alone. Further, there are several facts that give us optimism that our results might serve at least as a rough guide for the effects of subsidies on other schools. First, we can construct the ratio of students enrolled in schools filing a form 990 to all private-school students; if this ratio changes in response to the passage of a school subsidy, it might raise a concern that schools using subsidies concurrently decide to file. Estimating such a regression using the baseline specification below suggests that the fraction of filing schools does not change when subsidies are introduced; the estimated impact of a subsidy on the fraction of students in filing schools is small, statistically insignificant, and produces a confidence interval ruling out a modest increase (or decrease) in the relative size of filing schools. ${ }^{22}$

Second, we can explore trends in teacher and enrollment populations in our sample and in the PSS overall; evidence of strongly divergent trends would also raise a concern about the generalizability of our sample. Figure 3 shows trends over time in average enrollment (Panel A) and in average number of teachers (Panel B). Clearly the schools in our sample are larger and have more teachers. But the two panels show that in both samples there is a slight decline in enrollment over the period of study and that the number of teachers

\footnotetext{
${ }^{21}$ One might ask why we do not simply construct the sample using NTEE codes, dispensing with the PSS entirely. First, some schools may not be identified under these codes, as discussed in the appendix. Second, some schools identified in this fashion cannot be matched to PSS data, so we cannot calculate revenue-per-student (the tax return information does not give the number of students in a school), which we use in some estimates below.

${ }^{22}$ Using a specification matching column 5 of Table 6 below, where the dependent variable is the fraction of students in filing schools (mean of 0.199, standard deviation of 0.10), the coefficient on the School Subsidy Laws variable is 0.0044 and the state-clustered standard error is 0.0036 , producing a $95 \%$ confidence interval from -0.0029 to 0.012 .
} 
is reasonably flat. The trends in these characteristics for schools in our sample seem reasonably comparable to the trends for all schools in the PSS. ${ }^{23}$

Third, for the year 2007, we obtained from Arizona school-by-school information on the amount of taxcredit-eligible scholarships claimed; using this information, we can explore whether the schools in our sample receive disproportionate amounts of subsidies. Evidence of this might affect the perceived generalizability of our results. In this particular state and year, the schools in our sample received about $18 \%$ of all tax-credit scholarships. We have $60 \mathrm{AZ}$ schools in our sample this year while the PSS lists 334, so that the fraction of schools in our sample $(60 / 334=0.1796)$ matches the fraction of school subsidy funds captured by our sample quite well.

Finally, while we do not have financial information in the PSS, we do have enrollment, and below we can compare the estimated effect of enrollment for our sample to the effect for all schools. The precision of the results (for both samples) can vary based on the construction of our standard errors, but fortunately the estimates are qualitatively similar and suggest that the change in enrollment seen in our sample reflects the change in enrollment for other private schools. We can also use this enrollment-based comparison to mediate our out-of-sample predictions for our financial results and below we do so. We will also use tuition information in the Schools and Staffing Survey to adjust these predictions; doing so suggests that our tax sample has reasonable predictive content for other private schools. In sum then, our sample includes only a fraction of private schools and these schools differ in certain observable ways from the typical private school. But we are optimistic that the results below may be informative for other private schools as well.

After constructing our tax-return sample, we then drop several types of observations. First, we drop a small number observations with multiple matches between the PSS and NCCS. We also exclude a few schools that report being located in different states in different years, including any that fail to report a state in any year. We also drop tax returns for schools in outlying US territories, which we cannot match to enrollment records, since the PSS does not cover these territories. We exclude observations that report zero or negative program service revenue or do not report program service revenue on their tax returns. Lastly, and perhaps most notably, the NCCS guidelines themselves note that the tax return dataset sometimes lists very large revenue values; we drop observations where revenue per student figures are extremely high; over $\$ 100,000$. This amounts to about 4 percent of the sample. It is possible that a legitimate private school has per-student revenue of over $\$ 100,000$ but we expect that most of these observations are erroneous, or may reflect the returns of parent organizations, such as a hospital or university, that offer education or daycare

\footnotetext{
${ }^{23}$ Since the tax sample is less likely to be religiously affiliated, one might wonder if there are divergent trends in the share of the samples made up by religious schools. Appendix Figure 2 shows that from the mid 1990s on the two samples show similar trends (although again different levels) in the share of schools that are Catholic, religious-but-not-Catholic, or not religiously affiliated.
} 
to children. Below we discuss estimates where this $\$ 100,000$ cutoff is altered; the coefficients from samples with different cutoffs are typically qualitatively similar to the baseline estimates.

\section{Specification}

This section describes the specification we use for our baseline estimates. We first aggregate our sample to the state/year level. ${ }^{24}$ We estimate:

$$
y_{s y}=\alpha \operatorname{index}_{s y}+\beta \mathrm{X}_{s y}+\theta_{s}+\vartheta_{y}+\mathrm{T}_{s y}+\varepsilon_{s y}
$$

where, for the baseline specification, $y_{s y}$ is total private-school revenue in state $s$ in year $y$ in year 2012 dollars, index is an index for school subsidy laws (described below), $\mathrm{X}$ is a matrix of regressors, including controls for state median income, the state unemployment rate, the population density, the fraction of a state's residents that are non-citizens, the fraction born abroad, the total population, the population of white children ages $6-17$, and the population of nonwhite children ages $6-17$. These variables are taken from the Bureau of Labor Statics, the Census, and the American Community Survey; see the appendix for details. The term $\theta_{s}$ represents a set of state dummies, $\vartheta_{y}$ represents a set of year dummies, and $T_{s y}$ represents a set of state-specific time trends and their coefficients; both linear and quadratic trends will be used. The term $\varepsilon_{s y}$ is noise.

The index used in the baseline specification simply equals the number of different types of school subsidy laws present in a state: restrictive individual income-tax credits, unrestricted individual credits, corporate income tax credits (all are restricted), or traditional vouchers (all are restricted). The index takes on values zero (no school subsidy), one (one school subsidy program) or two (two types of school subsidy program, true in Florida after 2001, Arizona after 2006, and Iowa after 2006). However, estimates will also be presented allowing different types of program to have different effects.

This specification will allow us to capture effects of subsidies both on intensive margins (existing schools realizing changed outcomes) and extensive margins (the number of schools in communities changing) that would be missed by (e.g.) school-level regressions with school fixed effects. Also, the policy variation we focus on is at the state/year level. Further, this specification will motivate the additional results below based on school-level regressions, regressions on the number of schools, and extensive-versus-intensive effects, and this specification also facilitates our discussion of elasticities and welfare effects. But an obvious caveat to

\footnotetext{
${ }^{24}$ As discussed in the appendix, the number of fiscal year 1998 NCCS returns is quite small, apparently because of a regulatory change in the dissemination of IRS 990 forms that year. After aggregating the data, we linearly impute revenue figures for fiscal year 1998.
} 
this specification is that our programs vary by size, so that the coefficients must be interpreted with this variation in program size in mind. We also report results using logged outcome variables below; the use of logs helps to mitigate any effects of variety in program size. Fortunately, the results from logged regressions are similar to the baseline results using the above specification.

In constructing the index, it can be unclear whether a law enacted in a certain year would first have an impact in the current school year or instead would impact subsequent school years. For our baseline regressions, we create our index based on the year a school subsidy program was enacted, but, to account for the uncertainty in the timing of donations following enactment, include a dummy variable that equals unity the year a state enacts a school-subsidy law (and zero all other years). There are a few exceptions to the basic rule of coding a law based on year of enactment. First, Iowa's first law was enacted in 1987-before our sample begins - but was expanded in 1996 and again in 1998. State administrative data show a large increase in the program after the 1998 reform; we consequently code Iowa's index as going from zero to one in $1998 .^{25}$ Next, Arizona's individual credit was enacted in 1997, but donations were not eligible for a credit until 1998, and use of the program was limited until 1999 (Arizona Department of Revenue, 2008). We code Arizona's first year as 1998 .

Finally, while the McKay voucher program began in 1999, it was initially a pilot program; the program saw a rapid expansion in 2001. ${ }^{26}$ We thus code both Florida programs beginning in 2001. Altering the timing of these laws to their earlier enactments, or simply dropping the year of enactment and the year following enactment from the regressions for all states, yields similar estimates to those shown here.

The specification above can be interpreted as a "difference-in-difference" style estimate. States adopting school subsidy laws are allowed to differ from other states, and can even have different trends over time given our trend controls. The specifications also account for changing economic and demographic trends across states and over time. However, the number of treatment states (five) is relatively small. As Conley and Taber (2011) note, inference with difference-in-difference style estimates using a small number of treatment groups can be problematic, as estimates can be subject to a finite-sample-bias. They propose an inference technique to account for the small number of treatment groups in the estimation. In the results that follow, we both report conventional state-clustered standard errors, as well as 95-percent confidence intervals, using an approach based off of Conley and Taber's method. We discuss the method in the appendix but provide a synopsis here. First, we estimate, using OLS on the full sample, the equation

$$
y_{s y}=\beta \mathrm{X}_{s y}+\theta_{s}+\vartheta_{y}+\mathrm{T}_{s y}+\varepsilon_{s y}
$$

\footnotetext{
${ }^{25}$ Program expenditures tripled from 1997 to 1998 , going from $\$ 3$ million to $\$ 9$ million (Iowa Department of Revenue, 2012).

${ }^{26}$ Enrollment grew from 970 students in 00/01 to 5,013 in the 01/02 school year (Florida Office of Independent Education \& Parental Choice, 2006).
} 
where the index coefficient has been removed, and create residuals $\tilde{\varepsilon}_{s y}$. We next assign the treatment states' index values to the control states, where the assignment is done at the state level (e.g., the index values for all years in Arizona are assigned to Alabama). After the five true state-index profiles have randomly been assigned to five new states, we regress the new-states' residuals $\tilde{\varepsilon}_{s y}$ on the state-index profiles, state and year dummies, and record the coefficient. We run 5,000 such regressions to estimate a distribution of coefficients that "should" be zero, but may be nonzero or non-symmetric due to finite sample bias. Using the null-hypothesis that the true coefficient value for the actual-law-change regression is zero, we can "invert" this distribution to construct a 95-percent confidence interval that takes the finite sample bias into account. The confidence intervals produced by this approach are often similar to those suggested by the standard errors. But, particularly when the number of treatment states in a specification is very small (e.g., three), the Conley-Taber approach can produce much less precise results. This may partly reflect limited statistical power of their test-in Table 3 of their paper they report Monte Carlo results where, for a very small number of law changes, the power of their test (the ability of their test to reject a null that is false) is poor, with a genuinely false null rejected (at the $5 \%$ level) only 30 percent of the time with two law changes. We explored several asymptotically equivalent ways of constructing Conley-Taber style confidence intervals and here we report the least precise; other Conley-Taber-based approaches (see the appendix) provided greater precision. Fortunately, many of the key results below are similarly precise either using standard errors or the alternate CT confidence intervals.

Table 2 provides selected means for variables of interest. The first row, total revenue, reflects total program service revenue added up for all schools in a given state and year; the mean of this variable in the first column of the table is the mean of aggregated total revenue, averaged over all states and years. The typical observation in our sample thus records a little over $\$ 200$ million in private school revenue. The means given in column 2 are for the 62 state/year combinations where school subsidies were greater than zero. Total revenue is somewhat smaller in observations with unrestricted programs, as shown in the last column. The second row, total enrollment, refers to total enrollment in our matched sample. The third row is unweighted revenue per student, suggesting per student revenue of about $\$ 10,000$ across our sample. The typical school has about 238 students, reflecting (as in Figure 3) that tax-sample schools are slightly larger than the average private school overall. "Spending on School Subsidies" is constructed as before, reflecting vouchers, individual credits and corporate credits. The final row is subsidies per "user" where user is constructed as in Figure 2. As noted earlier, unrestricted programs are smaller than the average subsidy program; Table 2 shows that they are about half the size of the average program. We will keep this in mind when discussing the estimates below. 


\section{Estimates}

\section{A. Baseline Estimates}

Before turning to regression estimates, Figure 4 shows the basic result by plotting out total revenue before and after a state first imposes a school subsidy law. We calculate average private-school revenue in year 2012 dollars in our treatment states four years before a school law changed, three years before, and so on, up to four years after. Of course, in theory it is possible that the revenue effect will be zero. But the figure shows a clear and persistent jump in total revenue following the law change. Accounting for the pre-existing upward trend before the law change, the size of this jump appears to be about $\$ 30$ million to $\$ 40$ million in magnitude. We interpret a jump of this size below. It is also noteworthy that there is an absence of any clear jump up or down in the year prior to the laws' enactment (although we can test for this more formally).

Table 3 shows baseline regression results. The dependent variable is total program service revenue, in $\$ 1000$ s, for all schools in a state/year. Coefficients for the school-policy index are shown in each column, below that is the state-clustered standard error and below that the $95 \%$ confidence interval as adapted from Conley and Taber (2011). The first column shows that, when an additional school subsidy policy is introduced (increasing the index's value by 1), total program service revenue in our sample increases by about $\$ 25$ million. This is about 10 percent of average revenue (slightly more for all observations, slightly less for those with a subsidy) as shown in Table 2. Typical school-subsidy spending is about $\$ 60$ million annually; the estimates indicate that-within our sample alone-this spending raises revenue substantially. We take up the extension of these effects to all private schools momentarily.

The rest of the table explores this result under other specifications. Column 2 removes the right-hand-side controls, but this does not alter the estimates. In column 3, we include only the sample of states that currently have school-subsidy laws, that had them prior to our sample, or that adopted them after our sample ends. ${ }^{27}$ If the policy changes we are studying are from a highly selected group, then this alteration of our control group could lead to different estimates. Fortunately, this is not the case, and comparing the states that made the policy changes we use here to those that adopted similar policies just a few years later does not change the estimates. The next column adds quadratic (rather than just linear) state-specific trends, but the estimate is not sensitive to this change. ${ }^{28}$ Column 5 adds in schools identified using the NTEE Classification System code, rather than just crosswalking schools between the PSS and the NCCS datasets. This raises

\footnotetext{
${ }^{27}$ At the suggestion of a referee, we also redid the baseline estimate using only states with court-blocked programs (mentioned in the text in Section 2) as a control. These estimates are often similar to the estimates here, but feature a much smaller sample and are (unsurprisingly) sometimes less precise.

${ }^{28}$ It is possible to obtain results similar to ours without the use of time trends, but these results can be sensitive to changes in the specification and can be less precise. Typically, however, results based on variation closer to our law cutoffs (e.g., results without trends that limit the sample to years near the law changes, omitting the influence of secular trends in the data far before or after the law changes) produce results closer to the main estimates.
} 
the number of individual school/year observations in the sample from about 61,000 to about 78,000 . If the estimates change significantly here, it might raise concerns over the sample selection process of matching PSS and NCCS data. In fact, in this case the result is somewhat larger in magnitude. ${ }^{29}$ Overall, Table 3 indicates that the average subsidy program raised revenue by about $\$ 30$ million, a number roughly comparable to the jump shown Figure $4 .^{30}$

Appendix Table 3 presents an additional robustness check of this result; the first column in that appendix table repeats the baseline estimate in Table 1 but adds in five "lead" dummies that equal zero (e.g.) one year before a school-subsidy law is enacted and zero all other years. The table shows there is no evidence of pre-existing trends in revenue, revenue per student, or total students in states that passed a school subsidy law, suggesting that the results here are not driven by reverse-causation or by some other unobservable driver in these states. The last three columns add post-enactment lags as well. Looking at these coefficients, there does not appear to be a clear pattern (at least within the first few years) of program growth across outcomes, although the diminishing (in absolute value) post-lag coefficients for enrollment in the last column suggest that enrollment effects may increase somewhat over time.

Table 4 presents an alternate test of this possibility. As mentioned above, the tax returns include NTEE codes which identify an organization's primary purpose. In Table 4 we estimate regressions on total revenue for a variety of nonprofits that we do not expect to respond to school subsidies. As mentioned in the appendix, many schools in the PSS may not be designated as schools by the NTEE. Using our data matched to the PSS, we counted the number of PSS schools within each NTEE code, and in Table 4 report results for the six NTEE categories with few (less than 30, although alternate cutoffs give similar results) matches in the PSS. These regressions use the baseline estimations shown in column 1 of Table 3. Revenues are again in 1000s of 2012 dollars and as before groups with zero or negative revenues are excluded along with organizations with revenue above the 99th percentile in each code. If all types of nonprofit organizations, such as zoos and aquariums or voter registration groups, saw a surge in revenue that coincided with school subsidy laws, this would raise a concern that the increase we identify might be driven by some coincidental growth in nonprofits generally. But the findings in Table 4 indicate that this is not the case. The estimates are all close to zero and, with the exception of public safety, insignificant.

Table 5 explores the effect of school subsidies across different types of program. In particular, we explore whether programs that restrict what students may use the subsidies differ from unrestricted programs. Table

\footnotetext{
${ }^{29}$ As mentioned earlier, using different revenue-per-student cutoffs provide similar estimates for the results in Table 3. For example, using the full sample regardless of per-student revenue yields a baseline estimate for total revenue of 43,779 [std err $=28,586]$. In contrast, limiting the sample to schools that have less than $\$ 25,000$ in revenue per student yields total revenue coefficient of $43,867[17,456]$.

${ }^{30}$ Redoing column 1 with logged revenue, the coefficient of interest becomes 0.083 [se $=0.38$ ], suggesting an effect close to the that in the levels regression.
} 
5 thus adds to the regressions in Table 3 an additional variable that is simply a dummy which equals unity if a state had an unrestricted subsidy program in effect. The first row of the table thus reflects the states with corporate credit laws, along with one traditional voucher law (the McKay voucher in Florida). The unrestricted dummy will indicate how unrestricted laws differ, and the sum of these two coefficients will show the absolute (rather than the relative) effect of the unrestricted laws.

The first column, which repeats the baseline regression in Table 3 with the new dummy variable added, suggests that the increase in school revenue is smaller for unrestricted programs than for restricted programs. However, as noted in Table 2, unrestricted programs are also typically smaller (about half of the size) in terms of dollars spent, and later specifications in Table 5 suggest that the impact of unrestricted programs is about half the size of the other programs, indicating that the dollar-for-dollar impact of these programs may be comparable. Further, while the standard errors on the unrestricted coefficients suggest a significant difference in several specifications, the confidence intervals are less precise. The imprecision may in part reflect power problems for the CT method when the number of treatment groups is very small, as noted earlier. In any case, Table 5 suggests that the dollar-for-dollar effect of unrestricted subsidies may be similar to or perhaps smaller than other school subsidy programs. As in Table 3, the results are qualitatively similar across a variety of specifications. ${ }^{31}$

Looking at revenue per student will allow us to see whether schools' increased revenue is derived by increasing enrollment, or by raising tuition \& other fees, or both. ${ }^{32}$ Table 6 presents results on the incidence of school subsidies by exploring how subsidies affect per-student revenue, both for all schools in the sample combined and by type of law. Since these regressions, unlike those in Tables 3, 4, and 5, are per-student, they are weighted by number of students. (Unweighted estimates are similar.) The baseline estimate is statistically insignificant. Its point estimate suggests that schools increase per-student revenue (e.g., by raising tuition) by a little over $\$ 250$ when a new school subsidy program is introduced. Perhaps the closest estimate to this in the literature is in Angrist, Bettinger, Bloom, King, and Kremer (2002), who find that winning a lottery in Bogotá for a voucher worth $\$ 190$ raised average private-school tuition and fees by $\$ 52$, so that every dollar of voucher funding raised tuition and fees by about 25 cents, close to what the point estimate here suggests. We note, however, that their research design compares voucher-lottery winners and losers. This approach, while excellent for the focus of their paper, could miss market changes in response to vouchers affecting all students, so that comparability of the estimates is ex ante unclear. The estimate here should be interpreted

\footnotetext{
${ }^{31}$ When using logged expenditures, the baseline index coefficient becomes 0.076 [0.37] and the unrestricted dummy becomes 0.028 [0.136]. This suggests similar proportional effects between the types of programs (perhaps slightly larger for unrestricted) which would fit with the results in Table 5 given that the revenue bases for the two types of programs differ.

${ }^{32}$ If schools price discriminate, than increases in actual tuition paid might occur even if the sticker price remains unchanged; this is an advantage of our measure. If schools respond to subsidies by cutting actual prices to some students, or increasing prices for others, our measure will capture the net effect of these behaviors.
} 
as reflecting changes in price from several channels, including: schools price discriminating against voucher students, schools raising tuition and fees generally, marginal students entering the private market choosing schools with different prices than the average private-school student, and infra-marginal students choosing more expensive private schools.

The next column separates out unrestricted laws, and here the point estimates are different: the coefficient suggests that unrestricted laws see an increase in per-student revenue relative to other laws. While the CT confidence interval is large, the standard error for the unrestricted coefficient indicates the differential impact of these laws is statistically significant. ${ }^{33}$ Further, a Wald test of the hypothesis that the sum of the two coefficients is zero is rejected at the one percent level, suggesting that unrestricted laws raise prices absolutely (and not just relatively). The implied increase in per student revenue in response to an unrestricted program is over $\$ 1000$ per student and reasonably close to our estimate of subsidy-funding-per-user noted at the end of the prior section. Thus we cannot reject the hypothesis that the incidence of the subsidy falls entirely on families for the restricted laws, but we can reject full incidence on families for unrestricted laws, where the estimates are compatible with schools capturing the entire subsidy. The data are compatible with the incidence of subsidies falling entirely on schools for one type of law and entirely on families for another type of law. The following columns consider similar robustness tests as before (the table omits results adding NCCS-identified schools to the sample as student counts are unavailable for these schools and the number of students is now used in the dependent variable). In column 4, a Wald test again rejects that the sum of the coefficients is zero and the combined coefficients, while slightly smaller than before, are still reasonably close to the overall subsidy-per-user average.

Together, Tables 5 and 6 suggest potentially similar dollar-for-dollar effects of subsidies on revenue across different programs but potentially different dollar-per-student effects, indicating that the laws have different effects on enrollment. Table 7 shows results with total enrollment in private schools in a state and year as the dependent variable; these results confirm the findings in Tables 5 and 6 . In column 2, the corporate credit programs and McKay voucher see an increase in student enrollment of about 2,000 students. The average statewide private school enrollment for observations with a restricted subsidy is a little over 20,000, so the coefficient indicates a reasonably large increase of about $10 \%$ in enrollment which is clearly statistically significant. This effect is smaller than the simulated prediction of a roughly one-third increase in enrollment from a $\$ 1000$ voucher in Ferreyra (2007), although her modeling of the voucher is different from here and she assumes full mobility of households. ${ }^{34}$ Further, the results for the unrestricted laws are strikingly different; the estimates indicate that these laws saw zero enrollment growth and standard errors indicate that this

\footnotetext{
${ }^{33}$ The logged revenue-per-student result is similar, with the index coefficient at $0.008(\mathrm{se}=0.032)$ and the unrestricted dummy coefficient at $0.089(0.038)$.

${ }^{34}$ See the first row in Table $5 \mathrm{~A}$ of her paper.
} 
difference is statistically significant. ${ }^{35}$ Using quadratic trends produces similar results. ${ }^{36}$

The last two columns of Table 7 report estimates using total enrollment from the Private School Universe Survey as the dependent variable. The sample size is smaller as the PSS is only biennial. The specification is the same as in columns 1 and 2 except that the year-of-enactment dummy is also set to 1 for the year following enactment. The coefficient on restricted programs is a little over 3 times as large in the PSS sample. ${ }^{37}$ While the standard errors are larger, the CT confidence intervals again suggest an increase for school subsidy laws. The coefficients suggest that our tax sample may have slightly larger increases in enrollment than would be the case if the sample were perfectly representative, although the precision of the estimates certainly would allow for the tax sample to be representative. Moreover, the estimates in the last two columns are qualitatively similar to the results using the tax return data, with restricted subsidies increasing enrollment much more clearly than unrestricted ones.

In summary, the above estimates suggest that school-subsidy laws have reasonably large effects on private school revenue. However, we find evidence that the mechanisms by which revenue increases are different across types of laws; in particular we find that unrestricted laws lead to higher per-student revenue with little evidence of any change in student enrollment. In the appendix (Figures 3, 4, and 5) we provide simple state-by-state graphical evidence of these results. The figures show moving averages of revenue, revenue-per-student, and enrollment before and after a state first adopts a subsidy. The data show revenue jumps for all states (except perhaps Iowa); the jumps for restricted subsidies are more visually compelling (although again their revenue bases and programs are on average relatively larger). Similarly, the unrestricted states see clear enrollment jumps, while the overall revenue-per-student results are (unsurprisingly) more mixed. A simple visual inspection across the states fits well with the estimations shown here.

Why do the effects of these laws differ? There are a few possible explanations. First, it may be that private schools enjoy a greater degree of market power for students they have already enrolled who then qualify for an unrestricted subsidy. Importantly, unrestricted laws allow families to target funding towards children already in private schools, including their own children, while other laws place restrictions on student eligibility based on income, disability, or a student's prior enrollment. For the case of unrestricted laws, schools with relatively high market power can thus raise their tuition or other fees to capture the rent created by the subsidy. In contrast, the market may be more competitive for disabled students in public

\footnotetext{
${ }^{35}$ The Tables 6 and 7 estimates are typically similar when including only schools with per-student revenue below $\$ 25,000$ or when including all schools. The only notable difference is that, when using only schools with less than $\$ 25,000$ per student revenue in the sample, both restricted and unrestricted subsidies lead to higher revenue-per-student, with the coefficient in column 1 in Table 6 becoming 0.65 [0.20]. But the results in the second column of Table 7, that there is a positive enrollment effect for restricted programs and no such effect for unrestricted, is found in all samples.

${ }^{36}$ Again, estimates using logs are qualitatively similar; using logged enrollment here produces an index coefficient of 0.079 (0.30) and an unrestricted coefficient of $-0.092(0.073)$.

${ }^{37}$ While small, the unrestricted effect (the difference 5516 - 5477 in column 6 versus 1951 - 1944 in column 2 ) is a little over 5 times larger for the PSS.
} 
school or low income students in public school who subsequently become interested in attending private school after qualifying for a restricted scholarship. If the marginal cost of adding one of these students is low, it is possible that schools may compete for these latter students by increasing enrollment with minimal changes in tuition or other student fees. A difference in market power could thus reconcile the estimates here.

A second, non-exclusive, explanation is based on information. If schools want to cream skim potential entrants, the nature of this skimming might vary between the different laws. When restricted subsidies are provided, e.g., via STO organizations, schools may partner with these organizations to identify and vet attractive students. With unrestricted subsidies provided via individual credits, this screening device is unavailable. If schools are faced with an increase in demand following an unrestricted subsidies' implementation, and if (for example) family income is positively related to the unobservable characteristics that schools want to select on, then schools may subsequently be able to raise tuition to improve their screening process.

\section{B. Intensive and Extensive Margin Effects}

The above specifications use aggregate data from all schools to capture effects from existing schools realizing different outcomes along with the composition of schools changing over time. In Table 8, we examine the importance of these different channels. The first three columns of panel A limit the aggregated sample to "long term" schools that are observed in the tax data at least 15 years. We see that about half of the revenue growth found for all schools in Table 3 is realized by these long term schools, with about half or slightly less of all enrollment growth accruing to these schools. Thus these schools, which make up about half of the sample, see roughly proportional-to-market-share revenue and enrollment increases. Subsidies thus increase enrollment and revenue from "long-standing" schools as well as relatively younger schools. Panel B shows that, as expected, these effects are stronger for restricted subsidies.

The last three columns in each panel run school-level regressions including school fixed effects so that these estimates will thus be identified from "intensive-margin" variation within schools over time. (Results without fixed effects, which would confound intensive-margin effects with other effects, are smaller and less precise). Column 4 in panel A suggests that revenue increases by about $\$ 59,000$ for the typical school when a subsidy is introduced. There are about 110 schools in the typical state/year with a subsidy, so the revenue increase from changes within schools over time is about $\$ 6.5$ million $(59 \times 110=6,490)$. This is notably smaller than the amount seen in the baseline estimates of even column 1 of Table 8 -the revenue growth realized by long-term schools alone is larger than that suggested by within-school revenue growth for all schools. We return to this observation momentarily. Before doing so, we note that in column 5 of panel B 
the revenue-per-student effects for unrestricted programs are smaller and less significant than before. This suggests that at least some of the driver for the increases in revenue-per-student is that students choose to attend more expensive schools than before (rather than schools raising revenue per student while enrollment is static as a static-enrollment story would lead to larger estimates in panel B). Looking lastly at enrollment, the story is much the same as with revenue, with relatively small within-school estimates. This suggests that extensive margin effects-changes in the number of schools-play an important role in changing revenue and enrollment outcomes.

Table 9 considers this by estimating regressions on the number of schools in a state/year observation. The first two columns, using all schools, suggest about 10 new schools for restricted programs and no growth for unrestricted. Table 2 indicates that the typical school in a subsidy state has about $\$ 2.5$ million in revenue. If the marginal school driving the estimates in Table 9 has revenue close to the average, than revenue growth from the extensive margin would be about $\$ 25$ million. Adding the $\$ 6.5$ million intensive margin effect from the Table 8 estimates would produce revenue gains similar, and slightly larger, than the revenue effects estimated earlier (although the difference could be reconciled, for instance, if marginal schools had lower-than-average revenue). The estimates thus suggest that revenue increases both from extensive margin changes (changes in the number of schools) and intensive margin (within-school) revenue growth, with the former being quite important.

Interestingly, the next two columns of Table 9 suggest that this is in part driven by survival of long term schools (rather than just younger schools). The number of long-term schools increases with subsidies. Again using a $\$ 2.5$ million average revenue-per-school, and supposing that the aggregate $\$ 6.5$ million within-school estimate from Table 8 applies to this sample of schools, the implied revenue effect on long term schools would be $4 \times 2.5=\$ 10$ million on the extensive margin and $\$ 6.5$ million on the intensive, for a total revenue effect of about $\$ 16.5$ million, which is close to the implied effect in the first column of Table 8 earlier. In other words, the discrepancy in revenue results in Table 8 can be resolved by appealing to the extensive margin.

Total school size can also be estimated for all schools in the PSS, not just those in the tax sample. The last two columns of Table 9 report results on the total number of schools each state/year in the PSS. As mentioned earlier our sample consists of about $1 / 9^{\text {th }}$ of all schools, so that one might expect PSS coefficients about nine times as large. The coefficients suggest an effect about seven times as large, although again the precision of the estimates (which as before varies across inference methods) would allow the tax sample to be fully representative. In the next section, we use both the tax sample and the full PSS sample to make out-of-sample revenue predictions. 


\section{C. Effects for All Private Schools}

One could use these results to provide estimates for the effect of subsidies on all private school revenue. Taking revenue as simply $P \times Q$, where the price is per-student revenue and quantity is total enrollment (and is a function of price), for a small change in private school subsidization rate sub one would have the change in revenue as $\frac{\delta P}{\delta s u b} Q+P \frac{\delta Q}{\delta P} \frac{\delta P}{\delta s u b}$. This formula might best be thought of as appropriate for small changes in a subsidy, but larger changes would require an additional "large effect" adjustment of $\frac{\delta P}{\delta s u b} \frac{\delta Q}{\delta P} \frac{\delta P}{\delta s u b}$. This gives the revenue equation:

$$
\frac{\delta P}{\delta s u b} Q+P \frac{\delta Q}{\delta P} \frac{\delta P}{\delta s u b}+\frac{\delta P}{\delta s u b} \frac{\delta Q}{\delta P} \frac{\delta P}{\delta s u b}
$$

This is illustrated in figure 5 ; the two shaded areas represent the effect of a small change (where $\Delta Q=\frac{\delta Q}{\delta P} \frac{\delta P}{\delta s u b}$ and $\left.\Delta P=\frac{\delta P}{\delta s u b}\right)$, but the unshaded rectangle of area $\Delta P \Delta Q$ will become relevant in calculations as the change in the subsidy grows large.

Moreover, the basic supply/demand model in the figure obviously makes questionable assumptions for the private education market; we note a few of these below but we can first check whether this revenue formula provides a decent within-sample estimate of the change in revenue from subsidization. Further, since our estimates earlier provide the total change in revenue-per-student for all students, our use of the formula does not impose the assumption in the picture that the subsidy raises prices for all students, nor does our calculation assume that all students are charged the same price.

Beginning with a within-sample use of the formula, we can estimate the incidence on schools, $\frac{\delta P}{\delta s u b}$, using column 1 of Table 6 divided by the per-student-funding estimate of $\$ 820$, the enrollment change $\frac{\delta Q}{\delta P} \frac{\delta P}{\delta s u b}$ using column 1 of Table 7 over the per-student funding estimate, and for $P$ and $Q$ we can use the sample averages for states with subsidies, which are about $\$ 9,586$ and 21,000 respectively (as opposed to using the full sample means in Table 2). This yields a calculated revenue effect of:

$$
\frac{\delta P}{\delta s u b} Q+P \frac{\delta Q}{\delta P} \frac{\delta P}{\delta s u b}+\frac{\delta P}{\delta s u b} \frac{\delta Q}{\delta P} \frac{\delta P}{\delta s u b}=\left(\frac{280}{820} 21000+9586 \frac{1512}{280} \frac{280}{820}+\frac{1512}{280}\left(\frac{280}{820}\right)^{2}\right) \cong 24,850
$$

which is quite close to the baseline estimate of 24,311 .

Turning to estimates for all schools, we can estimate $\frac{\delta Q}{\delta P} \frac{\delta P}{\delta s u b}$ using the PSS estimate in column 5 of Table 7 again divided by full-sample subsidy estimate of $\$ 820$; we can use the PSS to calculate average enrollment in our treatment states and we can estimate per-student revenue using average tuition in the Schools and Staffing Survey (which is much smaller and available far fewer years than our sample, but will provide a 
representative national tuition average); the SASS data suggests that in 2003 (about the midpoint for our post-subsidy sample) that average tuition for all private schools in the country (in year 2012 dollars) was about $\$ 8250$. Tuition in the SASS is based on highest charged tuition; it may overestimate $P$ if tuition is lower for some students but it may underestimate $P$ as it does not include other fees. We thus use $\$ 8250$ as a reasonable benchmark. The only term in the formula we do not have a direct estimate for is the price effect of subsidies for all schools, $\delta P$.

Table 10 reports estimated revenue effects, the estimated price elasticity of supply, and estimated dollar for dollar effects for all private schools using the above revenue formula and a variety of assumptions for $\delta P$. We focus on the effects of all schools since the dollar-for-dollar effects appear to be roughly comparable across types of programs. The first row shows the change in revenue using the above formula (with block bootstrapped Conley-Taber-based 95\% confidence intervals; their construction is described in the appendix), the second row shows the assumed change in revenue per student, and the bottom two rows estimate the elasticity of supply and the effect on private school revenue for each dollar of funding spent.

The first column reports estimates under the assumption that price (that is, revenue per student) does not change when subsidies are introduced; here any revenue increase comes from a quantity increase alone. Column 2 assumes that the effect on per student revenue for all schools is half of the effect we estimate for the tax sample. Column 3 assumes that the incidence of subsidies in our sample matches the incidence in all schools. Column 4 assumes that the incidence for other schools is twice the incidence in our sample, and the last column assumes full incidence, $\frac{\delta P}{\delta s u b}=1$.

Regardless of the assumption on how school subsidization affects revenue per student, we find that subsidies lead to large increases in revenue, with all estimates suggesting that funding raises revenue on close to a dollar-for-dollar basis or more. (Figure 5 shows how a greater-than-dollar-for-dollar effect is quite possible, as the rectangle $A B P_{D} P_{S}$ could easily be smaller than the area covered by the change in revenue.) A naive calculation of incidence could be made by simply multiplying our tax-sample revenue estimate 24,311 by 5 , implying a dollar for dollar effect of $5 \times 24,311 / 57,420=2.12$; which is comparable to several of the numbers in the table. Overall, Table 10 suggests that subsidies have large impacts on school revenue for all private schools, and that the results from our tax sample provide a reasonable first-order guide for all schools even if the incidence of schools out of our sample diverges widely from what we observe here.

\section{D. Deadweight Loss and the Elasticity of Demand}

One could also use our estimates to calculate the deadweight loss of school subsidy programs. As a very simple starting point, one could simply estimate a traditional "deadweight loss triangle" created by the subsidy, 
where the base of the triangle would reflect the increase in student enrollment as a school subsidy program is enacted, and the height of the triangle would be "per-student" spending on an average school subsidy program. We could then divide the area of the triangle by the total spent on the average subsidy program, creating a "deadweight-loss-per-dollar spent estimate." (The calculation of the triangle is illustrated in Figure 5.)

Such a calculation of course involves several assumptions, including that the market structure would facilitate such a deadweight loss calculation and that our estimates can be extrapolated to private schools not in the sample. The latter assumption is implicitly made here when we calculate the height of the triangle as statewide subsidy spending over the statewide number of students assisted. (The revenue estimates in Table 10 suggest that our results seem representative on some margins, and we can use our PSS enrollment estimates for this calculation.) A more rigorous depiction of the market structure would have to take a strong stand on the objective function of private schools, which is beyond the scope of this paper. Here we take all the laws together for our calculation, although one could consider differing effects. Our simple calculation also ignores any change in deadweight loss from any "spillover" benefits from greater private education. The calculation also is static and ignores dynamic effects of the laws. Further, the calculation ignores any distortions in the public education sector and any changes to these distortions that subsidies create. $^{38}$ If subsidies lessen distortions stemming from the non-competitive public education sector, or improve educational outcomes generally in other ways, then the calculation here may be too pessimistic. These benefits of subsidies may also increase over time, so that dynamic considerations could again lead us to overstate deadweight loss here. On the other hand, if long-term enrollment gains from subsidies are larger than the estimates here (as households become more mobile over time), this will mechanically increase estimated deadweight loss (the triangle would get bigger), although even a much larger enrollment response (e.g., twice as large as estimated here) would still lead to a relatively small deadweight loss calculation. Our estimate would also of course be larger by considering the distortionary effects of taxation (as taxes are raised to pay for the subsidies), but, as noted below, the canonical estimates of this distortion are also relatively small. Given these caveats, we think presenting a deadweight loss estimate is worthwhile for motivating future work, for adding context to our estimates, and as a starting baseline, but we suggest the estimate be interpreted with care.

Using the PSS estimate which treats all laws the same in Table 7 to calculate deadweight loss in this way yields a deadweight loss per dollar spent of $\$ 0.03$, with a $95 \%$ confidence interval (calculated using the delta method) of -0.04 to 0.11 . We know of no similar calculation to put this into perspective, although we might

\footnotetext{
${ }^{38}$ For a discussion of cross-market deadweight loss effects, as well as a discussion of deadweight loss calculation more generally, see Hines (1999).
} 
note that the canonical deadweight loss estimates of income taxation in Harberger (1964) for high-income families are similar. The fact that we estimate an (arguably) modest deadweight loss is not surprising, given that the estimate on student enrollment is not large.

One could also use the coefficients here to construct an estimated elasticity of demand for private school. Such an elasticity might best be interpreted as applying to marginal students responding to a subsidy program, and again will be based on the assumption that the relevant estimated price changes from our sample can extend to the population of private schools. For this estimate we can take the increase in enrollment from the PSS estimate in Table 7 for the change in quantity. The change in price is generated from the baseline per-student-revenue estimate in Table 6 minus average per-student subsidy funding for states with a school subsidy law. Dividing the change in quantity by the change in price, and then multiplying by the ratio of average price over average enrollment yields an elasticity of -0.52 , with a $95 \%$ confidence interval of -1.1 to $0.07 .{ }^{39}$ This is slightly larger in absolute value than the baseline elasticity of -0.19 in Dynarski, Gruber, and Li (2009). However, as their elasticity might reflect the price responses of families with siblings already in private school, one might interpret our estimate as not surprising if families with siblings in private school are less price sensitive than marginal families responding to subsidies.

\section{Conclusion}

This paper investigates how private school subsidies impact private school finances. Despite the current explosion of state-instituted subsidy programs, we know of no work that discusses the impacts of large subsidy programs on private schools, or that explores the incidence of school subsidies, or that calculates elasticities or traditional welfare effects in the context of large-scale school-choice-based subsidization.

We find that school subsidy programs raise school revenues, and that the effects are dollar for dollar or larger. There is evidence that different types of programs impact schools differently. In particular, unrestricted and restricted subsidies appear to increase revenue in different ways, with the latter raising revenue through increases in student enrollment while the former raise revenue through increases in per-pupil expenditures. As we note above, these results may suggest that schools view the market for students currently attending public schools as more competitive than is the market for students already enrolled in private school. Alternately, these results might suggest that private schools cream skim students, and that the STOs and other organizations involved in providing restricted subsidies allow schools to cream skim students in a way that other subsidy programs do not. Back-of-the-envelope calculations indicate that the

\footnotetext{
${ }^{39}$ The elasticity estimate uses coefficients from two different regressions; we estimate them together using Seemingly Unrelated Regression and use the resulting variance-covariance matrix for estimating the variance of the elasticity when applying the delta method.
} 
deadweight loss of school subsidies overall may be reasonably moderate in size.

There are several caveats to our findings. First, as noted above, even in cases where our results suggest no change in enrollment in the face of school subsidization, this does not necessarily mean that the composition of students stayed the same after subsidies were introduced. Even if total enrollment is unchanged it could be that school subsidies allow newly marginal students to "crowd out" other students who are either screened out, or unwilling to pay the higher tuition (or both) following the policy reform. For example, subsidization may have led nontraditional (e.g., minority) students towards private education. Rinz (2015) gives a rigorous investigation of this possibility, and considers how large voucher programs may have changed student/teacher ratios and other educational inputs for students of different races. Next, while our laws have commonalities with many very-recently-enacted laws, the overall impact of these new laws will only be known with certainty in the future. Additionally, the simulation-based work noted in the introduction often assumes fully mobile households; if household mobility is greater over a long period of time, then the findings here may underestimate the long-term impacts of subsidies. Extending our results to more recent programs as they grow in the future represents an excellent area for future work. 


\section{References}

[1] Adams, Helen. 2002. "Very Quietly, Voucher Plan Works" Sunday News July 7, page A1.

[2] Alliance for School Choice. 2012. School Choice Now: The Year of School Choice. Washington DC: Alliance for School Choice.

[3] Angrist, Joshua, Eric Bettinger, Erik Bloom, Elizabeth King, and Michael Kremer. 2002. "Vouchers for Private Schooling in Colombia: Evidence from a Randomized Natural Experiment," The American Economic Review 92(5), 1535-1558.

[4] Arizona Department of Revenue. 2007. "Individual Income Tax Credit for Donations to Private School Tuition Organizations: Reporting for 2007, Executive Summary." Accessed July 292013 at http://www.azdor.gov/Portals/0/Reports/private-school-tax-credit-report-2007.pdf

[5] Averett, Nancy, and James Wilkerson. 2002. "Tax Law Little Aid to Poor Students" The Morning Call, August 4.

[6] Bland, Karina. 2000. "School Tax Credits Wide Open to Abuse," Arizona Republic, April 9.

[7] Brewer, Jan. 2012. Press Release in Response to Maricopa County Superior Court decision on the Constitutionality of Arizona Empowerment Scholarship Accounts, January 30. Accessed at http://www.hcreo.com/press-releases/?Tag=National\%20School\%20Choice\%20Week on July 29, 2013

[8] Cameron, Colin, Jonah Gelbach, and Douglas Miller. 2008. "Bootstrap-Based Improvements for Inference with Clustered Standard Errors," The Review of Economics and Statistics 90(3), 414-427.

[9] Caputo, Marc. 2013. "Marco Rubio's School Voucher Plan Shows Strong Jeb Bush Ties," Miami Herald, February 12.

[10] Center on Education Policy. 2011. Keeping Informed about School Vouchers. Research report accessed 7/19/13 at www.cep-dc.org/cfcontent_file.cfm?Attachment=Usher_Voucher...pdf

[11] Chakrabarti, Rajashri. 2013. "Vouchers, Public School Response, and the Role of Incentives: Evidence from Florida," Economic Inquiry 51(1), 500-526.

[12] Chan, Winnie. 2006. "School Choice and Public School Performance" University of Toronto Working Paper.

[13] Conley, Timothy, Christopher Taber. 2011. 'Inference with 'Difference in Differences' with a Small Number of Policy Changes," The Review of Economics and Statistics 93(1), 113-125. 
[14] Crothers, Julie. 2014. "Vouchers, Teaching of Creationism Raise Questions," The Miami Herald, February 9 .

[15] Daniels, Mitch. 2011. "Indiana Go. Mitch Daniels Signs Historic Voucher Bill into Law," PRNewswire, May 5.

[16] Dinerstein, Michael, and Troy Smith. 2014. "Quantifying the Supply Response of Private Schools to Public Policies," Working paper.

[17] Dynarski, Susan, Jonathan Gruber, and Danielle Li. 2009. "Cheaper by the Dozen: Using Sibling Discounts at Catholic Schools to Estimate the Price Elasticity of Private School Attendance," NBER working paper 15461.

[18] Duncan, Kyle. 2003. "Secularism's Laws: State Blaine Amendments and Religious Persecution," Fordham Law Review 72(3), 493-593.

[19] Epple, Dennis and Richard Romano. 1998. "Competition Between Private and Public Schools, Vouchers, and Peer-Group Effects," The American Economic Review 88(1), 33-62.

[20] Ferreyra, Maria Marta. 2007. "Estimating the Effects of Private School Vouchers in Multidistrict Economies," The American Economic Review 97(3), 789-817.

[21] Figlio, David. 2009. "Voucher Outcomes," in Brends, Springer, Ballou, and Walberg (eds.) Handbook of Research on School Choice, New York: Routledge.

[22] Fischel, William. 2006. "The Courts and Public School Finance: Judge-Made Centralization and Economic Research," in Hanushek and Welch (eds.) Handbook of the Economics of Education, Vol. 2, Elsevier.

[23] Florida Office of Independent Education \& Parental Choice. 2008. "John M. McKay Scholarship Program June Quarterly Report," accessed November 24, 2014 at http://www.floridaschoolchoice.org/Information/McKay/quarterly_reports/mckay_report_june2008.pdf

[24] Florida Office of Independent Education \& Parental Choice. 2013. "John M. McKay Scholarships for Students with Disabilities Program," accessed November 24, 2014 at http://www.floridaschoolchoice.org/Information/McKay/files/Fast_Facts_McKay.pdf

[25] Florida Office of Independent Education \& Parental Choice. 2006. "John M. McKay Scholarships for Students with Disabilities Program," Information taken from the May 2, 2006 version of www.floridaschool- 
choice.org/Information/McKay/files/Fast_Facts_McKay.pdf using web.archive.org (i.e., the "wayback machine")

[26] Forster, Greg. 2008. Lost Opportunity: An Empirical Analysis of How Vouchers Affected Florida Public Schools. Study released by the Friedman Foundation for Educational Choice, the Foundation for Excellence and the James Madison Institute. Accessed 12/1/2014 from edchoice.org

[27] Friedman Foundation, 2013. The ABCs of School Choice: the comprehensive guide to every private school choice program in America. Accessed 7/19/2013 from edchoice.org

[28] Greene, Jay. 2001. An Evaluation of the Florida A-Plus Accountability and School Choice Program. Center for Civic Innovation, Manhattan Institute, New York.

[29] Harberger, Arnold. 1964. "Taxation, Resource Allocation, and Welfare," in Due (ed.) The Role of Direct and Indirect Taxes in the Federal Revenue System. Princeton, NJ: Princeton University Press.

[30] Hines, James Jr. 1999. "Three Sides of Harberger Triangles," Journal of Economic Perspectives 13(2), 167-188.

[31] House Concurrent Resolution No. 3037. Sixty Third Legislative Assembly of North Dakota.

[32] Hoxby, Caroline. 2003. "School Choice and School Productivity: Could School Choice be a Tide that Lifts All Boats?" in Hoxby (ed.) The Economics of School Choice. University of Chicago Press.

[33] Hoxby, Caroline and Sonali Murarka. "Comprehensive yet Simple: Florida's Tapestry of School Choice Programs," in Peterson (ed.) Reforming Education in Florida: Recommendations from the Koret Task Force, Hoover Institution Press, 2007.

[34] Huerta, Luis, and Chad d'Entremont. 2007. "Education Tax Credits in a Post-Zelman Era: Legal, Political, and Policy Alternatives to Vouchers?" Education Policy 21(1), 73-109.

[35] Illinois Department of Revenue. 2013. "Annual Report of Collections and Distributions, Fiscal Year 2011 and Fiscal Year 2012," accessed November 24, 2014 at http://tax.illinois.gov/publications/AnnualReport/Annual-Report-2011-2012.pdf

[36] Iowa Department of Revenue. 2012. "Iowa's Tuition and Textbook Tax Credit: Tax Credits Program Evaluation Study," accessed July 29, 2013 at http://www.iowa.gov/tax/taxlaw/TuitionTextbookEvaluationStudy.pdf 
[37] LeFevre, Andrew. 2014. "Pennsylvania's Education Improvement Tax Credit Program: A Winning Educational Partnership." Show-Me Institute. Accessed November 24, 2014 at http://showmeinstitute.org/documentrepository/doc_view/473-pennsylvanias-education-improvement-tax-credit-program-a-winning-educational-partnership.l

[38] Minnesota House of Representatives Research Department. 2011. "Income Tax Deduction and Credits for Public and Nonpublic Education in Minnesota," Research report accessed July 19, 13 at http://www.house.leg.state.mn.us/hrd/pubs/educcred.pdf

[39] Murray, Sheila, William Evans, and Robert Schwab. 1998. "Education Finance Reform and the Distribution of Education Resources," The American Economic Review 88(4), 789-812.

[40] Nechyba, Thomas J. 2000. "Mobility, Targeting, and Private-School Vouchers," The American Economic Review 90(1), 130-146.

[41] People for the American Way. 2003. "Who Gets the Credit? Who Pays the Consequences?" Special Report released March 4.

[42] Pollak, Thomas H. and Kathryn L. S. Pettit. 1998. "The Finances of Operating Public Charities, 1989-1995," Unpublished paper, National Center of Charitable Statistics, The Urban Institute, Washington, D.C.

[43] Reese, Michelle. 2009. "Private School Tax Credits Rife with Abuse," East Valley Tribune, August 1.

[44] Rinz, Kevin. 2015. "Undone by the Market? The Effects of School Vouchers on Educational Inputs." Unpublished working paper.

[45] Schaeffer, Adam. 2009. "Education Tax Credits," in Brends, Springer, Ballou, and Walberg (eds.) Handbook of Research on School Choice, New York : Routledge.

[46] U.S. Department of Education. 2009. Education Options in the United States. Publication from the Office of Innovation and Improvement, Accessed 7/19/2013 at http://www2.ed.gov/parents/schools/choice/educationoptions/educationoptions.pdf

[47] Welner, Kevin (2008) NeoVouchers. Lanham, MD: Rowman \& Littlefield Publishers, Inc.

[48] Wolf, Tom. 2015. The 2015-2016 Pennsylvania Governor's Executive Budget. Accessed on 10/21/2015 at http://www.portal.state.pa.us/portal/server.pt/document/1481984/2015-16_budget_document_pdf 


\section{Appendix A: Additional Description of State School-Subsidy Pro- grams (for online publication)}

\section{Arizona}

In 1997, Arizona offered a tax credit to individual taxpayers for donations made to STOs. The credit was initially equal to the amount of the donation made and capped at $\$ 500$. STOs are required to spend at least $90 \%$ of the money they receive on scholarships and may not limit scholarship recipients to only one school. Some details of Arizona's credit have changed over time. Married and unmarried taxpayers were initially eligible for the same $\$ 500$ credit, but over time, the limit for married taxpayers has gradually increased to $\$ 1,000$. Since the program's inception, donors have been prohibited from requiring that their gifts be used to fund a scholarship for any of their dependents. However, there is evidence that in fact many parents did ensure that their contributions resulted in scholarship support for their children, either by "suggesting" their child as a recipient or by (e.g.) making a quid-pro-quo agreement with another family where each family would designate a gift towards the other family's child (Reese, 2009; Bland, 2000). In response to such behavior Arizona later (after the period of this study) prohibited donors from designating their gifts for any particular student.

Through 2009, Arizona's individual tax credit was claimed by an average of just over 55,000 taxpayers per year, with each donating an average of $\$ 700$ to STOs (2012 dollars). Over the same period, STOs awarded an average of 19,000 scholarships annually, with the average scholarship being worth nearly $\$ 1,700$ (2012 dollars). ${ }^{40}$ Neither the scholarships nor the tax credits that generate the funding that supports them are means tested, and individual scholarship award amounts are not limited by law. Some students may receive scholarships from multiple STOs. STOs may use any criteria in awarding scholarships, but must consider financial need. Details of that consideration are not specified, however, and this seems to amount to a requirement to collect information on income from scholarship applicants. Scholarship applicants face no eligibility requirements, and schools receiving scholarship students are required only to abide by a limited set of non-discrimination rules. Schools with scholarship students are not prohibited from discriminating on the basis of religion.

Arizona's corporate tax credit, which was launched in 2006, is somewhat more restrictive on certain dimensions than its individual credit. Although there is no per taxpayer limit on the credit, there is an

\footnotetext{
${ }^{40}$ Minnesota House of Representatives Research Department, 2011.
} 
aggregate limit on the total value of credits awarded each year. In return for donations to STOs, tax credits are awarded dollar-for-dollar to corporate taxpayers on a first-come, first-served basis until the aggregate limit is reach. Over our period of study, the aggregate limit ranged from $\$ 10$ million to $\$ 17$ million annually (though the cap was not reached each year). Taxpayers may not designate their contributions for use by particular students. STOs must spend at least $90 \%$ of revenue they receive through the corporate tax credit on scholarships for children with family incomes below $185 \%$ of the federal free or reduced price lunch program cutoff. In order to receive a scholarship, students must have been enrolled in a public school the previous year, be just starting school, or have previously received a scholarship. Scholarships were capped at $\$ 4,200$ - $\$ 4,500$ for grades K-8 and $\$ 5,500$ - $\$ 5,800$ for grades 9-12 during our period of study. Very few scholarships were awarded in the program's first year, but from 2007-2009, Arizona's corporate tax credit financed over 2,800 scholarships per year worth an average of $\$ 2,500$ annually (2012 dollars). ${ }^{41}$

\section{Florida}

In 2001, Florida established a tax credit for corporate tax payers that made donations to organizations similar to Arizona's STOs. The credit is limited to 75 percent of a taxpayer's liability, although taxpayers can carry forward unused claims for up to three years. Credits are awarded dollar for dollar with donations, excluding the amount by which donations may affect federal tax liability. As Table 1 shows, scholarships awarded by STOs under this program are restricted to low income students. The maximum scholarship awarded ranged from $\$ 3,500$ in 2002 up to $\$ 3,950$ in 2009 . Over that period, donations funded scholarships for 18,000 students per year on average. STOs award new scholarships on a first-come, first-served basis; priority is given to scholarships being renewed. STOs may not reserve scholarships for use at particular private schools or award scholarships to the children of owner/operators of STOs or private schools.

To be eligible to receive a scholarship, students must be eligible for free or reduced-price school lunches and have been enrolled in a public school the year before, have received a scholarship from an STO the year before, or be entering kindergarten through fifth grade. Siblings living with students meeting these criteria are also eligible for scholarships, as are students currently or recently placed in foster care. Scholarships may be renewed as long as the student's family income remains below $230 \%$ of the federal poverty level (below $200 \%$ FPL before 2008). Between 200\% and 230\% FPL, the value of the scholarship is reduced. Students may not receive multiple scholarships. STOs may also award scholarships to cover the cost of transportation to a public school outside a student's home district, but the share of students receiving this type of support is small (Hoxby and Murarka, 2007). Taxpayers may not designate specific children to benefit from their contributions to STOs.

Florida's corporate tax credit program was preceded by the establishment of the McKay Voucher program

\footnotetext{
${ }^{41}$ Minnesota House of Representatives Research Department, 2011.
} 
in 1999. This voucher program provides fairly generous voucher payments to students with disabilities (as defined in Table 1). The maximum possible payment equals the lesser of (a) the amount the student would have "received" in public school or (b) the amount of the private school's tuition and fees. In order to be eligible for a voucher, students must have spent the previous year in a public school or the Florida School for the Deaf and Blind, or have received specialized instruction under a current individualized education plan, or be the dependent child of a member of the military who was recently relocated to Florida. Students participating in the program may attend another public school that meets their needs or receive a voucher for use at a participating private school. Vouchers are not means tested and can be used until the student returns to public school, graduates, or turns 22 years old. Although Table 1 shows that this program began in 1999, participation in the program was quite limited in its first two years (the program in 1999 was in fact a pilot program). From 2001 through 2009, vouchers were awarded to an average of 15,600 students per year, with per student spending averaging nearly $\$ 7,300$ (2012 dollars) over that period. ${ }^{42}$ Although students in the program have the option of attending a different public school, these figures pertain only to vouchers used in private schools.

Iowa

Iowa's credit for tuition and textbook expenses was enacted in 1987; it initially offered a non-refundable, $5 \%$ credit on the first $\$ 1,000$ of tuition and textbook expenses per dependent to tax filers with adjusted gross income under $\$ 45,000$ who claimed the standard deduction or a deduction of up to $\$ 1,000$ to those who itemized. In 1996, the deduction was eliminated, the tax credit was made available to all filers, the match rate was increased to $10 \%$, and the income restriction was eliminated. In 1998, the match rate was again increased to $25 \%$, and the list of eligible expenditures was expanded to include some fees, as well as expenses associated with extracurricular activities. Expenses related to the teaching of religious doctrines are not eligible; at religiously affiliated schools, credits are pro-rated based on the share of time students spend in non-religious classes.

From 1998-2009, the portion of our analysis period in which Iowa's tax credit was in widespread use, about 162,000 Iowa taxpayers claimed it annually, receiving an average credit of $\$ 99$ (2012 dollars). ${ }^{43}$ Iowa's credit is applicable to expenses incurred on behalf of dependent students at accredited public and private schools in Iowa. In 2010, 7.2 percent of claimants reported the maximum allowable level of educational expenses (i.e. $\$ 1,000$ per dependent child), claiming the maximum credit. Iowa does not collect information on the types of schools dependent children attend, but taxpayers claiming reporting the maximum level of educational expenses are likely paying private school tuition; that proxy for private school attendance

\footnotetext{
${ }^{42}$ Florida Office of Independent Education and Parental Choice, 2006, 2008, and 2013.

${ }^{43}$ Minnesota House of Representatives Research Department, 2011.
} 
matches the share of all Iowa students attending private schools in 2010-11. ${ }^{44}$

Illinois

In 1999, Illinois adopted a credit providing a non-refundable credit equal to $25 \%$ of educational expenses above $\$ 250$ incurred on behalf of dependent children. The maximum value of the credit is $\$ 500$ per family. Eligible expenses include private school tuition as well as book and lab fees that may be incurred by students in either public or private schools. Observers have noted that while the program can cover public-school expenses, families with public-school students "receive very little in the form of tax credits...the credit serves primarily as a reward for Illinois parents who send their children to private schools" (People for the American Way, 2003).

In order for a student's expenses to be eligible for this credit, that student must be an Illinois resident, under 21 years of age at the end of the school year for which the credit is claimed, and enrolled full time in one a K-12 program that provides instruction in English, including homeschooling. Schools must be in compliance with Title IV of the Civil Rights Act of 1964 in order for their students expenses to qualify for the tax credit. Between 2000 and 2009, an average of 214,000 families claimed the tax credit each year. The average tax credit over that period was worth $\$ 382$ (2012 dollars). ${ }^{45}$ This level of tax credit implies average educational expenses of more than $\$ 1,775$ (2012 dollars).

\section{Pennsylvania}

Pennsylvania enacted a corporate credit in 2001; corporations can claim a nonrefundable credit for contributions to STOs (although the state's legislation refers to them simply as "scholarship organizations") up to 75 percent of contributions made, or 90 percent of contribution if a corporation provides "a written commitment" to provide such a scholarship with the same contribution for two consecutive tax years. The overall credit amount is limited by a fixed appropriation which grew from $\$ 20$ million in 2001 to about $\$ 44$ million in 2009. A tax credit for any corporation is limited to $\$ 300,000$ per tax year. Tax credits are not awarded for activities that are part of the normal course of a firm's business.

During the period of study here, scholarships could be awarded to families with less than $\$ 50,000$ in income; this figure has changed since the time period of this study. Students with disabilities are subject to less restrictive family income requirements. Scholarships must be used within Pennsylvania at schools that comply with Title VI of the Civil Rights Act of 1964. Between the 2001 and 2009 academic years, Pennsylvania's tax credit generated nearly $\$ 40$ million of contributions toward K-12 scholarships per year, funding scholarships averaging $\$ 1,260$ for 31,500 students annually (2012 dollars). ${ }^{46}$ Beginning in 2004, tax credits were also available for donations to pre-kindergarten scholarship organizations, generating an

\footnotetext{
${ }^{44}$ Iowa Department of Revenue, 2012.

${ }^{45}$ Minnesota House of Representatives Research Department, 2011; Illinois Department of Revenue, 2013

${ }^{46}$ LeFevre (2014).
} 
additional $\$ 6.7$ million (2012 dollars) awarded as 4,800 scholarships per year. Scholarship values may not exceed the actual amount of tuition charged, or the amount charged to non-scholarship students.

\section{Appendix B: Description of Data (for online publication)}

\section{Enrollment and Tax Data}

The financial data we use come primarily from the Core Financial Files produced by the National Center for Charitable Statistics (NCCS) from the Internal Revenue Service's (IRS) Return Transaction Files. These files contain financial information collected from Internal Revenue Service Form 990 and Form 990-EZ for 501(c)(3) public charities with at least $\$ 25,000$ in gross receipts. ${ }^{47}$ Many religiously affiliated organizations, such as Catholic schools, are not required to file Form 990 or Form 990-EZ and are not included in these data. $^{48}$

There are two notions of "year" to consider in the Core Files. The first is the fiscal year reported on a tax return; this is the notion of a year that is most relevant for our study. The second is the "circa year," which refers to the year that a particular set of tax returns was assembled by the NCCS for inclusion in the Core data files. The NCCS creates its "circa year" data files at the beginning of each year by collecting financial information from the most recent available tax return for each organization. ${ }^{49}$ We combine these files for 1989-2010 to create our sample. The term "circa year" thus refers to the year that a set of tax returns was collected. This may not be the same as the fiscal year since, when the NCCS collects its data and assembles a "circa year" dataset, the most recent available tax record for a nonprofit may not be from the most recent fiscal year, and an organization may thus have the same fiscal year record appear in multiple circa years. In these cases, we keep the record from the most recent circa year and drop older records of the duplicated fiscal year. We match the tax-return data to other datasets using the fiscal year reported on the tax return, rather than the circa year.

Our primary financial variable of interest is "program service revenue." Reported in Part VIII, line $2 \mathrm{~g}$ of the 2012 version of Form 990, program service revenue is income a non-profit organization generates by charging for the provision of its tax-exempt service. ${ }^{50}$ Private school tuition is a canonical example of program service revenue, but this variable could also include revenue derived from other sources, such as the

\footnotetext{
${ }^{47}$ Beginning in tax year 2010 , the filing threshold was $\$ 50,000$ in gross receipts.

${ }^{48}$ Although the information on these forms is collected for tax compliance purposes, researchers have concluded that error rates are suitably low for use in academic research. See Pollak and Pettit (1998).

${ }^{49}$ More specifically, a circa year file will include all the returns received by the IRS in a certain calendar year as well as returns of organizations that have filed in the previous two years but do not appear in the present year's files. In more recent years, NCCS has started creating files that are organized by fiscal year rather than circa year. However, these fiscal year files are not available for the period of our study.

${ }^{50}$ The previous version of Form 990 reported program service revenue in Section I, Line 2. Form 990-EZ also reports program service revenue in Section I, Line 2. The definition of program service revenue does not change across years or forms.
} 
provision of food service or the sale of school supplies.

For data on enrollment and other school characteristics, we use the Private School Universe Survey (PSS). Conducted biennially by the National Center for Education Statistics (NCES), the PSS is meant to be a census of private schools in the United States. Response rates are routinely in excess of $90 \%$. The survey covers enrollment, grades offered, number of teachers, religious affiliation, and racial composition, but it does not include any financial information about schools. We next describe the procedure of matching these two datasets.

\section{Crosswalk and School Identification Procedures}

In order to create a dataset that contains financial and enrollment information for the same schools, we create a crosswalk between the NCCS data and the PSS. Although the two datasets do not contain a common identifier, the PSS data contain schools' names beginning in 2005-06 and schools' street addresses beginning in 2007-08. The NCCS data contain names and addresses in all years. Using all years of NCCS data and the 2005-06, 2007-08, and 2009-10 rounds of the PSS, we match names and addresses to create a crosswalk between the two datasets that links an organization's Employer Identification Number (EIN), reported on its tax forms, to its NCES-assigned PIN number. We then use this EIN-PIN correspondence to match tax and enrollment records in all available years of data.

In constructing our crosswalk, we collect four types of matches: exact address matches (street address, zip code and state), exact name matches within the same zip code, similar names within "zip plus four" area, and exact name matches within the same state, allowing for zip code mismatches. Address-based matches in the last two cases were inspected and names compared manually to ensure accuracy. This procedure generates a small number of cases in which we match a single EIN to multiple PINs or vice versa. We discard all such matches. ${ }^{51}$

In addition to those matched using our crosswalk, we identify schools in the NCCS data using their National Taxonomy of Exempt Entities (NTEE) Classification System codes, which the IRS uses to classify non-profit organizations. We consider schools that are classified using codes B20 (elementary and secondary schools), B24 (primary and elementary schools), and B25 (secondary and high schools). We do not consider preschools (code B21), since the scholarships financed by the tax credits we study generally cannot be used to attend preschool. This approach also does not identify any organizations that function as schools but are identified using other codes. A Christian high school, for example might be identified by NTEE code X20,

\footnotetext{
${ }^{51}$ One could imagine cases in which one identifier or the other might change for legitimate reasons (e.g. a school could come under new management, or it could reincorporate itself as a tax entity, leading a single PIN to match, appropriately, to multiple EINs, or a single non-profit organization operates multiple schools, leading a single EIN to match to multiple PINs). However, the EIN in the NCCS data and the PIN in the PSS are generally intended to be permanent identifiers, so in most cases they should not change over time.
} 
a code used for organizations related to Christianity, instead of B25. Similarly, a school for developmentally disabled children might be classified using code P82 (developmentally disabled centers) rather than one of the codes we consider. Since organizations are only classified using one NTEE code, we are unable to identify any schools that are not classified primarily as schools.

\section{Differences between Enrollment and Tax Samples}

The PSS and NCCS data are collected with very different goals, and so there are important differences between the types of schools found in each sample. The PSS is intended to include all schools that offer classroom instruction in at least one grade from kindergarten through twelfth grade and are not supported by public money. There are no enrollment, revenue, or religious affiliation requirements for inclusion in the PSS. Since charter schools are supported by public money, they are not covered by the PSS. ${ }^{52}$

The NCCS data describe non-profit organizations generally and only incidentally include schools. Moreover, since filing requirements are designed to apply generally, broad categories of schools are likely to be under-represented in the NCCS data. Most notably, many religious organizations are not required to pay taxes, file tax returns, or even register with the IRS. Many religious organizations also operate private schools. Schools operated by religious organizations, therefore, are less likely to be included in the NCCS data than they are to be included in the PSS, which surveys schools of all religious affiliations. The NCCS data may also miss small schools with very low levels of revenue, since organizations with gross receipts under $\$ 25,000$ during our analysis period were not required to file Form 990 or Form 990-EZ. The vast majority of schools are likely exceed this threshold, but a small, kindergarten-terminal school, for example, could conceivably fall below the revenue cutoff for inclusion in the NCCS data while still appearing in the PSS, since it offers kindergarten.

These differences between the PSS and NCCS data also imply that the set of schools we are able to match to a tax record will differ from the set of schools we are not able to match. Across all years, matched schools have higher enrollment (both including and excluding preschool) and employ more teachers than unmatched schools. A substantially smaller share of matched schools are affiliated with the Catholic church, and a substantially larger share are nonsectarian. Matched schools have slightly lower rates of affiliation with religions other than Catholicism. Appendix Figure 2 plots the share of matched and unmatched schools that are religious (Catholic or not) or non religious. (Trends for total enrollment and total teachers are given in Figure 3 in the main text.) Although the levels differ, trends are similar across the two groups. These pictures look roughly the same if we produce them using all years of PSS data for schools in our crosswalk instead of just those years in which we match them to tax records.

\footnotetext{
${ }^{52}$ Charter schools are included in the Common Core of Data, the survey of public schools conducted by the NCES.
} 
Appendix Table 1 reports school counts and enrollment totals for the full PSS, crosswalk, and matched samples. As one would expect based on the procedure used to create our crosswalk, the crosswalk and matched samples include a larger share of total schools and total students in more recent years, with the matched sample including more than $20 \%$ of all students in 2005 and reaching $25 \%$ in 2009 .

\section{Who files Form 990? Why is our match rate so low?}

Failures to match PSS records with tax data are generally due to the absence of a school's return from the tax data or the limited nature of the information available for identifying matches. Tax returns may be unavailable for a variety of reasons. Although Catholic schools probably constitute the most significant group generally exempt from the requirement to file Form 990 for religious reasons, other religious schools may qualify for the exemption as well. In each year of the PSS, at least two thirds (and up to 84\%) of schools report having a religious orientation or purpose, and at least half of those religious schools are non-Catholic. Religious exemption from the requirement to file Form 990 requires a school to be affiliated with a church or religious order, so religiously oriented schools without such an affiliation can and do appear in our tax data, but there is clearly substantial scope for schools not to appear in the tax data due to religious exemption from the filing requirement. A school's return could also fail to appear in the tax data if it typically has gross receipts under $\$ 25,000$, if it is operated by an organization that files taxes under a section of the Internal Revenue Code other than 501(c)(3), or if it is negligent in its responsibility to file, though taken individually each of these are likely less important factors than the religious exemption. The limited nature of the information available for identifying matches likely also leads to failures to match records from the PSS to the tax data. Our matches are based on school names and addresses. At the time we matched these records, school names were only available in the PSS in three years, and school addresses were available in only two. Although we processed and checked the data thoroughly to identify matches, the inherent variability in how different people write information like this on forms may have lead to some failures to match. Even in some cases in which a school's name and address are recorded correctly, we are unable to match it to a tax record if the organization that operates it (and files its tax return) does not share its name or address.

Appendix Table 2 gives information on our matching success across states for different types of school. The first column is the average number of private schools observed in a round of the PSS in a state. The next column, "crosswalked" observations, gives the average number of schools in a round of the PSS that we are able to match to the tax data in any year (i.e. the number of schools from our PSS-tax data crosswalk that appear in the PSS in an average year). The "cross walk \%" column reports column 2 over column 1: 
the average percent of schools in a wave of the PSS that we observe in our tax data. Focusing on this percent column, most match rates are around $20 \%$ to $25 \%$; the worst is Wisconsin, and the best is Vermont. Our treatment states appear fairly close to other states, with Pennsylvania the lowest. Looking at the middle set of columns, our success in matching Catholic schools is (unsurprisingly) poor, with a success rate of 5 to 10 percent for most states. Again, the treatment states' matching rates are not remarkably different, although Pennsylvania is again the least matched. The matching rate for other religious schools is higher, but still somewhat small, with typically about the same match rate as for the overall sample. Among the treatment states, Pennsylvania is lowest while Iowa is somewhat higher than most observations (a $36 \%$ matching rate versus a $20-25 \%$ rate for most observations), but this notwithstanding, the overall collection of treatment states is again similar to the controls in matching success. Lastly, for nonsectarian schools, the matching rate is somewhat higher, about $40 \%$, while the treatment states are slightly lower than the average with most having match rates around 30\%. Overall, as expected we do a better job (but still far from perfect) matching nonsectarian schools than religious schools, and our treatment states have matching rates that appear reasonably close to what is seen for the overall sample.

\section{Standardizing Fiscal and Academic Years}

The task of matching each school's financial information to its enrollment information for the appropriate year is complicated by the fact that many schools use fiscal years that differ from their academic years. The PSS asks administrators to report enrollment at the beginning of October, and schools often require students to have paid tuition at the beginning of the school year. It is important, therefore, to make sure that the tax records we match to each enrollment record includes the beginning of the academic year.

We address this issue by assigning an academic year to each NCCS observation based on the calendar year in which the October of its fiscal year falls. For example, suppose we observe a tax record for a school with a July 1, 2003 - June 30, 2004 fiscal year. The October of this school's fiscal year is in 2003, so we assign this tax record to the 2003-04 academic year. If this school used a January 1, 2003 - December 31, 2003 fiscal year, this tax record would still be assigned to the 2003-04 academic year, because its fiscal year contains October 2003. However, if the school instead used a November 1, 2003 - October 31, 2004 fiscal year, this tax record would be assigned to the 2004-05 academic year.

For the schools in our data, the most commonly used fiscal year runs from July 1 through June 30, with over $60 \%$ of tax records in each circa year following this calendar. This means that financial and enrollment information align very well for most of our matched schools. There is a large drop in the number of schools with fiscal-year 1998 tax returns in the data; this drop is driven by a decline in the number of organizations 
with a fiscal year ending in June and is not a product of our crosswalk procedure, but rather is observed in the "raw" Core data. This decline appears to be driven by a change enacted in June of 1999 affecting public disclosure of nonprofit 990 forms. ${ }^{53}$

\section{Covariates}

Our control variables come from a variety of sources. We use median incomes reported by the Census Bureau and unemployment rates reported by the Bureau of Labor Statistics. For the purpose of calculating population densities, we obtain the land area of each state from the Census Bureau's Statistical Abstracts of the United States, 2002 edition. Population and the fraction who are noncitizens, born abroad, and in various age-race/ethnicity groups are calculated using data obtained from IPUMS for the 1990 and 2000 censuses, as well as the American Community Survey from 2001-2009. We linearly interpolate to produce values of the shares of residents who are noncitizens and born abroad for 1991-1999. For the age-race/ethnicity covariates, we produce values for 1991-1999 by assigning individuals in the 2000 census to the appropriate state-age-race/ethnicity group for each of those years, using state of residence in 2000.

\section{Sample Restrictions for School-level Analysis}

For schools with matched financial and enrollment records, we construct a measure that approximates tuition by dividing total program service revenue by total enrollment. While we believe this to be the best available method of estimating tuition, it does produce some figures that are implausibly large, reaching into the hundreds of thousands and even millions of dollars. To some extent, seemingly high estimates of tuition arise from the fact that program service revenue includes income from both tuition and other sources, but this cannot explain tuition estimates of seven figures or more. High tuition estimates could also be a product of matches between a school's enrollment record and the tax return of a parent organization that also receives substantial revenue from other sources. For example, a university could operate a kindergarten-terminal preschool for the children of its staff. If the enrollment record of that preschool matched to the university's tax return, our measure of that preschool's tuition could easily reach tens or hundreds of millions of dollars. Finally, high tuition estimates could simply be a result of outliers in the data. The NCCS data documentation

\footnotetext{
${ }^{53}$ Beginning in June 1999, IRS regulations required all 501(c) organizations except private foundations to provide copies of their tax forms to anyone who requested them. If this disclosure requirement caused some schools with fiscal years ending in June 1999 (corresponding to the 1998-99 academic year) to file their tax returns late that year (that is, after NCCS collected its Core data at the beginning of 2000) before returning to filing on schedule in subsequent years (before the beginning of 2001), the NCCS data collection procedure could have missed these records. The most recent available tax record for these schools at the beginning of 2000 would have corresponded to the 1997-98 academic year, and the most recent available record in 2001 would have corresponded to the 1999-2000 academic year, missing 1998-99. Since NCCS does not update a given circa year Core file as additional records become available, our dataset constructed from those files would be missing any tax records filed late in this manner.
} 
repeatedly notes (and suggest correcting for) the presence of outliers. We address excessively high tuition figures in our baseline estimates by excluding schools with estimated tuition of $\$ 100,000$ or more.

We apply several other restrictions to produce our school-level analysis sample. In both the tax data and the PSS, we exclude schools that report being located in different states in different years, including any that fail to report a state in any year. We also drop tax returns for schools in outlying US territories, which we cannot match to enrollment records, since the PSS does not cover these territories. Finally, we exclude schools that report zero or negative program service revenue on their tax returns.

\section{Appendix C: Description of Conley-Taber Confidence Intervals (for online publication)}

This appendix provides a synopsis of the method we adopt from Conley and Taber (2011); readers seeking more detail are directed to their paper. Consider a difference-in-difference model $Y_{j t}=\alpha d_{j t}+X_{j t}^{\prime} \beta+\theta_{j}+$ $\gamma_{t}+\eta_{j t}$, where $d$ is a (possibly non-binary) policy variable, $X$ is a matrix of regressors, and $\theta$ and $\gamma$ are group and time fixed effects. The parameter of interest is $\alpha$. After projecting the variables onto time and group fixed effects and taking residuals, we have $\tilde{Y}_{j t}=\alpha \tilde{d}_{j t}+\tilde{X}^{\prime}{ }_{j t} \beta+\tilde{\eta}_{j t}$. The number of groups where $d$ changes value, denoted $N_{1}$, and the number of time periods $T$ are taken as fixed as the number of groups where $d$ does not change, $N_{0}$, grows. The integers from $N_{1}+1$ to $N_{1}+N_{0}$ are understood to index the $N_{0}$ control groups. Under reasonable conditions (see Assumption 1 in Conley and Taber, 2011), it can be shown that as $N_{0} \rightarrow \infty$, the OLS estimator $\hat{\alpha}$ converges in probability to $\alpha+W$, where, where

$$
W=\frac{\sum_{j=1}^{N_{1}} \sum_{t=1}^{T}\left(d_{j t}-\bar{d}_{j}\right)\left(\eta_{j t}-\bar{\eta}_{j}\right)}{\sum_{j=1}^{N_{1}} \sum_{t=1}^{T}\left(d_{j t}-\bar{d}_{j}\right)^{2}}
$$

where $\bar{d}_{j}=\frac{1}{T} \sum_{t=1}^{T} d_{j t}$ and similarly for $\bar{\eta}_{j}$. Defining the conditional distribution of $W$ as $\Gamma(w)$; it can be shown that under reasonable conditions a consistent estimator (as $N_{0} \rightarrow \infty$ ) of this distribution is

$$
\hat{\Gamma}(w)=\left(\frac{1}{N_{0}}\right)^{N_{1}} \sum_{l_{1}=N_{1}+1}^{N_{1}+N_{0}} \cdots \sum_{l_{N_{1}}=N_{1}+1}^{N_{1}+N_{0}} 1\left(\frac{\sum_{j=1}^{N_{1}} \sum_{t=1}^{T}\left(d_{j t}-\bar{d}_{j}\right)\left(\tilde{Y}_{l_{j} t}-\tilde{X}_{l_{j}}^{\prime} \hat{\beta}\right)}{\sum_{j=1}^{N_{1}} \sum_{t=1}^{T}\left(d_{j t}-\bar{d}_{j}\right)^{2}}<w\right)
$$

where $\hat{\beta}$ is the OLS estimator.

As described in the text, first we estimate, using OLS on the full sample, the equation $y_{s y}=\beta \mathrm{X}_{s y}+\theta_{s}+$ $\vartheta_{y}+\mathrm{T}_{s y}+\varepsilon_{s y}$, where the index coefficient has been removed, and use this regression to create residuals $\tilde{\varepsilon}_{s y}$. We next randomly assign the treatment states' index values to the control states, where the assignment is 
done at the state level (e.g., the index values for all years in Arizona are assigned to Alabama). After the five true state-index profiles have randomly been assigned to five new states we regress the residuals of the five new states on the state-index profiles, state and year dummies, and record the coefficient. The inclusion of the state and year dummies means the estimate is done on $\tilde{d}_{j t}$, rather than the within-group difference of $d$, although these should be asymptotically equivalent (see equation A2 and related discussion in Conley and Taber's appendix). Our approach using $\tilde{d}_{j t}$ is conservative and produces larger confidence intervals than the within-group-difference approach. We run 5,000 such regressions to estimate a distribution of coefficients.

Using these 5,000 coefficients we can construct a $p$ value by calculating, if $\hat{\alpha}>0(\hat{\alpha}<0), p=2 \times f$, where $f$ is the fraction of coefficients greater than (less than) our true estimate $\hat{\alpha} .{ }^{54}$ We can take the 97.5 percentile value from the distribution of 5,000 and subtract this from $\hat{\alpha}$; this is the lower-bound for our 95 percent confidence interval. We can subtract the 2.5 percentile value of this distribution from $\hat{\alpha}$ to generate the upper bound of the confidence interval.

Our estimator $\hat{\Gamma}(w)$ reflects the above representation of $\hat{\Gamma}(w)$ except that, rather than estimate the full distribution of $\hat{\Gamma}(w)$, we randomly assign the treatment variable and conduct 5,000 draws for each confidence interval. We are thus drawing 5,000 values of $\hat{\Gamma}(w)$ rather than the full distribution. ${ }^{55}$

For calculating confidence intervals for out-of-sample effects on revenue, where the formula is $\frac{\delta P}{\delta s u b} Q+$ $P \frac{\delta Q}{\delta P} \frac{\delta P}{\delta s u b}+\frac{\delta P}{\delta s u b} \frac{\delta Q}{\delta P} \frac{\delta P}{\delta s u b}$, we estimate a regression where enrollment (i.e. $Q$ ) is the dependent variable, and then for random-assignment regression $j$ we use the "placebo" coefficient $\tilde{\beta}_{j}$ to calculate $\Psi\left(\tilde{\beta}_{j}\right)=P \frac{\widetilde{\beta_{j}}}{\delta P} \frac{\delta P}{\delta s u b}+$ $\frac{\delta P}{\delta s u b} \frac{\widetilde{\beta}_{j}}{\delta P} \frac{\delta P}{\delta s u b}$, omitting the constant term $\frac{\delta P}{\delta s u b} Q$. The resulting distribution $\Psi\left(\tilde{\beta}_{j}\right)$ can then be inverted to construct confidence intervals as above.

\footnotetext{
${ }^{54}$ In the case where $f$ is greater than $\frac{1}{2}$, we use $2 \times(1-f)$.

${ }^{55}$ To estimate the full distribution of $\hat{\Gamma}(w)$ here, where $N_{0}$ is 45 and $N_{1}$ is 5 , would require $184,528,125$ regressions for each confidence interval.
} 


\section{Figure 1: Funding for School Subsidies, in \$1000s}

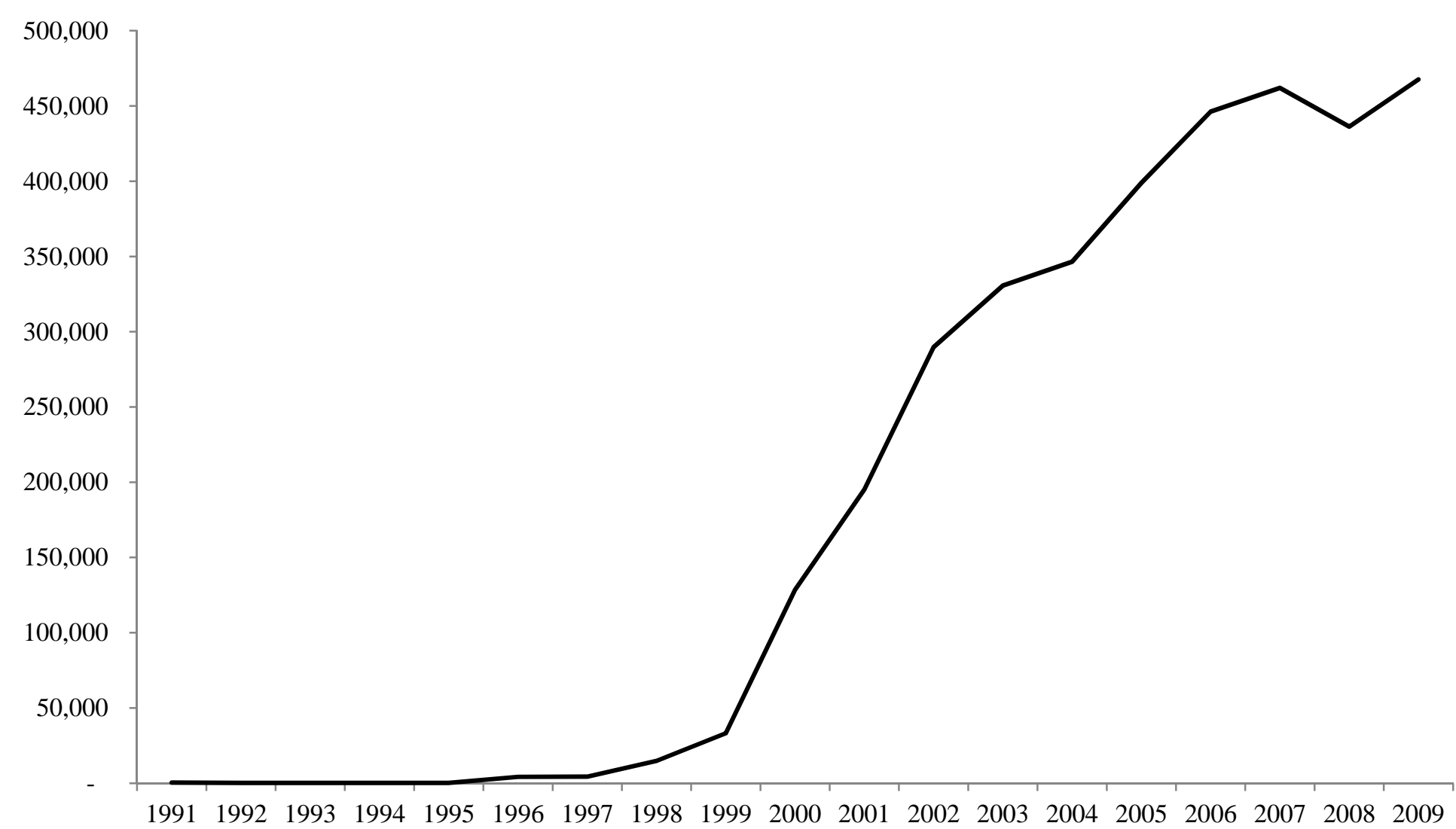

The figure shows the total amount of funding, in year 2012 dollars, for the statewide school subsidy funding programs in Arizona, Florida, Illinois, Iowa, and Pennsylvania. See text for more details on the specific programs here. 
Figure 2: Total Individuals Assisted By Statewide School Subsidy Laws

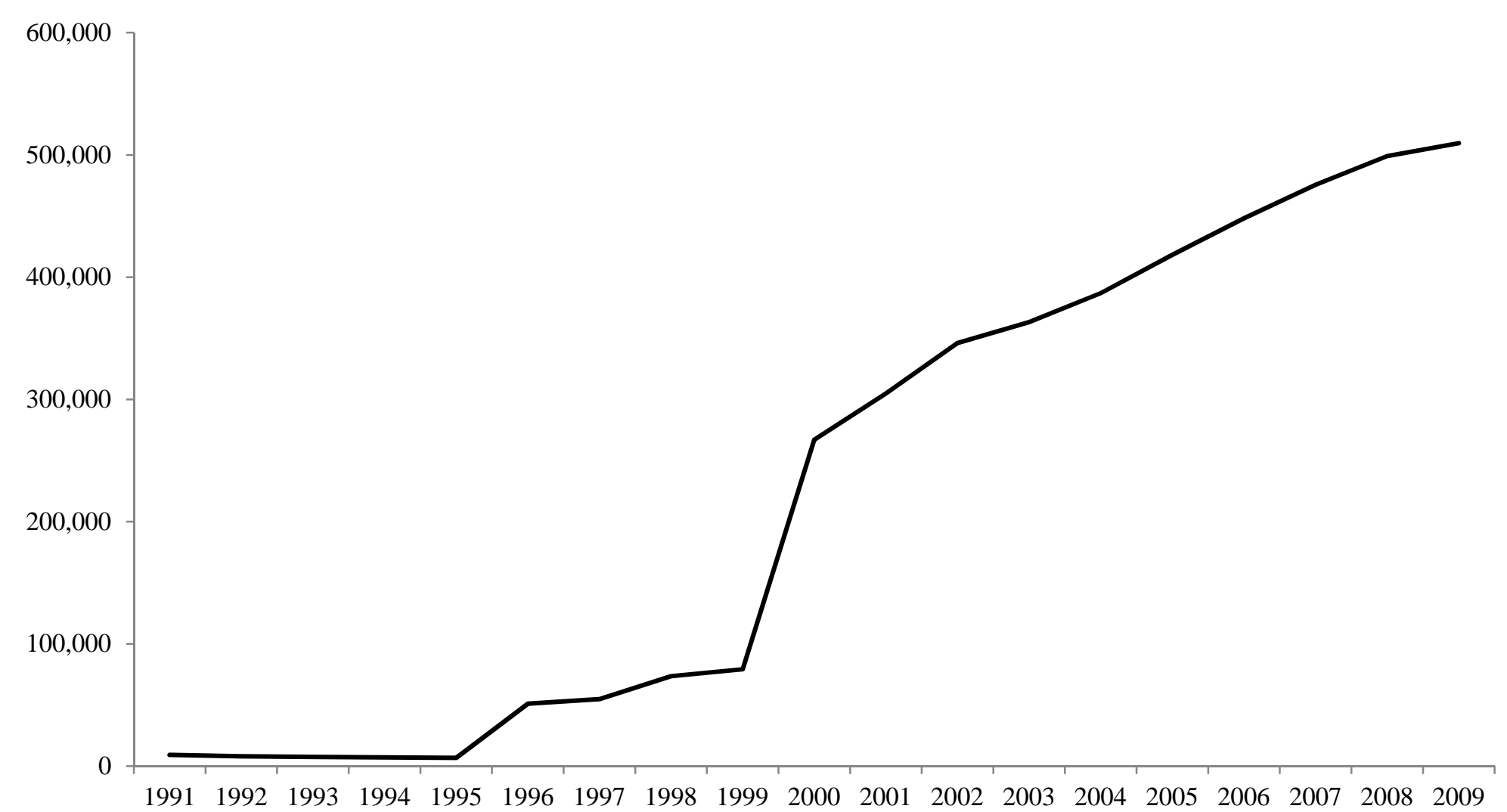

The figure shows the total number of individuals assisted by the school subsidy laws enacted in Arizona, Florida, Illinois, Iowa, and Pennsylvania. Specifically, the figure reports the number of individuals receiving a voucher, a tax-supported scholarship, or claiming a tax-credit for school expenditures (including tuition) in a given year. 
Figure 3: Trends in the 990 Sample Versus the PSS Sample

\section{Panel A: Enrollment}

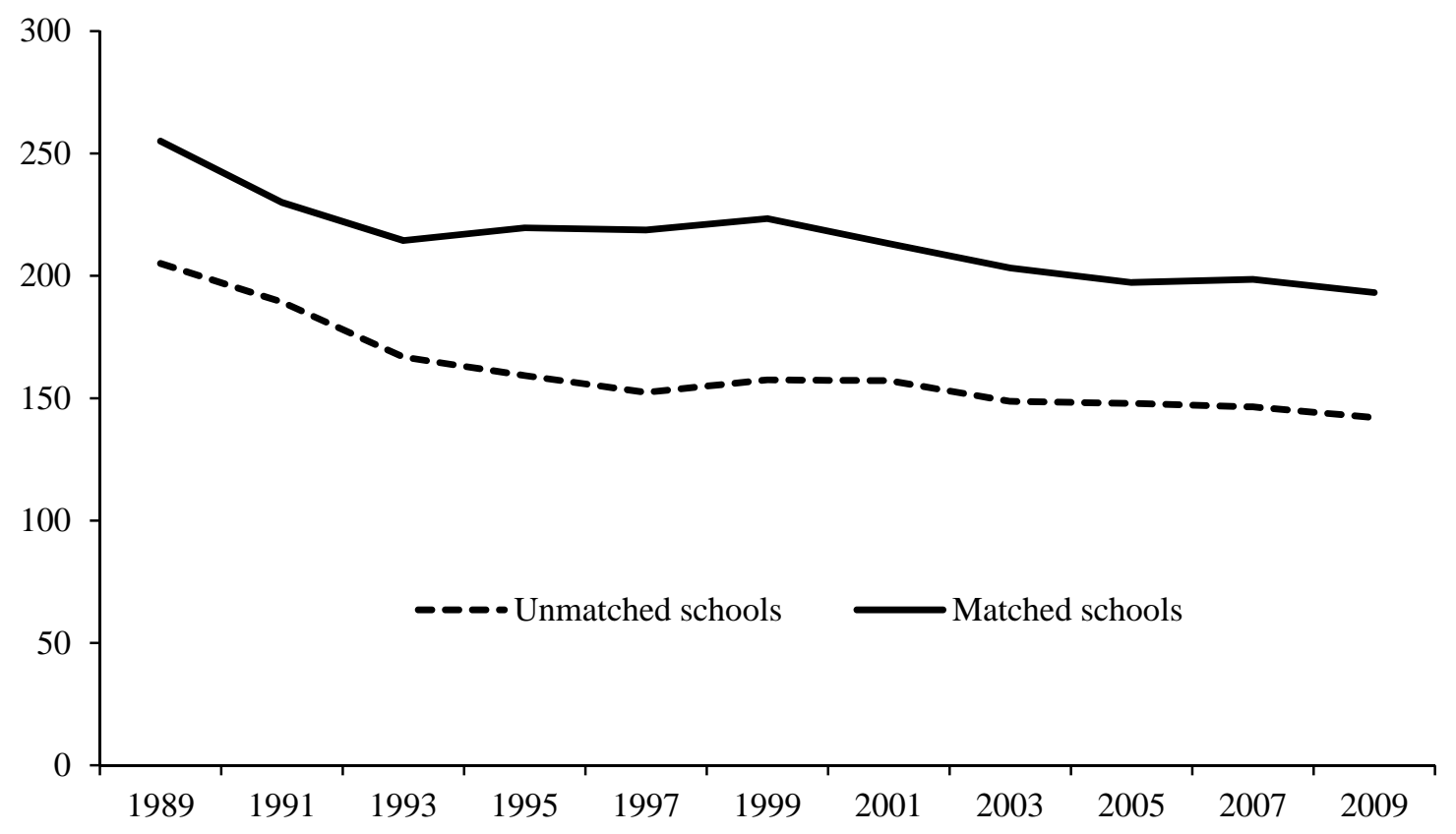

Note: Figure plots mean total enrollment in grades between kindergarten and twelfth grade for all schools in the PSS, including those that offer only a subset of those grades. A school is considered matched in a given academic year if it is linked to its tax record for the fiscal year that includes the October of that academic year.

\section{Panel B: Teachers}

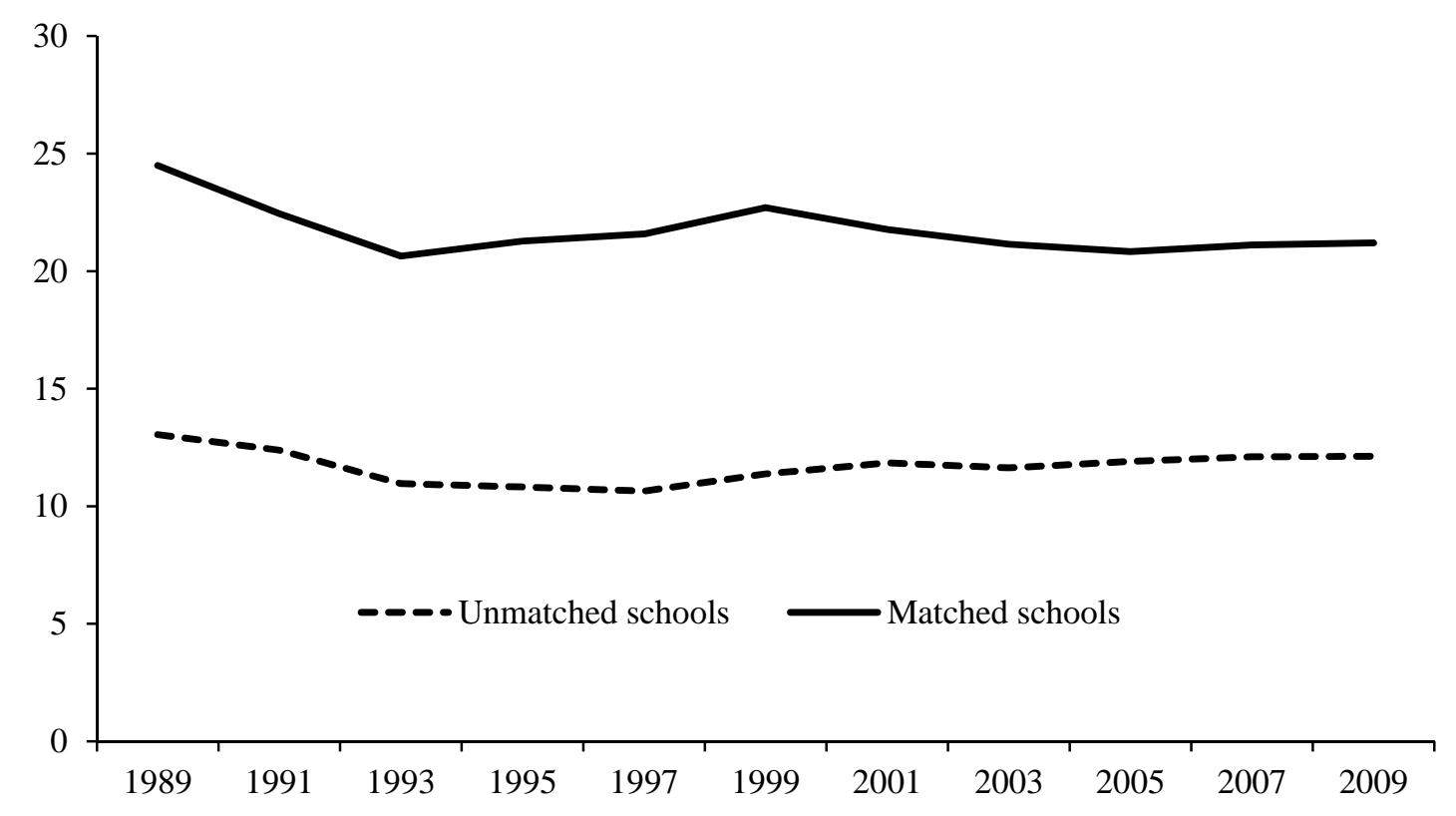

Note: Figure plots mean number of teachers at all schools in the PSS. A school is considered matched in a given academic year if it is linked to its tax record for the fiscal year that includes the October of that academic year. 
Figure 4: Private School Revenue pre- and post- School Subsidy Reform

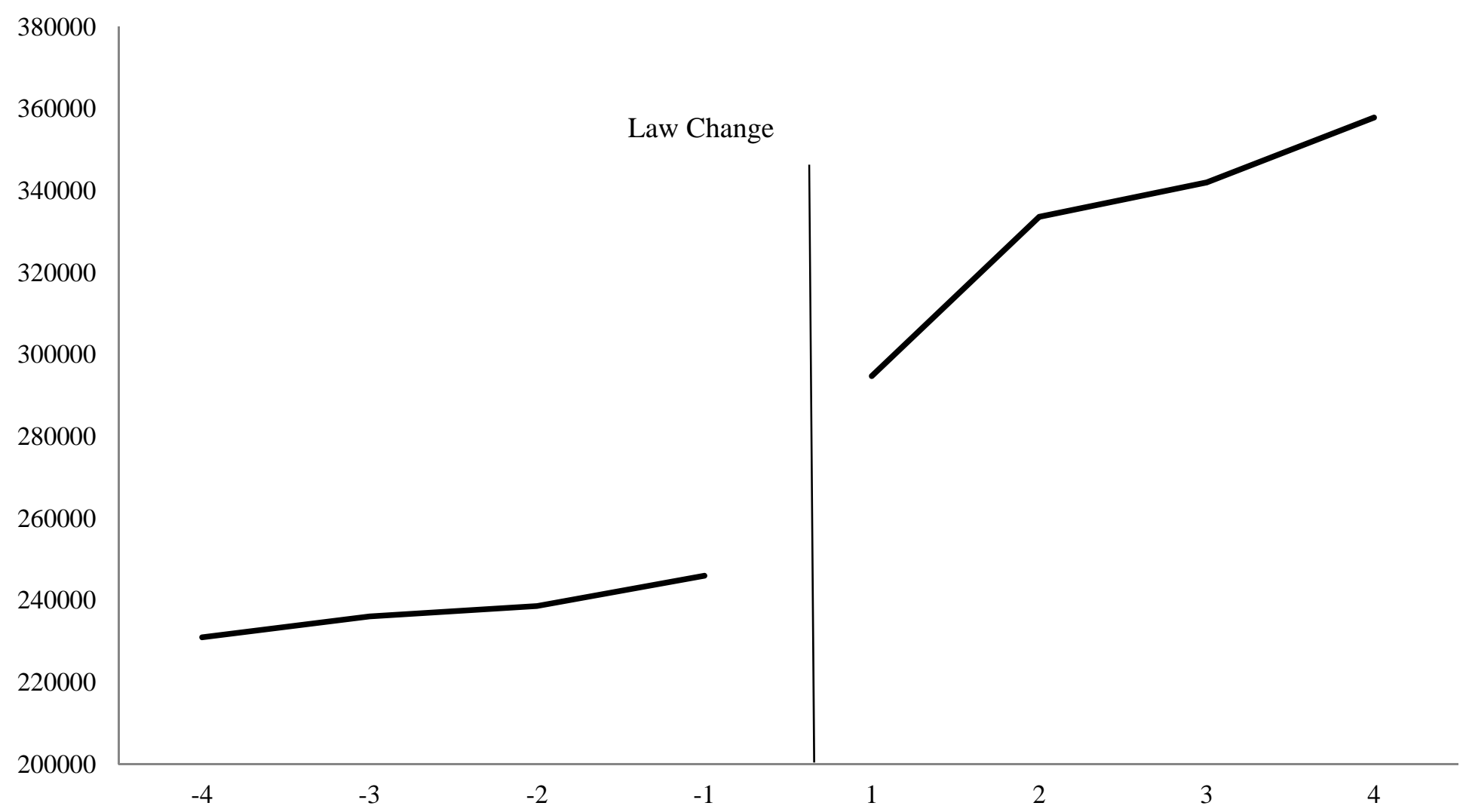

The figure shows average private school revenue, in 1000s of 2012 dollars for private schools filing 990 tax returns in states which enacted statewide school subsidy policies during the period of study (Arizona, Florida, Illinois, Iowa, and Pennsylvania). Average revenue across each state is calculated from 4 years before a policy change to 4 years after; the year of the policy change (year "zero") is omitted from the figure. 
Figure 5: Figure of Basic Revenue Effects and DWL Effects

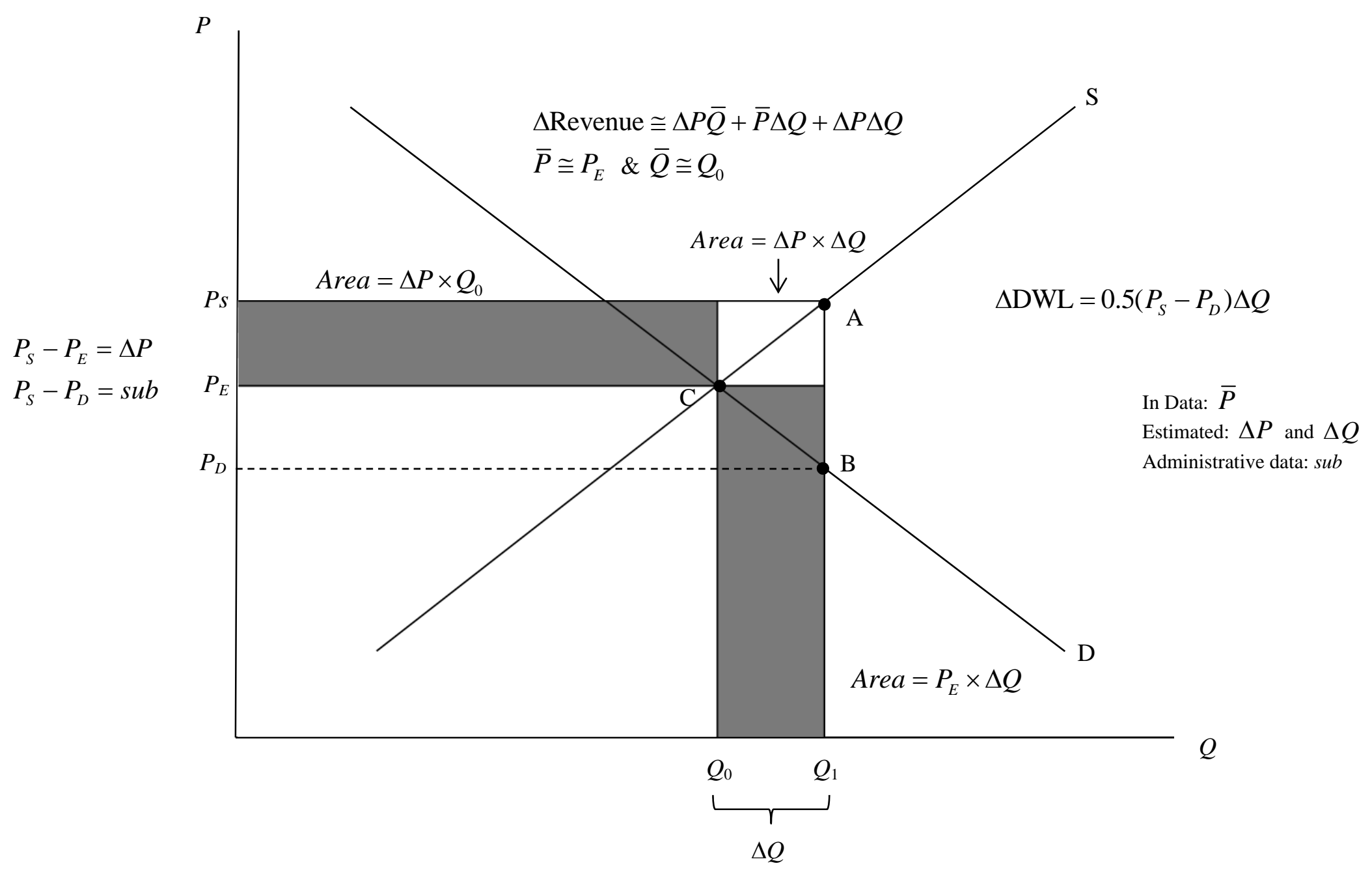


Table 1: Overview of Main School-Subsidy Laws Used

\begin{tabular}{|c|c|c|c|c|}
\hline State & Type of Law & $\begin{array}{l}\text { Year Enacted/ } \\
\text { Expanded }\end{array}$ & Restricted? & Details on Restrictions on Student Use \\
\hline Arizona & $\begin{array}{l}\text { Individual Tax } \\
\text { Credit }\end{array}$ & 1997 & No & $\begin{array}{l}\text { Original legislation prohibited designated STO contributions towards } \\
\text { one's own child, but accounts indicate that this restriction was } \\
\text { circumvented (see text in the appendix). }\end{array}$ \\
\hline Arizona & $\begin{array}{l}\text { Corporate Tax } \\
\text { Credit }\end{array}$ & 2006 & Yes & $\begin{array}{l}\text { STOs must not restrict donations to one school and corporate donations } \\
\text { cannot designate a specific recipient. The income of students receiving } \\
\text { scholarships must not exceed } 185 \text { percent of the free/reduced-price lunch } \\
\text { limit. Students must have either attended public school the previous year, } \\
\text { received a scholarship the previous year, or be entering kindergarten. }\end{array}$ \\
\hline Florida & $\begin{array}{l}\text { Voucher } \\
\text { (McKay) }\end{array}$ & 1999 & Yes & $\begin{array}{l}\text { The McKay voucher program is restricted to students who have been } \\
\text { issued an Individualized Education Plan or a } 504 \text { Accommodation plan. } \\
\text { Student must also have been enrolled and reported for funding by a Florida } \\
\text { school district the year prior to applying for a scholarship. Students with } \\
\text { parents in the Armed Forces may also be eligible. }\end{array}$ \\
\hline Florida & $\begin{array}{l}\text { Corporate Tax } \\
\text { Credit }\end{array}$ & 2001 & Yes & $\begin{array}{l}\text { Eligible students must qualify for free/reduced-price lunch and must have } \\
\text { either attended public school the previous year, received a scholarship the } \\
\text { previous year, or be entering kindergarten or first grade. }\end{array}$ \\
\hline Illinois & $\begin{array}{l}\text { Individual Tax } \\
\text { Credit }\end{array}$ & 1999 & No & $\begin{array}{l}\text { Taxpayer must be the "custodian" of a pupil, under age } 21 \text {, who is a full- } \\
\text { time student of an elementary or secondary school in Illinois. }\end{array}$ \\
\hline Iowa & $\begin{array}{l}\text { Individual Tax } \\
\text { Credit }\end{array}$ & $\begin{array}{l}\text { 1987, Expanded } \\
\text { 1996/98 and } 2006\end{array}$ & $\begin{array}{l}\text { Post- } \\
\text { Expansion: No }\end{array}$ & $\begin{array}{l}\text { Pre 1996: a household income limit was in place and expenses for } \\
\text { "extracurricular activities" beyond tuition were ineligible. Both of these } \\
\text { restrictions were eliminated starting in } 1996 \text {. }\end{array}$ \\
\hline Iowa & $\begin{array}{l}\text { Individual Tax } \\
\text { Credit }\end{array}$ & 2006 & Yes & $\begin{array}{l}\text { This program gives tax credits for donations to STOs. Contributing } \\
\text { taxpayers cannot identify students as scholarship recipients and recipient } \\
\text { eligibility was limited to households with income under } 300 \text { percent of } \\
\text { federal poverty guidelines. The original program restricted the credit to } \\
\text { donations from individuals and later expanded to include corporations. }\end{array}$ \\
\hline Pennsylvania & $\begin{array}{l}\text { Corporate Tax } \\
\text { Credit }\end{array}$ & 2001 & Yes & $\begin{array}{l}\text { Family income must be under } \$ 50,000 \text {; this is adjusted upwards by } \\
\$ 10,000 \text { for each dependent in the household. (These numbers have been } \\
\text { increased since the period of study here.) }\end{array}$ \\
\hline
\end{tabular}

Sources: the primary source of data for this table was the authored by the Research Department of the Minnesota House of Representatives (2011); this report was verified by using state statutes and other state publications. 
Table 2: Selected Means

\begin{tabular}{|l|c|c|c|}
\hline & All Observations & $\begin{array}{c}\text { Observations with a } \\
\text { Subsidy Program }\end{array}$ & $\begin{array}{c}\text { Observations with an } \\
\text { Unrestricted Subsidy Program }\end{array}$ \\
\hline Total Revenue (\$1000s) & 210,828 & 278,926 & 137,415 \\
{$[301,290]$} & {$[369,296]$} & {$[133,583]$} \\
\hline Total Enrollment & 14,813 & 20,740 & 11,206 \\
{$[8,979]$} & {$[18,433]$} & {$[, 646$} \\
& {$[17,229]$} & 9,586 & {$[3,493]$} \\
\hline Revenue Per Student & 11,025 & {$[4,523]$} & {$[62]$} \\
\hline Number of Schools per State/Year Observation & {$[5,596]$} & {$[84]$} & 158 \\
& {$[66$} & 178 & {$[44]$} \\
\hline Number of Students per School & 238 & {$[59]$} & 36,363 \\
& {$[205]$} & 57,420 & {$[30,884]$} \\
\hline Spending on School Subsidies (\$1000s) & - & 820 & 398 \\
& - & {$[1,477]$} & {$[474]$} \\
\hline
\end{tabular}

Each cell shows a mean and standard deviation in brackets. All monetary figures are in year 2012 dollars. All figures are calculated using taxreturn data matched to the PSS except for (a) spending on school subsidies and (b) subsidies per user, which are based on statewide administrative data. Spending on school subsidies equals the total amount of tax credits claimed and vouchers paid in any state with a tax credit or voucher program in the sample; there are 62 such state/year observations. As in Figure 2, users in the subsidies-per-user row include the number of individuals receiving a voucher, a tax-supported scholarship, or claiming a tax-credit for school expenditures (including tuition) in a given year. There are 926 state/year observations from 1991 to 2009; although student data is unavailable for two observations, so that the number of students and revenue per student are based off of 924 observations. In the final column, spending on school subsidies and subsidies per user are both calculated using only funds from unrestricted programs; in some instances both types of programs are present. Mean total spending on all programs in the presence of an unrestricted program is 37,857 [31,430] and mean spending per user is 410 [502]. 
Table 3:

The Effect of Subsidy Laws on School Revenue (in \$1000s)

\begin{tabular}{|c|c|c|c|c|c|}
\hline & Baseline & No RHS & $\begin{array}{c}\text { Future-Adoptee } \\
\text { States as Controls }\end{array}$ & Quadratic Trends & $\begin{array}{c}\text { Add NCCS- } \\
\text { identified Schools }\end{array}$ \\
\hline School Subsidy Laws & $\begin{array}{c}24,311 \\
{[13,020]} \\
(6,498 \sim 39,830)\end{array}$ & $\begin{array}{c}28,280 \\
{[6,532]} \\
(10,351 \sim 45,512)\end{array}$ & $\begin{array}{c}27,172 \\
{[7,409]} \\
(15,388 \sim 38,525) \\
\end{array}$ & $\begin{array}{c}29,614 \\
{[10,775]} \\
(13,007 \sim 44,809) \\
\end{array}$ & $\begin{array}{c}30,022 \\
{[11,833]} \\
(12,628 \sim 45,720)\end{array}$ \\
\hline RHS Controls & Yes & No & Yes & Yes & Yes \\
\hline State Quadratic Trends & No & No & No & Yes & Yes \\
\hline State Linear Trends & Yes & Yes & Yes & Yes & Yes \\
\hline Year Dummies & Yes & Yes & Yes & Yes & Yes \\
\hline State Dummies & Yes & Yes & Yes & Yes & Yes \\
\hline Observations & 926 & 926 & 344 & 926 & 926 \\
\hline R-squared & 0.99 & 0.99 & 0.99 & 0.99 & 0.99 \\
\hline
\end{tabular}

The dependent variable is total program service revenue, in 1000s, for private schools, in year 2012 dollars. The data are aggregated to the state level and cover the years 1991 to 2009. There are 61,102 school/year observations in the baseline regression. The standard errors in brackets are clustered by state; the 95\% confidence intervals are calculated based on 5,000 block-bootstrapped replications in an approach adopted from Conley and Taber (2011); see text. The regressor "School Subsidy Laws" is the number of statewide school subsidy programs in a given state and year. All regressions include dummy variables that equal unity the year a school subsidy policy was enacted. The right-hand side controls include controls for state median income, the state unemployment rate, the population density, the fraction of a state's residents that are noncitizens, the fraction born abroad, total population, total white population ages 6-17, and nonwhite population ages 6-17. Column 2 omits these extra controls. Colum 3 includes states that adopted a school subsidy law during or after the period of this sample; these states are AZ, CO, FL, GA, IA, IL, IN, LA, MN, MS, NC, NH, OH, OK, PA, RI, VA, VT, WI. Column 4 adds state-specific quadratic trends. The last column redoes column 4 but adds in schools identified using NCCS information; there are 77,655 school/year observations for this regression. 
Table 4:

School Subsidies and Revenue for Other Types of Nonprofits

\begin{tabular}{|c|c|c|c|c|c|}
\hline & Animal-Related & Civil Rights & $\begin{array}{c}\text { Medical } \\
\text { Research }\end{array}$ & Miscellaneous & Mutual Benefit \\
\hline & -647 & 150 & -662 & -152 & 797 \\
{$[690]$} & 2,308 \\
{$[1,248,131]$} & {$[6,206]$} & $(-1,179 \sim 791)$ & $(-7,653 \sim 8,280)$ & $(671 \sim 3,695)$ \\
\hline
\end{tabular}

The figure shows the coefficient for the school subsidy index from a regression of total revenues in 1000s of year 2012 dollars for several different types of nonprofit organizations. The categorization of nonprofits is done using the National Taxonomy of Exempt Entities Core Codes Classification System (NTEE-CC). The comparable specification is column 1 in Table 3 with a coefficient on private-school revenue of 24,311 $[13,020]$. The standard errors in brackets are clustered by state; the 95\% confidence intervals are calculated based on 5,000 block-bootstrapped replications in an approach adopted from Conley and Taber (2011). For each group, we drop the largest 1 percent of observations in terms of reported revenue, and we omit observations with zero or missing revenue. Examples of Animal-Related nonprofits include zoos, aquariums, and animal-protection groups. Examples of Civil Rights nonprofits includes civil liberty and voter registration groups. Examples of Medical Research nonprofits in includes cancer and autism research institutes. Examples of Mutual Benefit nonprofits includes pension funds and fraternal societies. Examples of Public Safety nonprofits include automotive safety and disaster preparedness nonprofits. 
Table 5:

Restricted and Unrestricted Subsidy Laws and School Revenue (in \$1000s)

\begin{tabular}{|c|c|c|c|c|c|}
\hline & Baseline & No RHS & $\begin{array}{c}\text { Future-Adoptee States } \\
\text { as Controls }\end{array}$ & Quadratic Trends & $\begin{array}{c}\text { Add NCCS-identified } \\
\text { Schools }\end{array}$ \\
\hline School Subsidy Laws & $\begin{array}{c}27,260 \\
{[14,488]} \\
(9,404 \sim 42,696)\end{array}$ & $\begin{array}{c}32,857 \\
{[6,656]} \\
(13,632 \sim 51,066)\end{array}$ & $\begin{array}{c}30,123 \\
{[7,963]} \\
(18,285 \sim 40,938)\end{array}$ & $\begin{array}{c}35,573 \\
{[10,132]} \\
(19,378 \sim 50,837)\end{array}$ & $\begin{array}{c}37,217 \\
{[10,497]} \\
(20,096 \sim 52,801)\end{array}$ \\
\hline Unrestricted Subsidy Laws & $\begin{array}{c}-13,107 \\
{[13,085]} \\
(-49,748 \sim 35,912)\end{array}$ & $\begin{array}{c}-20,078 \\
{[8,460]} \\
(-66,233 \sim 41,523)\end{array}$ & $\begin{array}{c}-15,452 \\
{[12,131]} \\
(-37,698 \sim 5,811)\end{array}$ & $\begin{array}{c}-22,284 \\
{[9,766]} \\
(-51,211 \sim 8,124)\end{array}$ & $\begin{array}{c}-26,771 \\
{[9,373]} \\
(-58,367 \sim 8,644)\end{array}$ \\
\hline RHS Controls & Yes & No & Yes & Yes & Yes \\
\hline State Quadratic Trends & No & No & No & Yes & Yes \\
\hline State Linear Trends & Yes & Yes & Yes & Yes & Yes \\
\hline Year Dummies & Yes & Yes & Yes & Yes & Yes \\
\hline State Dummies & Yes & Yes & Yes & Yes & Yes \\
\hline Observations & 926 & 926 & 344 & 926 & 926 \\
\hline R-squared & 0.99 & 0.99 & 0.99 & 0.99 & 0.99 \\
\hline
\end{tabular}

The dependent variable is total program service revenue, in 1000s, for private schools, in year 2012 dollars. The standard errors in brackets are clustered by state; the 95\% confidence intervals are calculated based on 5,000 block-bootstrapped replications in an approach adopted from Conley and Taber (2011); see text. The regressor "School Subsidy Laws" is the number of statewide school subsidy programs in a given state and year. The "Unrestricted Subsidy Laws" coefficient is a dummy that equals unity when a state enacts a subsidy law that does not restrict subsidy eligibility. All regressions include dummy variables that equal unity the year a school subsidy policy was enacted; see Table 3 for a description of the other right-hand-side controls. Column 2 omits extra RHS controls. Colum 3 includes states that adopted a school subsidy law during or after the period of this sample; see Table 3. Column 4 adds state-specific quadratic trends; the last column redoes column 4 but adds in schools identified using NCCS information. 
Table 6:

School Subsidies and Per-Student Revenue (in \$1000s)

\begin{tabular}{|c|c|c|c|c|c|c|}
\hline & \multicolumn{2}{|c|}{ Per-Student Revenue } & \multicolumn{2}{|c|}{ Future-Adoptee States as Controls } & \multicolumn{2}{|c|}{$\begin{array}{l}\text { Per-Student Revenue Quadratic } \\
\text { Trends }\end{array}$} \\
\hline School Subsidy Laws & $\begin{array}{c}0.28 \\
{[0.436]} \\
(-1.0 \sim 2.07)\end{array}$ & $\begin{array}{c}0.191 \\
{[0.422]} \\
(-0.92 \sim 1.98)\end{array}$ & $\begin{array}{c}0.447 \\
{[0.362]} \\
(0.09 \sim 0.82)\end{array}$ & $\begin{array}{c}0.38 \\
{[0.333]} \\
(0.002 \sim 0.76)\end{array}$ & $\begin{array}{c}0.309 \\
{[0.409]} \\
(-1.19 \sim 1.94)\end{array}$ & $\begin{array}{c}0.222 \\
{[0.400]} \\
(-1.35 \sim 1.92)\end{array}$ \\
\hline Unrestricted Subsidy Laws & ( & $\begin{array}{c}0.951 \\
{[0.427]} \\
(-2.35 \sim 3.57)\end{array}$ & 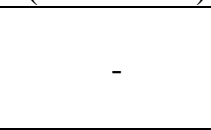 & $\begin{array}{c}0.502 \\
{[0.423]} \\
(-0.77 \sim 1.80)\end{array}$ & 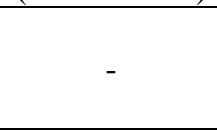 & $\begin{array}{c}0.910 \\
{[0.445]} \\
(-1.91 \sim 4.63)\end{array}$ \\
\hline RHS Controls & Yes & Yes & Yes & Yes & Yes & Yes \\
\hline St. Quad. Trends & No & No & No & No & Yes & Yes \\
\hline State Trends & Yes & Yes & Yes & Yes & Yes & Yes \\
\hline Year Dummies & Yes & Yes & Yes & Yes & Yes & Yes \\
\hline State Dummies & Yes & Yes & Yes & Yes & Yes & Yes \\
\hline Observations & 924 & 924 & 344 & 344 & 924 & 924 \\
\hline R-squared & 0.98 & 0.98 & 0.96 & 0.96 & 0.98 & 0.98 \\
\hline
\end{tabular}

The dependent variable is total program service revenue over total students for private schools in year 2012 dollars. The data are aggregated to the state level and cover the years 1991 to 2009. The standard errors in brackets are clustered by state; the 95\% confidence intervals are calculated based on 5,000 block-bootstrapped replications in an approach adopted from Conley and Taber (2011); see text. The regressor "School Subsidy Laws" is the number of statewide school subsidy programs in a given state and year. The "Unrestricted Subsidy Laws" coefficient is a dummy that equals unity when a state enacts a subsidy law that does not restrict subsidy eligibility. All regressions include dummy variables that equal unity the year a tax-credit policy was enacted; see Table 3 for a description of the other right-hand-side controls. Since these regressions report means across states and years (unlike the total revenue and student results), the regression are weighted by the number of students (unweighted regressions typically give similar results). The table omits NCCS-identified schools as student counts are unavailable for these schools. 
Table 7:

School Subsidies and Enrollment

\begin{tabular}{|c|c|c|c|c|c|c|}
\hline & \multicolumn{2}{|c|}{ Baseline } & \multicolumn{2}{|c|}{ With Quadratic Trends } & \multicolumn{2}{|c|}{ Total Students: PSS Data } \\
\hline School Subsidy Laws & $\begin{array}{c}1,512 \\
{[895]} \\
(378 \sim 2,510)\end{array}$ & $\begin{array}{c}1,951 \\
{[839]} \\
(772 \sim 2,926)\end{array}$ & $\begin{array}{c}1,870 \\
{[1,182]} \\
(797 \sim 2,777)\end{array}$ & $\begin{array}{c}2,445 \\
{[1,156]} \\
(1,342 \sim 3,330)\end{array}$ & $\begin{array}{c}4,875 \\
{[5,887]} \\
(580 \sim 8,915)\end{array}$ & $\begin{array}{c}5,516 \\
{[5,943]} \\
(1,303 \sim 9,683)\end{array}$ \\
\hline Unrestricted Subsidy Laws & 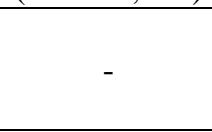 & $\begin{array}{c}-1,944 \\
{[1,111]} \\
(-5,334 \sim 1,160)\end{array}$ & - & $\begin{array}{c}-2,112 \\
{[1,277]} \\
(-4,266 \sim-476)\end{array}$ & (0) & $\begin{array}{c}-5,477 \\
{[5,898]} \\
(-14,890 \sim 3,757)\end{array}$ \\
\hline RHS Controls & Yes & Yes & Yes & Yes & Yes & Yes \\
\hline St. Quad. Trnds. & No & No & Yes & Yes & No & No \\
\hline State Trends & Yes & Yes & Yes & Yes & Yes & Yes \\
\hline Year Dummies & Yes & Yes & Yes & Yes & Yes & Yes \\
\hline State Dummies & Yes & Yes & Yes & Yes & Yes & Yes \\
\hline Observations & 924 & 924 & 924 & 924 & 479 & 479 \\
\hline R-squared & 0.99 & 0.99 & 0.99 & 0.99 & 0.99 & 0.99 \\
\hline
\end{tabular}

The dependent variable is total enrollment (kindergarten through grade 12) in private schools. The data are aggregated to the state level and cover the years 1991 to 2009. The PSS data are biennial and cover the years 1993 to 2011. The standard errors in brackets are clustered by state; the 95\% confidence intervals are calculated based on 5,000 block-bootstrapped replications in an approach adopted from Conley and Taber (2011); see text. The regressor "School Subsidy Laws" is the number of statewide school subsidy programs in a given state and year. The "Unrestricted Subsidy Laws" coefficient is a dummy that equals unity when a state enacts a subsidy law that does not restrict subsidy eligibility. All regressions include dummy variables that equal unity the year a tax-credit policy was enacted; see Table 3 for a description of the other right-hand-side controls. Estimating the baseline estimates using the future-law-changers sample produces estimates that are similar to those in the table and are omitted for brevity. 
Table 8: Alternate Specifications

Panel A:

\begin{tabular}{|c|c|c|c|c|c|c|}
\hline & \multicolumn{3}{|c|}{ Aggregated Data: Long-Term Schools Only } & \multicolumn{3}{|c|}{ School-Level Regressions } \\
\hline & $\begin{array}{c}\text { Total Revenue } \\
(1000 \mathrm{~s})\end{array}$ & $\begin{array}{c}\text { Per-Student } \\
\text { Revenue (1000s) }\end{array}$ & Enrollment & $\begin{array}{c}\text { Total Revenue } \\
(1000 \mathrm{~s})\end{array}$ & $\begin{array}{c}\text { Per-Student } \\
\text { Revenue (1000s) }\end{array}$ & Enrollment \\
\hline School Subsidy Laws & $\begin{array}{c}17,291 \\
{[10,016]} \\
(1,075 \sim 31,984)\end{array}$ & $\begin{array}{c}0.413 \\
{[0.541]} \\
(-1.82 \sim 2.21)\end{array}$ & $\begin{array}{c}680 \\
{[533]} \\
(-68 \sim 1,375)\end{array}$ & $\begin{array}{c}59 \\
{[24.2]} \\
(-12 \sim 131)\end{array}$ & $\begin{array}{c}-0.126 \\
{[0.250]} \\
(-0.89 \sim 0.67)\end{array}$ & $\begin{array}{c}4.3 \\
{[4.58]} \\
(-4.4 \sim 13.3)\end{array}$ \\
\hline
\end{tabular}

\section{Panel B:}

\begin{tabular}{|c|c|c|c|c|c|c|}
\hline & \multicolumn{3}{|c|}{ Aggregated Data: Long-Term Schools Only } & \multicolumn{3}{|c|}{ School-Level Regressions } \\
\hline & $\begin{array}{l}\text { Total Revenue } \\
\text { (1000s) }\end{array}$ & $\begin{array}{c}\text { Per-Student } \\
\text { Revenue (1000s) }\end{array}$ & Enrollment & $\begin{array}{l}\text { Total Revenue } \\
\text { (1000s) }\end{array}$ & $\begin{array}{c}\text { Per-Student } \\
\text { Revenue }(1000 \mathrm{~s})\end{array}$ & Enrollment \\
\hline School Subsidy Laws & $\begin{array}{c}18,766 \\
{[11,394]} \\
(2,554 \sim 33,794) \\
\end{array}$ & $\begin{array}{c}0.279 \\
{[0.500]} \\
(-1.93 \sim 2.04) \\
\end{array}$ & $\begin{array}{c}976 \\
{[442]} \\
(276 \sim 1,723) \\
\end{array}$ & $\begin{array}{c}67 \\
{[23.8]} \\
(-1.67 \sim 139) \\
\end{array}$ & $\begin{array}{c}-0.184 \\
{[0.232]} \\
(-0.96 \sim 0.62) \\
\end{array}$ & $\begin{array}{c}6.1 \\
{[3.66]} \\
(-2.35 \sim 15.4) \\
\end{array}$ \\
\hline Unrestricted Subsidy Laws & $\begin{array}{c}-6,595 \\
{[8,434]} \\
(-41,850 \sim 33,977)\end{array}$ & $\begin{array}{c}1.436 \\
{[0.625]} \\
(-2.16 \sim 4.94)\end{array}$ & $\begin{array}{c}-1,312 \\
{[781]} \\
(-3,538 \sim 904)\end{array}$ & $\begin{array}{c}-49 \\
{[50.0]} \\
(-500 \sim 594)\end{array}$ & $\begin{array}{c}0.496 \\
{[0.413]} \\
(-1.55 \sim 1.91)\end{array}$ & $\begin{array}{c}-11 \\
{[6.29]} \\
(-30 \sim 5.0)\end{array}$ \\
\hline
\end{tabular}

The regressions in the first three columns repeat the baseline regressions from earlier, except that the sample is limited to schools that appear in the data in at least 15 out of 19 years. The school level regressions estimate analogous specifications without aggregating to the state level. The standard errors in brackets are clustered by state; the 95\% confidence intervals are calculated based on 5,000 block-bootstrapped replications in an approach adopted from Conley and Taber (2011). Average revenue for a school in a state with a subsidy program is about 2.6 million (3.6 million for schools surviving at least 15 years in the data). 
Table 9:

School Subsidies and the Number of Schools

\begin{tabular}{|c|c|c|c|c|c|c|}
\hline & \multicolumn{2}{|c|}{ Baseline } & \multicolumn{2}{|c|}{ Long-Term Schools } & \multicolumn{2}{|c|}{ PSS Sample } \\
\hline School Subsidy Laws & $\begin{array}{c}9.94 \\
{[6.65]} \\
(3.93 \sim 15.2) \\
\end{array}$ & $\begin{array}{c}12.9 \\
{[5.21]} \\
(6.89 \sim 18.3) \\
\end{array}$ & $\begin{array}{c}3.93 \\
{[2.55]} \\
(0.49 \sim 7.3)\end{array}$ & $\begin{array}{c}4.89 \\
{[2.27]} \\
(1.49 \sim 8.44) \\
\end{array}$ & $\begin{array}{c}75.124 \\
{[79.9]} \\
(13.8 \sim 130) \\
\end{array}$ & $\begin{array}{c}78.2 \\
{[81.3]} \\
(19.1 \sim 133)\end{array}$ \\
\hline Unrestricted Subsidy Laws & 2 - & $\begin{array}{c}-13.1 \\
{[10.2]} \\
(-26.7 \sim 4.2)\end{array}$ & $x_{-2}$ & $\begin{array}{c}-4.26 \\
{[4.45]} \\
(-13.8 \sim 5.4)\end{array}$ & ( & $\begin{array}{c}-33.0 \\
{[67.3]} \\
(-153 \sim 85)\end{array}$ \\
\hline RHS Controls & Yes & Yes & Yes & Yes & Yes & Yes \\
\hline St. Quad. Trends & No & No & No & No & No & No \\
\hline State Trends & Yes & Yes & Yes & Yes & Yes & Yes \\
\hline Year Dummies & Yes & Yes & Yes & Yes & Yes & Yes \\
\hline \begin{tabular}{|l|} 
State Dummies \\
\end{tabular} & Yes & Yes & Yes & Yes & Yes & Yes \\
\hline Observations & 926 & 926 & 923 & 923 & 479 & 479 \\
\hline R-squared & 0.99 & 0.99 & 0.99 & 0.99 & 0.992 & 0.992 \\
\hline
\end{tabular}

The dependent variable is total number of schools in a state/year observation. The standard errors in brackets are clustered by state; the $95 \%$ confidence intervals are calculated based on 5,000 block-bootstrapped replications in an approach adopted from Conley and Taber (2011); see text. Columns 3 and 4 restrict the estimation to schools that are observed at least 15 out of a possible 19 years. The last two columns use data from the PSS. 
Table 10:

Estimated Revenue Impact for All Private Schools in Treatment States

\begin{tabular}{|c|c|c|c|c|c|}
\hline & $\begin{array}{c}\text { Zero Incidence } \\
\text { on Schools }\end{array}$ & $\begin{array}{l}\text { 1/2 Sample } \\
\text { Incidence }\end{array}$ & Sample Incidence & $\begin{array}{c}2 \times \text { Sample } \\
\text { Incidence }\end{array}$ & $\begin{array}{l}\text { Full Incidence on } \\
\text { Schools } \\
\end{array}$ \\
\hline $\begin{array}{l}\text { Change in Revenue } \\
\text { (1000s) }\end{array}$ & $\begin{array}{c}49,045 \\
(6,024 \sim 91,036)\end{array}$ & $\begin{array}{c}82,607 \\
(39,585 \sim 124,599)\end{array}$ & $\begin{array}{c}116,234 \\
(73,211 \sim 158,227)\end{array}$ & $\begin{array}{c}183,293 \\
(140,268 \sim 225,287)\end{array}$ & $\begin{array}{c}245,622 \\
(202,596 \sim 287,618)\end{array}$ \\
\hline$\Delta$ Revenue per Student & $\$ 0$ & $\$ 140$ & $\$ 280$ & $\$ 560$ & $\$ 820$ \\
\hline Elasticity of Supply & - & 1.5 & 0.7 & 0.4 & 0.2 \\
\hline $\begin{array}{l}\text { Dollar-for-Dollar Effect } \\
\text { of Subsidy Funding }\end{array}$ & 0.85 & 1.44 & 2.02 & 3.19 & 4.28 \\
\hline
\end{tabular}

The table shows the calculated impact of school subsidies on school revenue for all private schools. The formula for calculation is given in the text; here the "price" of schools is taken from the Schools and Staffing Survey, the quantity is from total enrollment in all private schools in the treatment states as reported in the Private School Survey, the subsidy amount is from administrative data for all programs, and the change in enrollment is from the earlier regressions on PSS data for all schools. The estimates in the table vary depending upon the assumed incidence on schools, i.e. the change in the per-student revenue from school subsidies. Column 1 assumes no change, column 2 assumes a change in per-student revenue equal to one half of the change in per-student revenue observed in the tax data, column 3 uses the same change in per-student revenue, column 4 uses twice the change, and column five assumes that the full incidence falls on schools. The bottom row divides the top row estimates by the average spending amount in Table 2: \$57,420. The 95\% confidence intervals in parentheses are calculated from block bootstrapping in an approach similar to the Conley-Taber based intervals used earlier; see text. 
Appendix Table 1: School Counts and Enrollment Totals by Year

\begin{tabular}{|c|c|c|c|c|c|c|}
\hline \multirow{2}{*}{} & \multicolumn{3}{|c|}{ Number of Schools } & \multicolumn{3}{c|}{ Total Enrollment } \\
\cline { 2 - 7 } & PSS & Crosswalk & Matched & PSS & Crosswalk & Matched \\
\hline 1991 & 23,766 & 3,735 & 2,086 & $5,286,398$ & $1,006,057$ & 546,289 \\
\hline 1993 & 36,633 & 4,453 & 2,552 & $5,103,811$ & $1,067,934$ & 597,099 \\
\hline 1995 & 28,622 & 4,960 & 3,007 & $5,918,044$ & $1,300,344$ & 774,850 \\
\hline 1997 & 30,255 & 5,464 & 3,825 & $5,944,322$ & $1,385,114$ & 974,820 \\
\hline 1999 & 29,159 & 5,608 & 3,120 & $6,018,280$ & $1,459,796$ & 853,777 \\
\hline 2001 & 30,812 & 6,352 & 4,008 & $6,319,646$ & $1,582,273$ & $1,005,443$ \\
\hline 2003 & 30,071 & 6,777 & 4,910 & $6,099,221$ & $1,649,958$ & $1,216,358$ \\
\hline 2005 & 29,784 & 7,417 & 5,526 & $6,073,243$ & $1,762,806$ & $1,336,708$ \\
\hline 2007 & 28,450 & 7,437 & 5,698 & $5,910,210$ & $1,851,425$ & $1,456,768$ \\
\hline 2009 & 28,217 & 7,593 & 5,837 & $5,488,491$ & $1,783,111$ & $1,377,590$ \\
\hline
\end{tabular}

Panel B

\begin{tabular}{|c|c|c|c|c|c|c|c|c|c|}
\hline & \multicolumn{2}{|c|}{ Number of Catholic Schools } & \multicolumn{2}{c|}{ Number of Other Religious Schools } & \multicolumn{3}{c|}{ Number of Nonsectarian Schools } \\
\hline & PSS & Crosswalk & Matched & PSS & Crosswalk & Matched & PSS & Crosswalk & Matched \\
\hline 1991 & 8,593 & 542 & 169 & 10,535 & 1,448 & 681 & 4,638 & 1,745 & 1,236 \\
\hline 1993 & 8,397 & 555 & 199 & 15,473 & 1,721 & 820 & 6,912 & 2,113 & 1,497 \\
\hline 1995 & 8,107 & 588 & 242 & 12,237 & 1,919 & 989 & 8,278 & 2,453 & 1,776 \\
\hline 1997 & 8,117 & 598 & 279 & 12,756 & 2,136 & 1,267 & 9,382 & 2,730 & 2,279 \\
\hline 1999 & 7,934 & 597 & 211 & 12,586 & 2,238 & 1,060 & 8,639 & 2,773 & 1,849 \\
\hline 2001 & 8,044 & 632 & 282 & 13,638 & 2,659 & 1,485 & 9,130 & 3,061 & 2,241 \\
\hline 2003 & 7,677 & 638 & 354 & 13,210 & 2,830 & 1,828 & 9,184 & 3,309 & 2,728 \\
\hline 2005 & 7,292 & 672 & 380 & 13,447 & 3,200 & 2,190 & 9,045 & 3,545 & 2,956 \\
\hline 2007 & 6,985 & 676 & 415 & 12,831 & 3,230 & 2,301 & 8,634 & 3,531 & 2,982 \\
\hline 2009 & 6,835 & 667 & 412 & 12,619 & 3,279 & 2,430 & 8,763 & 3,647 & 2,995 \\
\hline
\end{tabular}

Note: Figures in columns marked PSS are based on the unrestricted Private School Universe Survey sample. Crosswalk columns report statistics using all available years of PSS data for schools for which we match a PSS record to a tax record in at least one year, regardless of whether the match was for the year in question. The Matched columns report statistics based only on PSS records that are actually matched to a tax record in the same year. Total enrollment is calculated using sample weights. 
Appendix Table 2: Average Number of Schools per Year, by State, Match Status, and Religious Orientation

\begin{tabular}{|c|c|c|c|c|c|c|c|c|c|}
\hline & \multicolumn{3}{|c|}{ All Schools } & \multicolumn{2}{|c|}{ Catholic Schools } & \multicolumn{2}{|c|}{ Other Religious Schools } & \multicolumn{2}{|c|}{ Nonsectarian Schools } \\
\hline & PSS & Crosswalk & Crosswalk \% & PSS & In-Year Match & PSS & In-Year Match & PSS & In-Year Match \\
\hline $\mathrm{AL}$ & 363 & 85 & $23.4 \%$ & 46 & 2 & 218 & 23 & 93 & 27 \\
\hline $\mathrm{AK}$ & 67 & 15 & $22.4 \%$ & 6 & 1 & 48 & 4 & 11 & 5 \\
\hline $\mathrm{AZ}$ & 346 & 75 & $21.7 \%$ & 57 & 4 & 162 & 21 & 123 & 21 \\
\hline AR & 177 & 31 & $17.5 \%$ & 32 & 2 & 117 & 11 & 26 & 9 \\
\hline $\mathrm{CA}$ & 3,916 & 748 & $19.1 \%$ & 708 & 24 & 1,545 & 148 & 1,539 & 301 \\
\hline $\mathrm{CO}$ & 422 & 97 & $23.0 \%$ & 57 & 3 & 190 & 23 & 154 & 41 \\
\hline $\mathrm{CT}$ & 391 & 101 & $25.8 \%$ & 148 & 5 & 77 & 17 & 153 & 60 \\
\hline $\mathrm{DE}$ & 124 & 31 & $25.0 \%$ & 29 & 1 & 54 & 8 & 41 & 10 \\
\hline DC & 86 & 25 & $29.1 \%$ & 27 & 1 & 17 & 1 & 41 & 14 \\
\hline FL & 1,590 & 305 & $19.2 \%$ & 213 & 8 & 878 & 96 & 465 & 72 \\
\hline GA & 565 & 167 & $29.6 \%$ & 39 & 1 & 366 & 56 & 154 & 65 \\
\hline HI & 130 & 45 & $34.6 \%$ & 35 & 1 & 64 & 13 & 32 & 18 \\
\hline ID & 103 & 23 & $22.3 \%$ & 16 & 2 & 60 & 8 & 26 & 6 \\
\hline IL & 1,618 & 270 & $16.7 \%$ & 579 & 18 & 524 & 53 & 456 & 102 \\
\hline IN & 718 & 94 & $13.1 \%$ & 197 & 6 & 416 & 30 & 99 & 23 \\
\hline IA & 259 & 56 & $21.6 \%$ & 138 & 5 & 108 & 26 & 13 & 6 \\
\hline KS & 216 & 41 & $19.0 \%$ & 107 & 3 & 90 & 15 & 19 & 9 \\
\hline KY & 364 & 69 & $19.0 \%$ & 141 & 6 & 159 & 21 & 64 & 21 \\
\hline LA & 420 & 71 & $16.9 \%$ & 201 & 10 & 136 & 10 & 78 & 21 \\
\hline $\mathrm{ME}$ & 146 & 53 & $36.3 \%$ & 21 & 0 & 52 & 6 & 72 & 34 \\
\hline MD & 772 & 172 & $22.3 \%$ & 171 & 7 & 340 & 40 & 249 & 73 \\
\hline MA & 854 & 227 & $26.6 \%$ & 253 & 11 & 131 & 25 & 413 & 140 \\
\hline MI & 996 & 152 & $15.3 \%$ & 314 & 12 & 528 & 57 & 150 & 30 \\
\hline $\mathrm{MN}$ & 562 & 109 & $19.4 \%$ & 213 & 12 & 267 & 30 & 77 & 24 \\
\hline MS & 205 & 62 & $30.2 \%$ & 36 & 0 & 112 & 19 & 56 & 17 \\
\hline
\end{tabular}




\begin{tabular}{|c|c|c|c|c|c|c|c|c|c|}
\hline MO & 605 & 93 & $15.4 \%$ & 274 & 4 & 228 & 20 & 97 & 37 \\
\hline $\mathrm{MT}$ & 98 & 24 & $24.5 \%$ & 21 & 1 & 54 & 8 & 23 & 7 \\
\hline $\mathrm{NE}$ & 229 & 36 & $15.7 \%$ & 113 & 8 & 99 & 10 & 17 & 4 \\
\hline $\mathrm{NV}$ & 116 & 18 & $15.5 \%$ & 14 & 0 & 58 & 5 & 41 & 6 \\
\hline $\mathrm{NH}$ & 270 & 77 & $28.5 \%$ & 38 & 3 & 60 & 8 & 171 & 42 \\
\hline NJ & 1,135 & 241 & $21.2 \%$ & 407 & 10 & 276 & 50 & 447 & 108 \\
\hline NM & 194 & 53 & $27.3 \%$ & 33 & 2 & 91 & 11 & 68 & 24 \\
\hline NY & 2,032 & 379 & $18.7 \%$ & 777 & 28 & 736 & 62 & 486 & 177 \\
\hline $\mathrm{NC}$ & 543 & 153 & $28.2 \%$ & 39 & 1 & 355 & 46 & 138 & 54 \\
\hline ND & 55 & 12 & $21.8 \%$ & 28 & 2 & 20 & 3 & 6 & 2 \\
\hline $\mathrm{OH}$ & 1,047 & 177 & $16.9 \%$ & 499 & 21 & 343 & 45 & 185 & 54 \\
\hline OK & 182 & 45 & $24.7 \%$ & 34 & 1 & 116 & 24 & 22 & 6 \\
\hline OR & 394 & 101 & $25.6 \%$ & 55 & 6 & 191 & 27 & 141 & 41 \\
\hline PA & 2,217 & 319 & $14.4 \%$ & 645 & 14 & 1,016 & 77 & 535 & 126 \\
\hline RI & 174 & 41 & $23.6 \%$ & 60 & 1 & 19 & 7 & 88 & 26 \\
\hline $\mathrm{SC}$ & 378 & 92 & $24.3 \%$ & 28 & 1 & 258 & 21 & 89 & 38 \\
\hline SD & 87 & 19 & $21.8 \%$ & 29 & 1 & 43 & 7 & 14 & 3 \\
\hline $\mathrm{TN}$ & 488 & 114 & $23.4 \%$ & 48 & 2 & 310 & 43 & 117 & 37 \\
\hline $\mathrm{TX}$ & 1,400 & 298 & $21.3 \%$ & 266 & 14 & 760 & 112 & 315 & 71 \\
\hline UT & 105 & 21 & $20.0 \%$ & 13 & 0 & 34 & 6 & 58 & 8 \\
\hline VT & 112 & 52 & $46.4 \%$ & 15 & 1 & 25 & 3 & 72 & 36 \\
\hline VA & 619 & 181 & $29.2 \%$ & 72 & 4 & 314 & 43 & 230 & 79 \\
\hline WA & 544 & 165 & $30.3 \%$ & 92 & 9 & 264 & 43 & 184 & 63 \\
\hline WV & 142 & 19 & $13.4 \%$ & 34 & 2 & 90 & 6 & 16 & 3 \\
\hline WI & 966 & 120 & $12.4 \%$ & 373 & 11 & 493 & 34 & 91 & 35 \\
\hline WY & 38 & 9 & $23.7 \%$ & 7 & 1 & 23 & 2 & 8 & 4 \\
\hline
\end{tabular}

Summing match status figures across religious orientations may not give the number reported for all schools due to missing information on religious orientation for some schools. 
Appendix Table 3:

Baseline Estimates on Total Revenue with Pre-Law-Change Placebo Dummies

\begin{tabular}{|c|c|c|c|c|c|c|}
\hline & $\begin{array}{l}\text { Revenue } \\
\text { (\$1000s) }\end{array}$ & $\begin{array}{c}\text { Revenue Per } \\
\text { Student } \\
(\$ 1000 \mathrm{~s})\end{array}$ & Students & $\begin{array}{l}\text { Revenue } \\
\text { (\$1000s) }\end{array}$ & $\begin{array}{c}\text { Revenue Per } \\
\text { Student } \\
(\$ 1000 \mathrm{~s})\end{array}$ & Students \\
\hline Five-Year Lead & $\begin{array}{c}-3,503 \\
{[7,530]}\end{array}$ & $\begin{array}{c}-0.862 \\
{[0.301]}\end{array}$ & $\begin{array}{c}778 \\
{[362]}\end{array}$ & $\begin{array}{l}-6,506 \\
{[8,994]}\end{array}$ & $\begin{array}{c}-0.666 \\
{[0.238]}\end{array}$ & $\begin{array}{c}217 \\
{[337]}\end{array}$ \\
\hline Four-Year Lead & $\begin{array}{c}5,369 \\
{[9,000]}\end{array}$ & $\begin{array}{c}-0.741 \\
{[0.257]}\end{array}$ & $\begin{array}{l}1,436 \\
{[645]}\end{array}$ & $\begin{array}{c}6,269 \\
{[5,704]}\end{array}$ & $\begin{array}{c}-0.485 \\
{[0.200]}\end{array}$ & $\begin{array}{c}818 \\
{[493]}\end{array}$ \\
\hline Three-Year Lead & $\begin{array}{c}7,029 \\
{[10,917]}\end{array}$ & $\begin{array}{c}-0.661 \\
{[0.269]}\end{array}$ & $\begin{array}{l}1,625 \\
{[598]}\end{array}$ & $\begin{array}{c}11,138 \\
{[9,807]}\end{array}$ & $\begin{array}{c}-0.369 \\
{[0.201]}\end{array}$ & $\begin{array}{c}956 \\
{[512]}\end{array}$ \\
\hline Two-Year Lead & $\begin{array}{c}-1,532 \\
{[15,934]}\end{array}$ & $\begin{array}{c}-0.477 \\
{[0.312]}\end{array}$ & $\begin{array}{c}689 \\
{[862]}\end{array}$ & $\begin{array}{c}-756 \\
{[16,881]}\end{array}$ & $\begin{array}{c}-0.191 \\
{[0.275]}\end{array}$ & $\begin{array}{l}-269 \\
{[949]}\end{array}$ \\
\hline One-Year Lead & $\begin{array}{c}-7,485 \\
{[15,794]}\end{array}$ & $\begin{array}{l}-0.788 \\
{[0.318]}\end{array}$ & $\begin{array}{c}882 \\
{[657]}\end{array}$ & $\begin{array}{c}-5,990 \\
{[17,831]}\end{array}$ & $\begin{array}{l}-0.527 \\
{[0.224]}\end{array}$ & $\begin{array}{c}-47 \\
{[816]}\end{array}$ \\
\hline School Subsidy Laws & $\begin{array}{c}27,976 \\
{[19,139]}\end{array}$ & $\begin{array}{c}-0.258 \\
{[0.231]}\end{array}$ & $\begin{array}{c}2,887 \\
{[1,329]}\end{array}$ & $\begin{array}{c}33,941 \\
{[20,980]}\end{array}$ & $\begin{array}{c}-0.921 \\
{[0.369]}\end{array}$ & $\begin{array}{c}4,203 \\
{[1,612]}\end{array}$ \\
\hline One-Year Lag & - & - & - & $\begin{array}{c}-16,756 \\
{[24,261]}\end{array}$ & $\begin{array}{c}0.935 \\
{[0.346]}\end{array}$ & $\begin{array}{l}-2,740 \\
{[1,717]}\end{array}$ \\
\hline Two-Year Lag & - & - & - & $\begin{array}{c}7,529 \\
{[17,485]}\end{array}$ & $\begin{array}{c}1.474 \\
{[0.559]}\end{array}$ & $\begin{array}{c}-2,276 \\
{[961]}\end{array}$ \\
\hline Three-Year Lag & - & - & - & $\begin{array}{c}10,205 \\
{[12,892]}\end{array}$ & $\begin{array}{c}0.869 \\
{[0.448]}\end{array}$ & $\begin{array}{c}-1,264 \\
{[756]}\end{array}$ \\
\hline Four-Year Lag & - & - & - & $\begin{array}{c}-4,245 \\
{[12,391]}\end{array}$ & $\begin{array}{c}0.416 \\
{[0.415]}\end{array}$ & $\begin{array}{c}-1,272 \\
{[602]}\end{array}$ \\
\hline Five-Year Lag & - & - & - & $\begin{array}{c}-14,882 \\
{[15,728]}\end{array}$ & $\begin{array}{c}0.15 \\
{[0.215]}\end{array}$ & $\begin{array}{c}-1,148 \\
{[927]}\end{array}$ \\
\hline
\end{tabular}

The dependent variable is listed at the top of each column; monetary figures are in year 2012 dollars. In the first three columns, the regression specification matches the baseline specification in Table 3, except that "lead" dummies have been added that equal unity a given number of years before a state enacts a tax-credit law. For example, the three-year lead equals unity three years before a state enacts a law (and equals zero all other years). In the last three columns, five "lag” dummies have also been included in the specification. Standard errors clustered by state. 
Appendix Table 4: Alternate Confidence-Interval and Inference Calculations

\begin{tabular}{|c|c|c|c|c|c|c|}
\hline & \multicolumn{2}{|c|}{ Revenue (1000s) } & \multicolumn{2}{|c|}{ Revenue per Student (1000s) } & \multicolumn{2}{|c|}{ Enrollment } \\
\hline $\begin{array}{l}\text { School Subsidy Laws } \\
\text { State-Clustered CI } \\
\text { Conley Taber CI } \\
\text { Wild Bootstrap CI } \\
\text { Pairs Clustered CI } \\
\end{array}$ & $\begin{aligned} & 24,311 \\
& {[13,020] } \\
&(-1,854\sim 50,477) \\
&(6,498\sim 39,830) \\
&(-9,687\sim 58,535) \\
&(-1,016\sim 51,345) \\
&\end{aligned}$ & $\begin{array}{c}27,260 \\
{[14,488]} \\
(-1,853 \sim 56,373) \\
(9,404 \sim 42,696) \\
(-12,015 \sim 66,974) \\
(-703 \sim 52,319) \\
\end{array}$ & $\begin{array}{c}0.28 \\
{[0.436]} \\
(-0.595 \sim 1.16) \\
(-1.0 \sim 2.07) \\
(-0.318 \sim 0.87) \\
(-0.70 \sim 1.41)\end{array}$ & $\begin{array}{c}0.191 \\
{[0.422]} \\
(-0.66 \sim 1.04) \\
(-0.92 \sim 1.98) \\
(-0.42 \sim 0.77) \\
(-0.811 \sim 1.58)\end{array}$ & $\begin{array}{c}1,512 \\
{[895]} \\
(-286 \sim 3,310) \\
(378 \sim 2,510) \\
(-901 \sim 3,936) \\
(-108 \sim 3710) \\
\end{array}$ & $\begin{array}{c}1,951 \\
{[839]} \\
(264 \sim 3,637) \\
(772 \sim 2,926) \\
(-758 \sim 4,727) \\
(150 \sim 4,144) \\
\end{array}$ \\
\hline $\begin{array}{l}\text { Unrestricted Subsidy Laws } \\
\text { State-Clustered CI } \\
\text { Conley Taber CI } \\
\text { Wild Bootstrap CI } \\
\text { Pairs Clustered CI }\end{array}$ & - & $\begin{array}{c}-13,107 \\
{[13,085]} \\
(-39401, \sim 13188) \\
(-49,748 \sim 35,912) \\
(-35,980 \sim 10,658) \\
(-48,128 \sim 33,453)\end{array}$ & - & $\begin{array}{c}0.951 \\
{[0.427]} \\
(0.09 \sim 1.81) \\
(-2.35 \sim 3.57) \\
(-0.46 \sim 2.31) \\
(-1.35 \sim 3.89)\end{array}$ & - & $\begin{array}{c}-1,944 \\
{[1,111]} \\
(-4,177 \sim 289) \\
(-5,334 \sim 1,160) \\
(-4,200 \sim 284) \\
(-4,664 \sim 934)\end{array}$ \\
\hline
\end{tabular}

The table reports baseline estimates for revenue, revenue per student, and enrollment. The first row in each cell is the estimated coefficient. The second row shows the stateclustered standard error. The third row shows the 95-percent confidence interval constructed using the standard error. The fourth row shows the 95-percent confidence interval using a method based on Conley-Taber, as explained in the text (this interval matches the intervals reported in the main results in the paper). The fifth row shows a 95-percent confidence interval constructed a Wild bootstrap based on the null hypothesis of a zero coefficient. The final row shows a 95-percent confidence interval constructed using a Pairs Block-Bootstrap method. For details on the construction of the last two confidence intervals, see Cameron, Gelbach, and Miller (2008). 
Appendix Figure 1: Funding for School Subsidies, by State
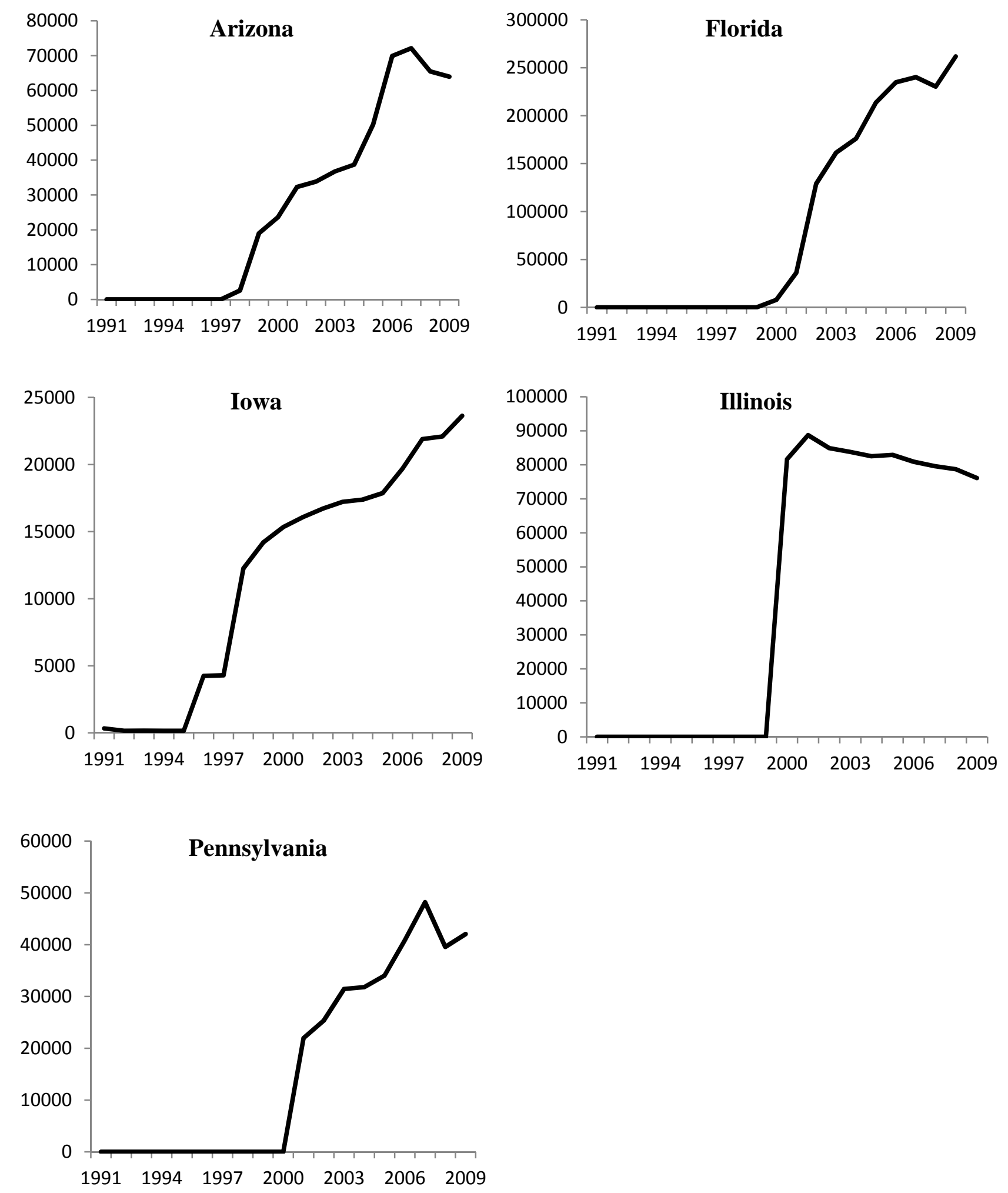

The figure shows the total amount of funding, in year 2012 dollars, for the statewide school subsidy funding programs in Arizona, Florida, Illinois, Iowa, and Pennsylvania. 


\section{Appendix Figure 2}

Panel A: Share of Matched and Unmatched Schools Affiliated with the Catholic Church

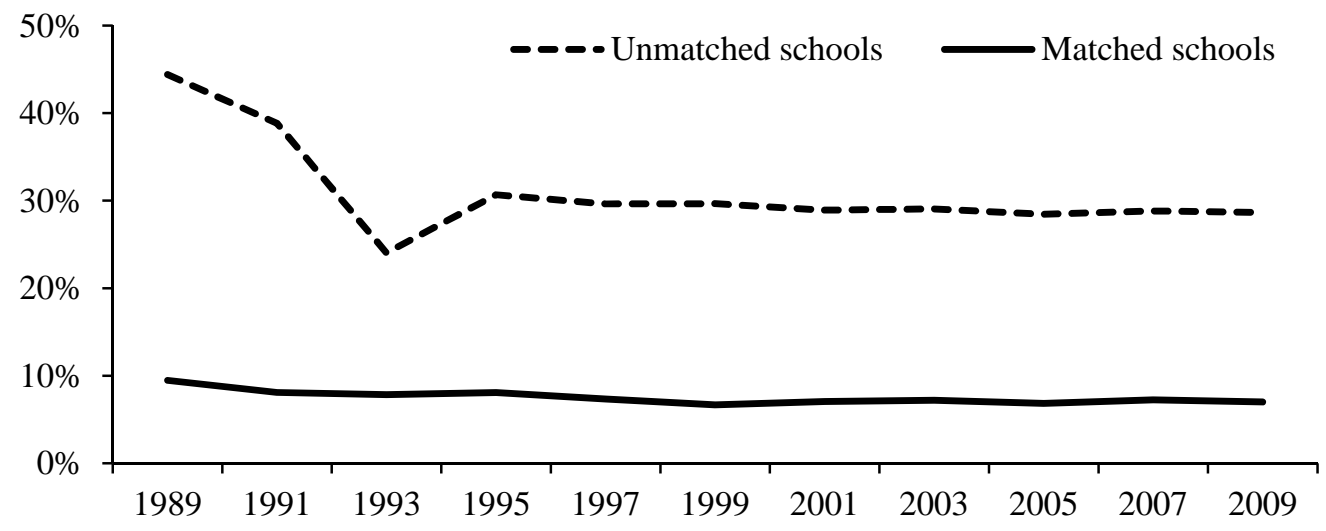

Panel B: Share of Matched and Unmatched Schools Affiliated with Non-Catholic Religious Organizations

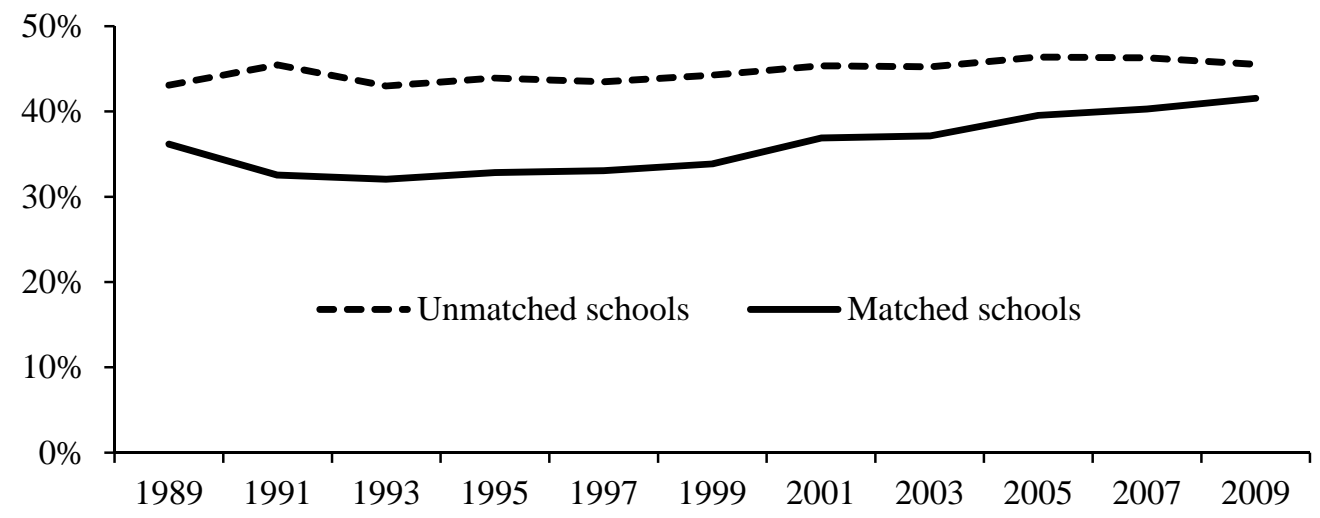

Panel C: Share of Matched and Unmatched Schools Not Religiously Affiliated

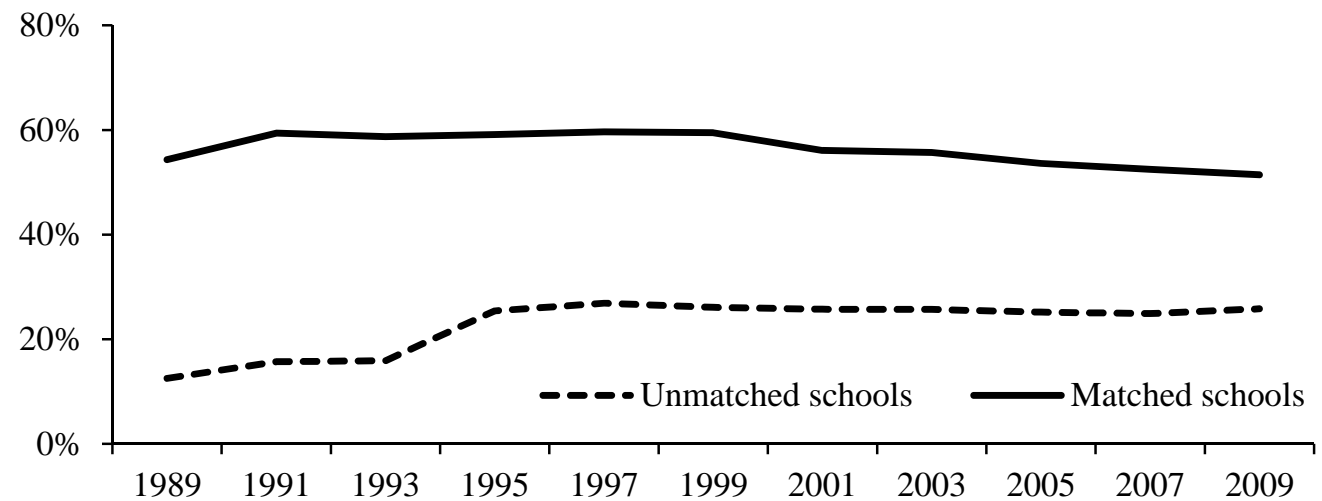

Note: Figure plots the share of schools in the PSS that are (panel A) affiliated with the Catholic Church, (B) affiliated with a religion other than Catholicism, and (C) nonsectarian. Sample weights are not used to produce these values. A school is considered matched in a given academic year if it is linked to its tax record for the fiscal year that includes the October of that academic year. 
Appendix Figure 3: Introduction of Subsidies and Revenue, by State

Arizona
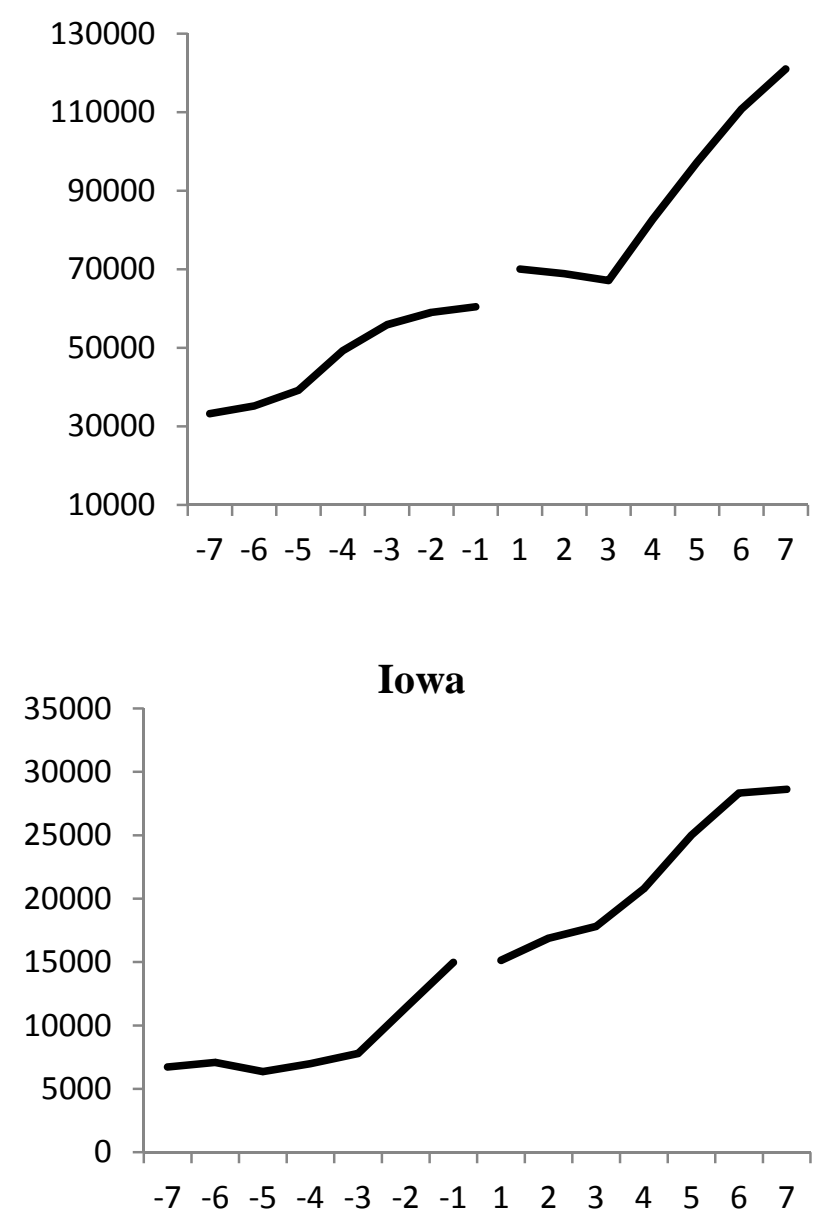

Florida

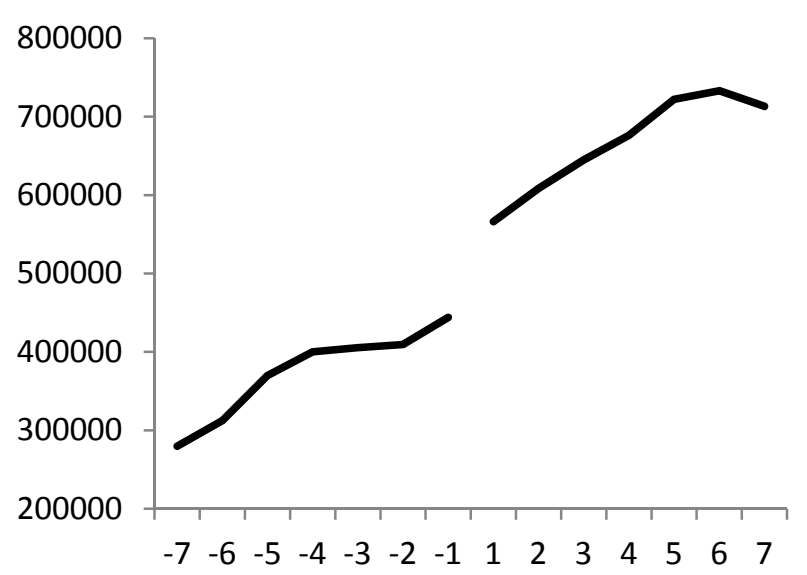

Illinois

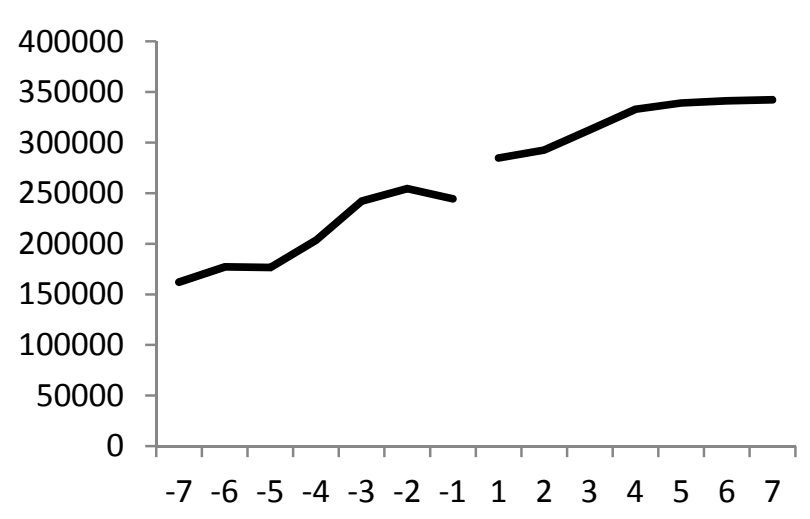

\section{Pennsylvania}

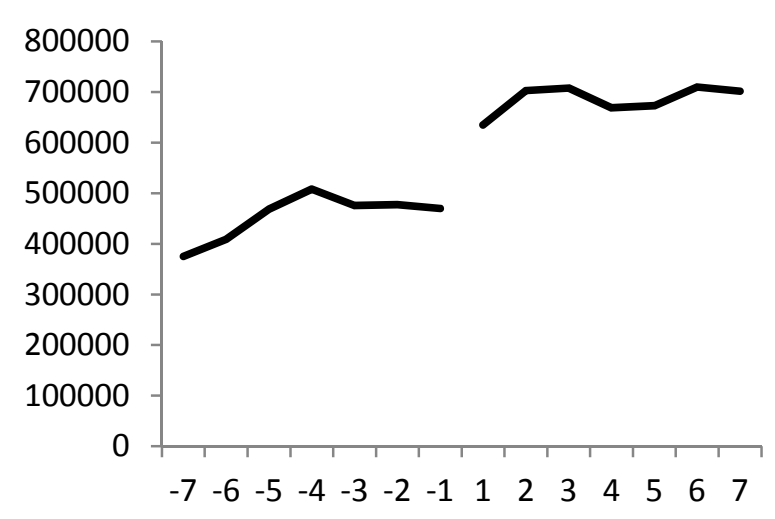

The figure gives a state by state breakdown of revenues for private schools (a two-year average, in 1000s of 2012 dollars) before and after a state introduces its first subsidy program (unrestricted in AZ, IA, and IL). Not-averaged data is similar but noisier. Note the $\mathrm{Y}$ axis range for each graph is different. 


\section{Appendix Figure 4: Introduction of Subsidies and Revenue per Student, by State}

Arizona

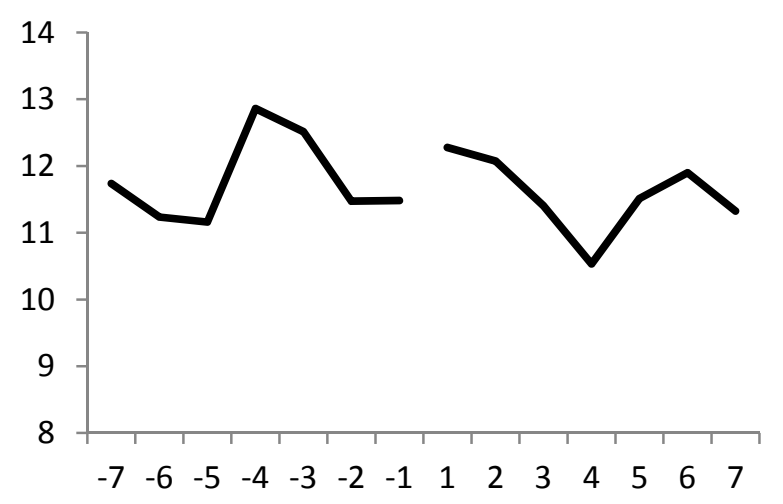

Iowa

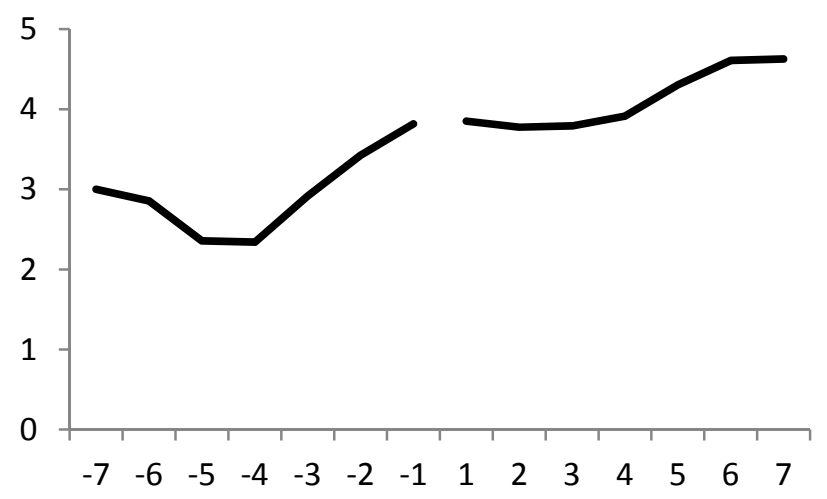

Florida

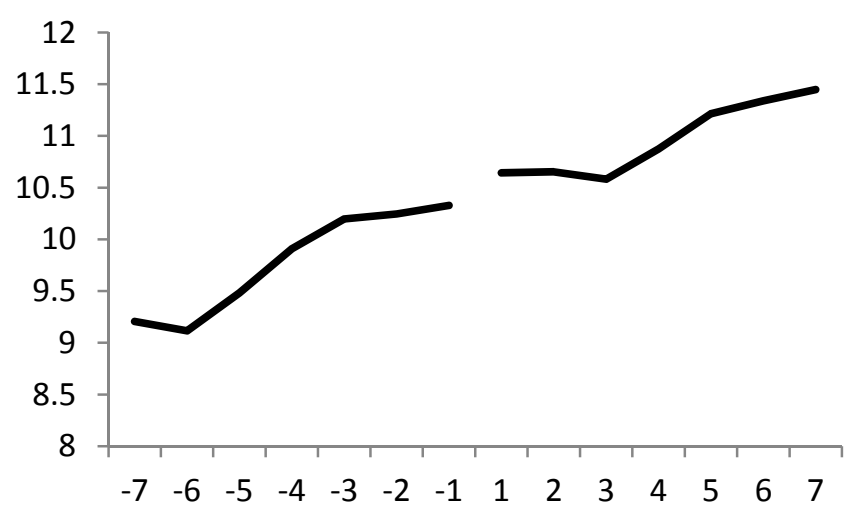

Illinois

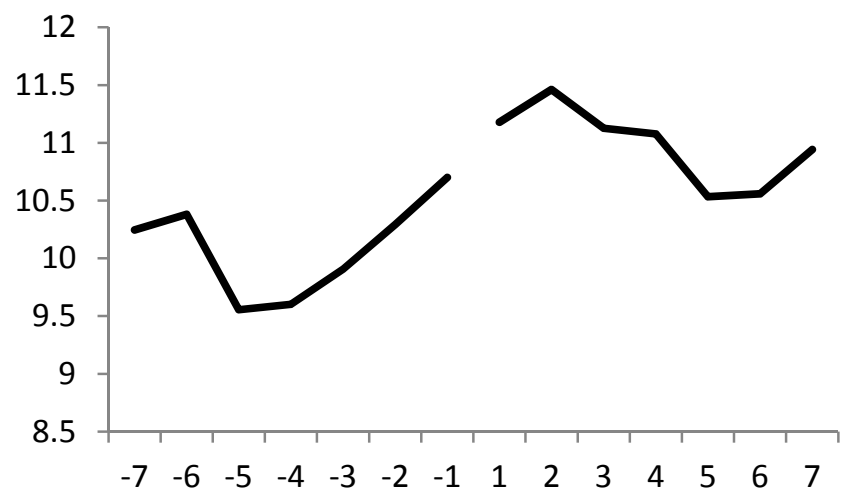

\section{Pennsylvania}

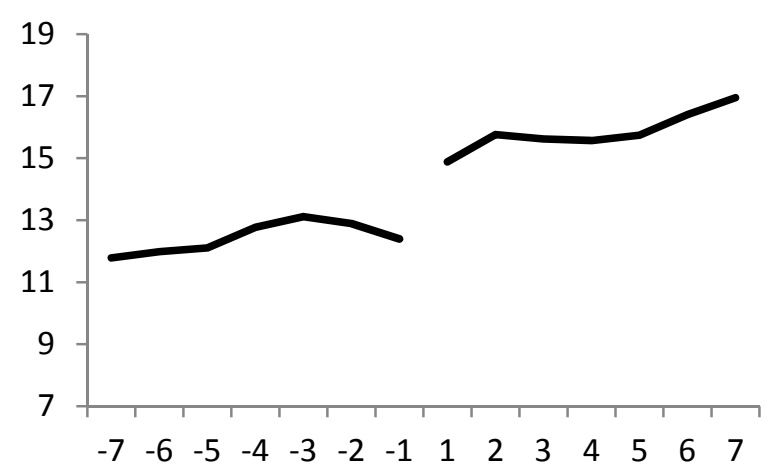

The figure gives a state by state breakdown of revenues per student for private schools (a two-year average, in 1000 s of 2012 dollars) before and after a state introduces its first subsidy program (unrestricted in AZ, IA, and IL). Not-averaged data is similar but noisier. Note the y-axis range for each graph is different. 


\section{Appendix Figure 5: Introduction of Subsidies and Enrollment, by State}

Arizona

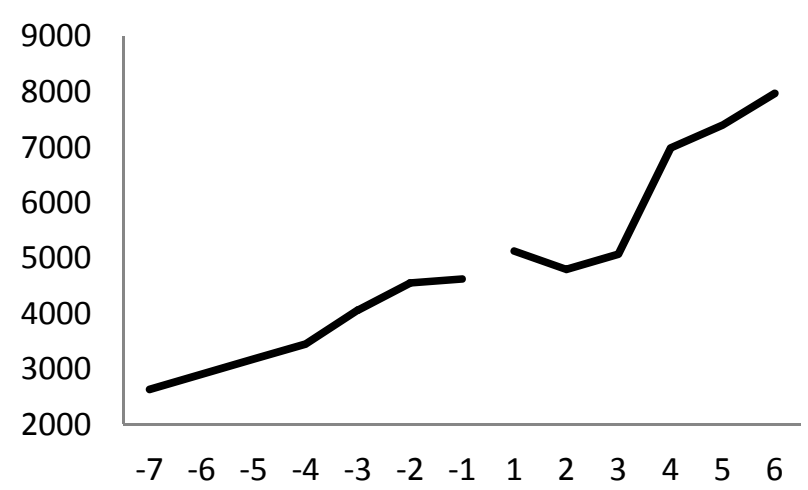

Iowa

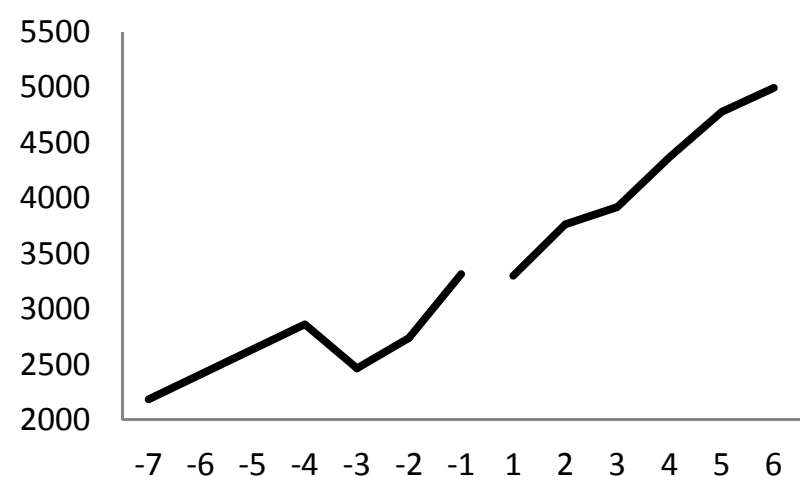

Florida

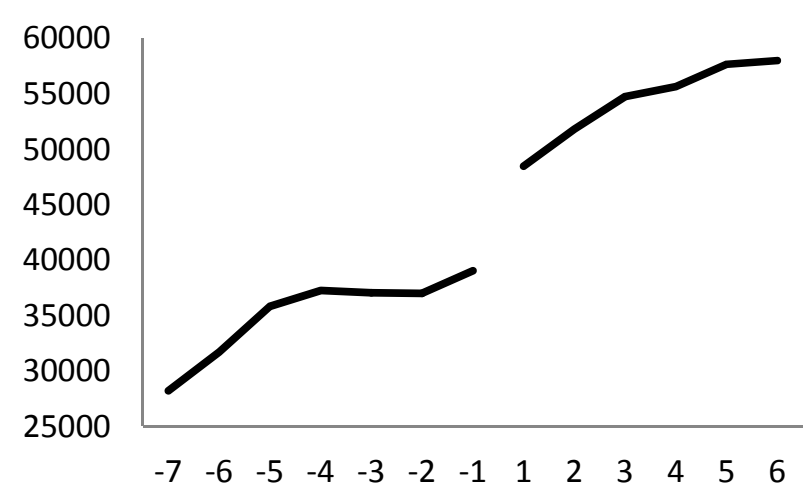

Illinois

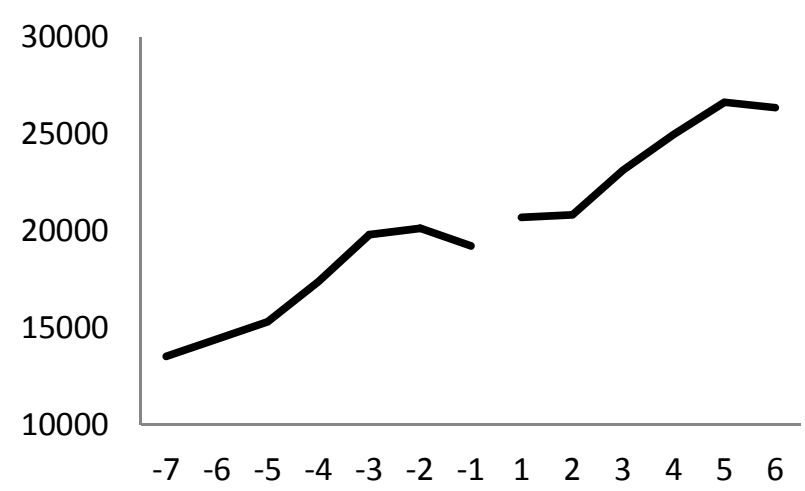

\section{Pennsylvania}

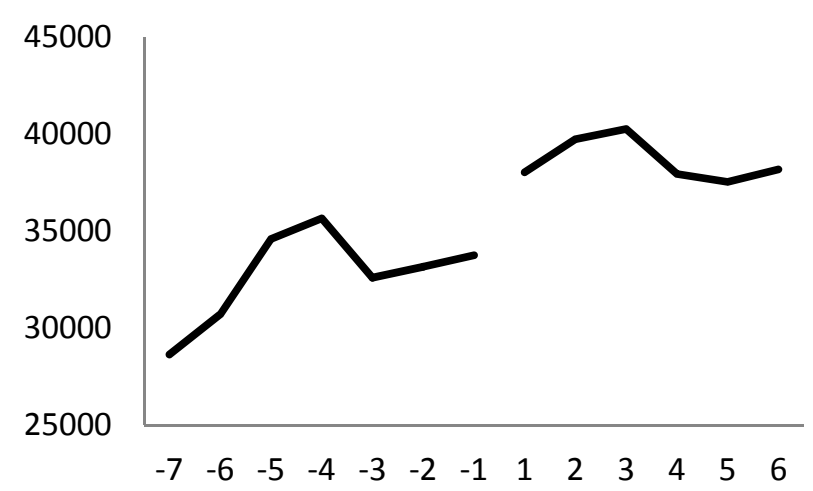

The figure gives a state-by-state breakdown of the change in enrollment for private schools (a two-year average) before and after a state introduces its first subsidy program (unrestricted in AZ, IA, and IL). Not-averaged data is similar but noisier. Note the y-axis range for each graph is different. 